Aus dem Department für Nutztierwissenschaften Abteilung Produktionssysteme der Nutztiere

\title{
Evaluation of non-invasive biomarkers for behaviour traits in beef and dairy cattle
}

\author{
Dissertation \\ zur Erlangung des Doktorgrades \\ der Fakultät für Agrarwissenschaften \\ der Georg-August-Universität Göttingen
}

vorgelegt von

Katrin Geburt (geb. Hille)

geboren in Braunschweig

Göttingen, Februar 2014 
1. Referent: Prof. Dr. Dr. Matthias Gauly

2. Korreferent: Prof. Dr. Georg Erhardt

Tag der mündlichen Prüfung: 07.02.2014 
Meiner Familie 


\section{Acknowledgements}

This work would never been generated without the help of several important people who should be mentioned here:

My sincere gratitude apply to my doctoral adviser Prof. Dr. Dr. Matthias Gauly for making me to one of his $\mathrm{PhD}$ students by including me in his working group, whose part I always really liked to be, giving me an interesting subject and supporting me with my work. I would like to express my gratitude to Prof. Dr. Georg Erhardt and Prof. Dr. Horst Brandt who agree kindly being my co-referee and third examiner. Special thanks go to my supervising tutor Dr. Uta König von Borstel, for her great help and professional support with my data analysis and whole PhD-work, what certainly made a lot of effort but hopefully were worth this trouble. I also would like to thank Dr. Morten Friedrich for helping me with my ELISA tests and Susanne Theis for her cooperation of our project.

Thankful acknowledge funding by the Federal Ministry of Education and Research (BMBF) within the project "Phenomics", Network of Competence of Agricultural and Nutritional Research (project number: 0315536G) which made this work possible.

My personal heartfelt gratitude goes to my best friend Catherine Zimmeck and to the "Power-Bauern" Sabrina Weber, Kerstin Wegner and Kalyakorn Wongrak, for our long hiking -tours through the Harz and the great years we spent together. Without you my PhD-time in Göttingen and my life would have been awful boring. Good friends are of great value what you cannot express with words.

I am very glad and thankful to have met you here Anna Stölzl, it is a lot of fun to have you as my friend and to share with you an office. As well as Denisse Garza, Miguel Camacho, Sophie Meyer-Hamme, Steffi Ammer, Bianca Hanke, Shayan Rahimian, Daniel Gieseke, Dr. Mazhar Shahin, Dr. Gürbüz Das, Dr. Ahmad Idris, Dr. Eva Moors and Dr. Christian Lambertz, I am grateful to had you as friends and colleagues in our working group. Moreover I will thank Birgit Sohnrey for her kind help in the lab and Erwin Tönges for nice days in winter and summer in Davos. Knut Salzmann of our research farm Relliehausen, the technical stuff of the research farm Frankenhausen and Arndt Roswag, your support in my experiments will not be forgotten. 
I will express my deepest gratitude to my husband Sebastian who always was my supporter in every possible, or for other people impossible circumstance. For your steady love, patience and encouragements you deserve my thanks and acknowledgement.

Meinen Eltern danke ich ganz herzlich für ihre Liebe, Fürsorge, Unterstützung und Aufopferung die sie mir während meiner langjährigen Ausbildung und in meinem ganzen bisherigen Leben haben zukommen lassen. 
TABLE OF CONTENT

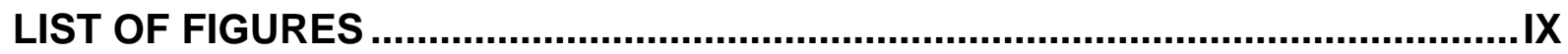

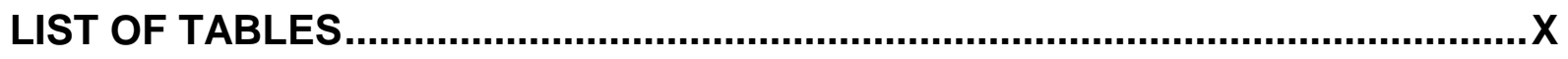

CHAPTER I GENERAL INTRODUCTION.......................................................... 11

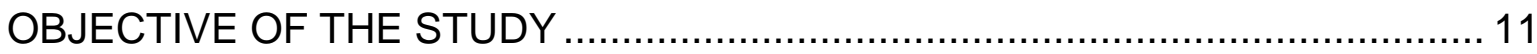

CHAPTER II INTRODUCTION TO THE LITERATURE ......................................... 12

2.1. Temperament of cattle .................................................................... 12

2.2. Tests of temperament for cattle .......................................................... 15

2.2.1. Tests with the limitation of movement of the animal .................................. 15

2.2.2. Tests without the limitation of movement of the animal ............................... 15

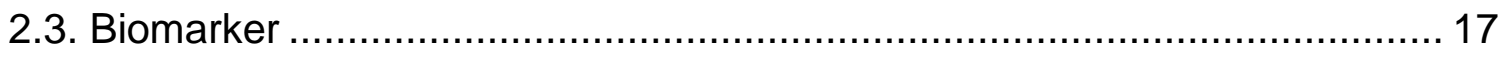

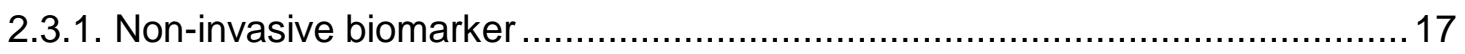

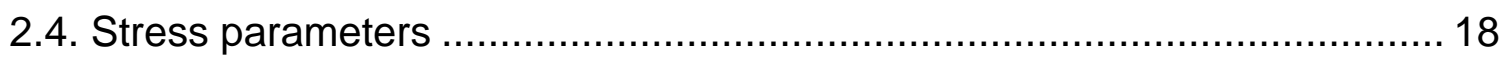

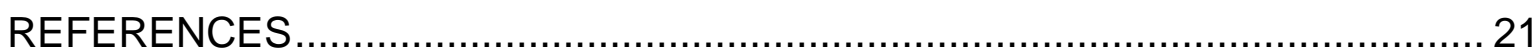

\section{CHAPTER III THERMOGRAPHY IN ANIMAL RESEARCH FOR THE} ASSESSMENT OF STRESS AND DISEASES .................................................... 27

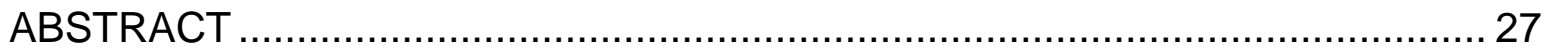

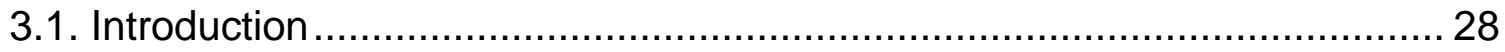

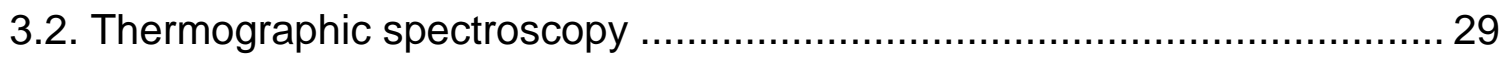

3.3. Applications of IRT to assessment of animal welfare................................. 30

3.3.1. Assessment of the heat stress and the general stress response ....................30

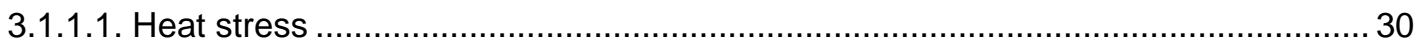

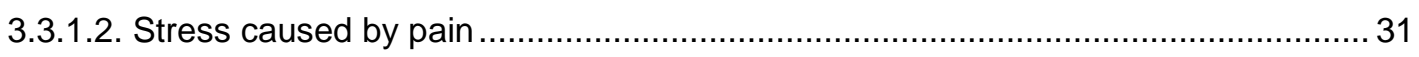

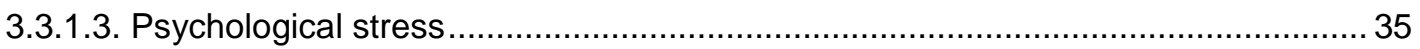

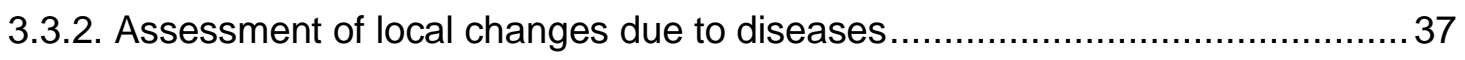

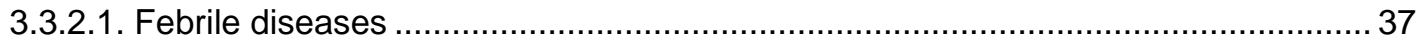

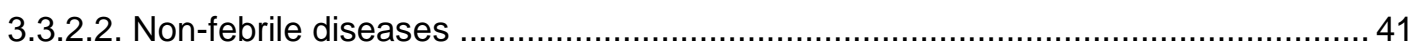




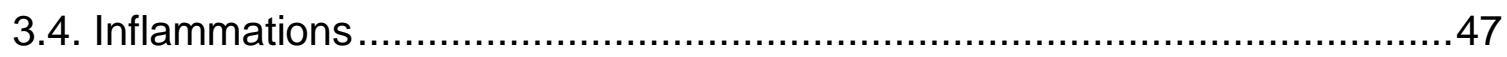

3.5. Factors influencing results obtained by thermal imaging ............................49

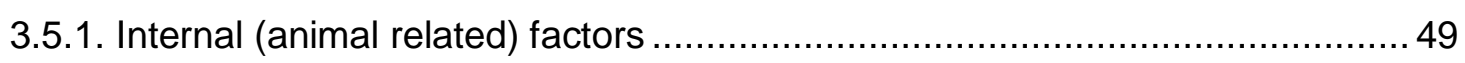

3.5.2. External (environmental) factors ………………................................... 51

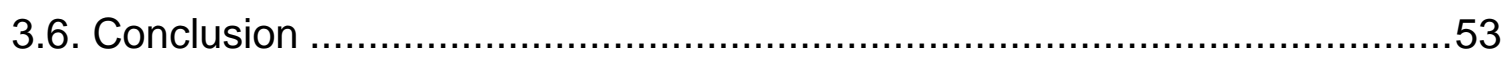

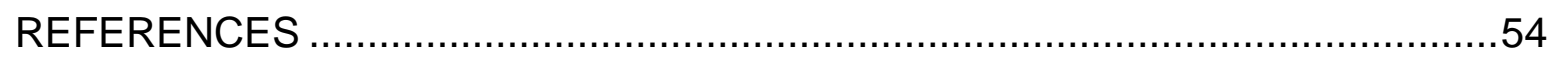

CHAPTER IV VALIDITY OF PHYSIOLOGICAL BIOMARKERS FOR MATERNAL BEHAVIOR IN COWS - A COMPARISON OF BEEF AND DAIRY CATTLE........62

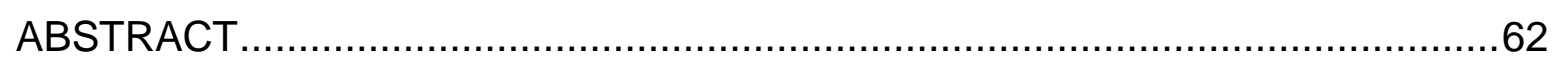

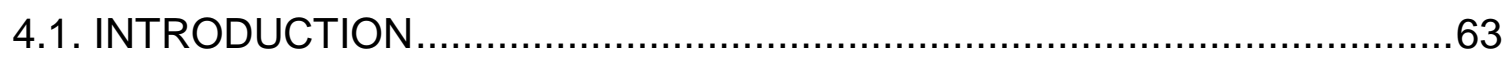

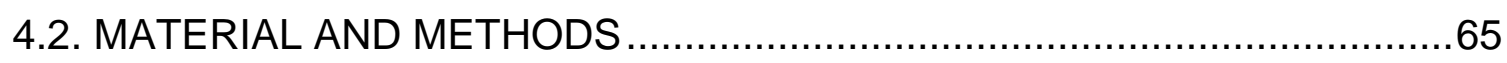

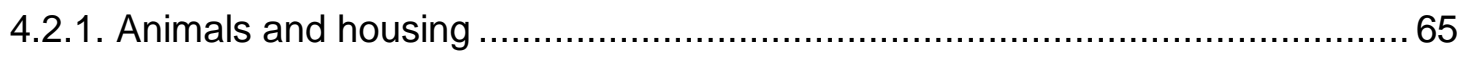

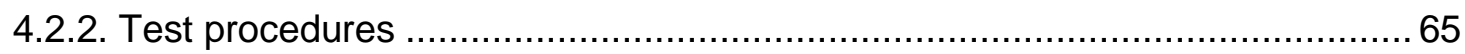

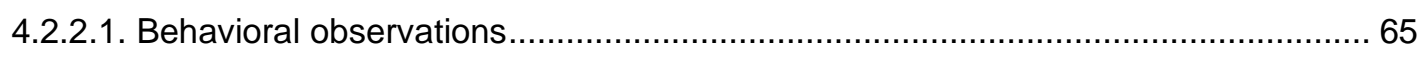

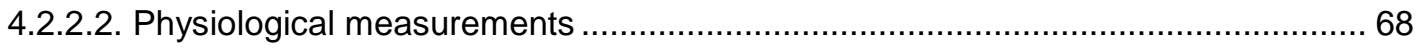

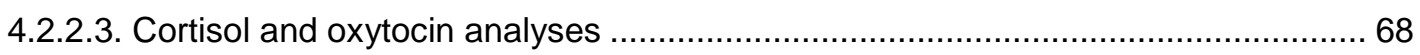

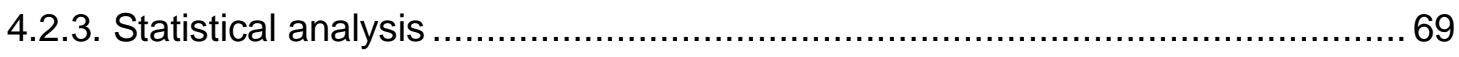

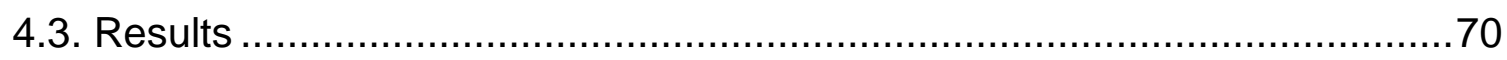

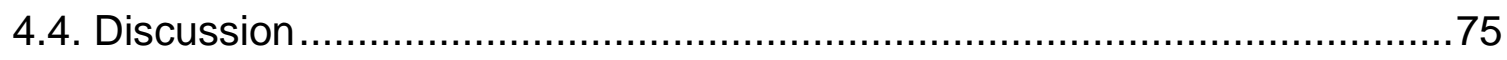

4.4.1. Breed differences in maternal ability ....................................................... 75

4.4.2. Differences between first and second measurement ................................... 77

4.4.3. Suitability of physiological parameters as biomarkers for maternal ability ....... 78

4.4.4. Influence of parity and calf weight on behavior and physiological parameters 79

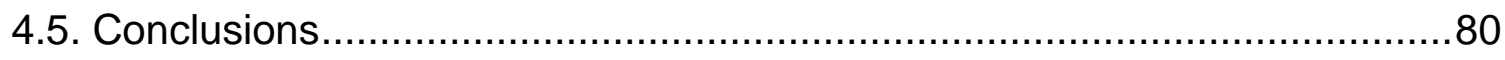

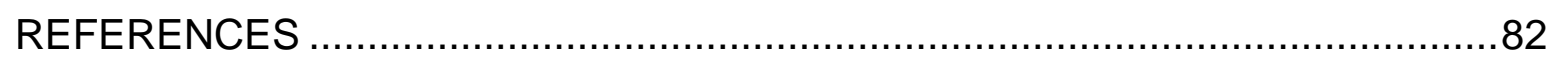

CHAPTER V INFLUENCE OF TESTOSTERONE ON THE DOCILITY OF GERMAN

SIMMENTAL AND CHAROLAIS HEIFERS DURING BEHAVIOR TESTS ..............88

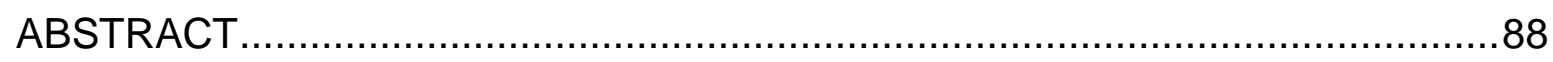

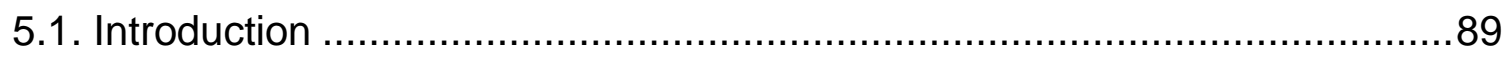




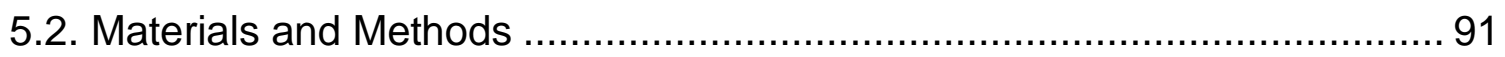

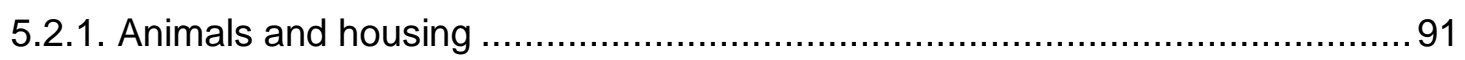

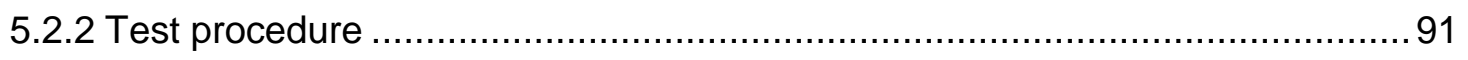

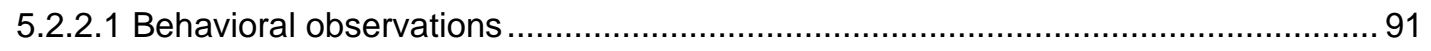

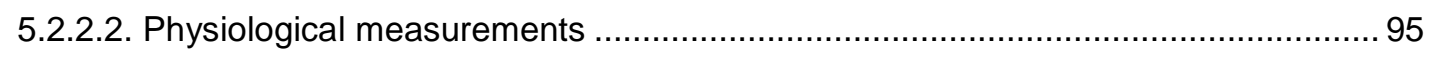

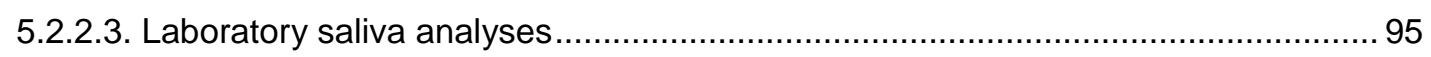

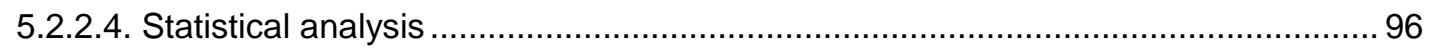

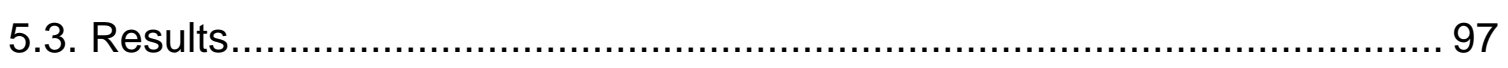

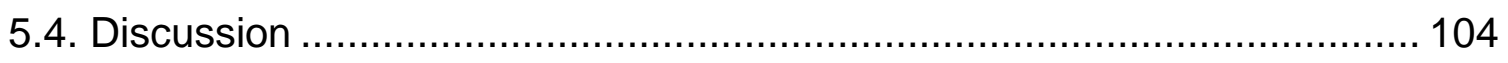

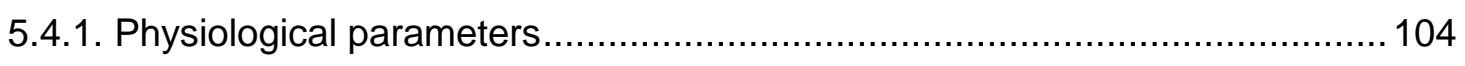

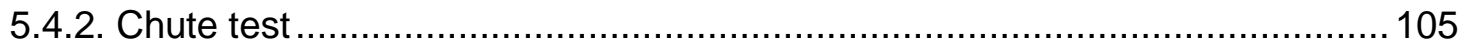

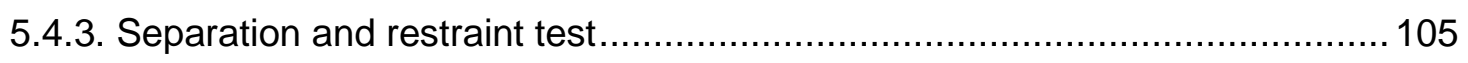

5.4.4. Repeatability and further correlations ............................................... 106

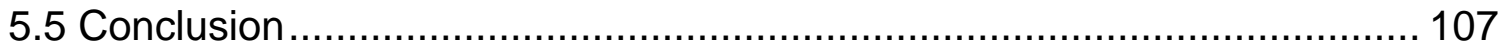

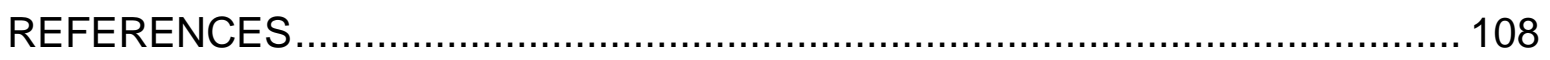

CHAPTER VI GENERAL DISCUSSION AND CONCLUSION............................. 112

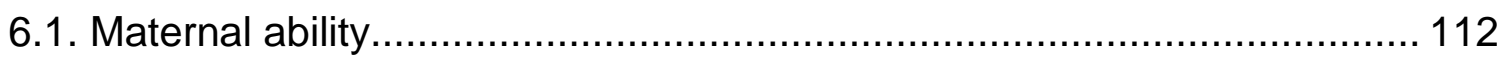

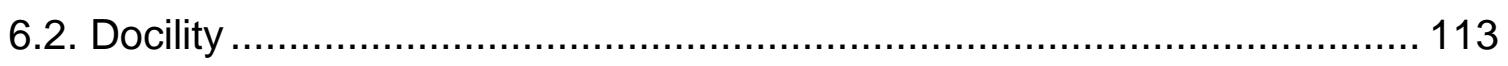

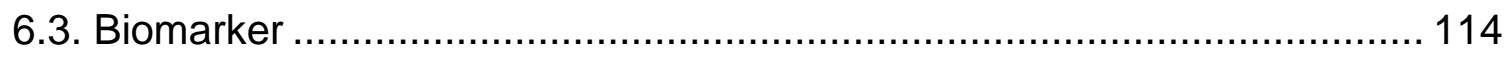

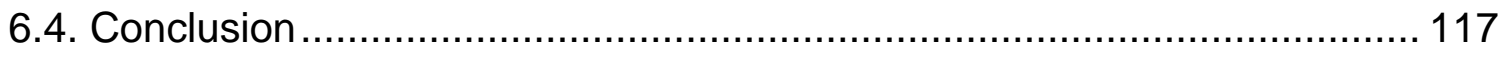

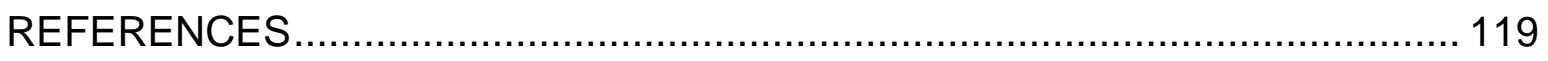

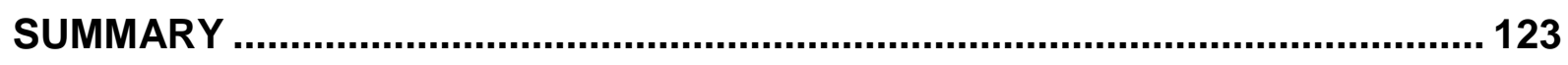

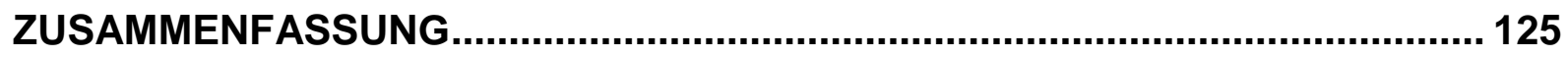

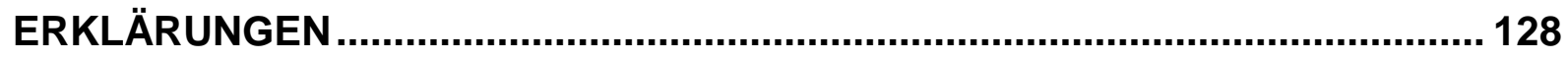




\section{LIST OF FIGURES}

Figure 1: Effect of breed and measurement on the parameters cow-calf-interaction , defence score, maternal ability scale and total motherliness

Figure 2: Effect of breed and measurement on the parameters heart frequency, cortisol, oxytocin and infrared thermography. .73

Figure 3: Paddock system for the Separation- and Restraint test .94

Figure 4: Least square means of heart rate and eye temperature and raw means of cortisol and testosterone by breed and their interaction with measurement for physiological parameters. .99

Figure 5: The behavioural parameters docility scale, weighing score and separation time are presented with identification marks for significant differences. 100 


\section{LIST OF TABLES}

Table 1: Heritability's with standard errors of different behavioural parameters of the tethering test, chute test, separation and restraint test and the maternal ability. ...... 14

Table 2: Common parameters for animals stress with their respective advantages and disadvantages.

Table 3: Usability of IRT for detection of Foot and Mouth Disease Virus (FMDV), Bovine Virus Diarrhea Virus (BVDV), Bovine Respiratory Disease Complex (BRD), Rabies, Lameness, Chronic Arthritis, Cranial cruciate ligament rupture, Hoof lesions and Mastitis.

Table 4: Internal and external factors influencing IRT measurements 52

Table 5: List and description of behavioral parameters assessed during the test..... 67

Table 6: Repeatability ( \pm Standard Error) of the different parameters across test day (2nd and 3rd day after parturition).

Table 7: Across-breed Pearson correlations coefficients for the parameters cow-calfinteraction (CCI), motherliness score (MS), defense score (DS), total motherliness (Mtotal), maternal ability measured on the visual analogue scale (MaS), heart rate $(\mathrm{HR})$, cortisol (Corti), oxytocin (Oxy), eye temperature (ET), and calf weight (Cw) .. 74

Table 8: Within-breed Pearson correlations coefficients for the parameters cow-calfinteraction (CCl), motherliness score (MS), defense score (DS), total motherliness (Mtotal), maternal ability measured on the visual analogue scale (MaS), heart rate $(\mathrm{HR})$, cortisol (Corti), oxytocin (Oxy) and eye temperature (ET). Above diagonal: German Black Pied Cattle; below diagonal: Simmental beef cattle. 


\section{CHAPTER I}

\section{GENERAL INTRODUCTION}

\section{OBJECTIVE OF THE STUDY}

Especially in extensive husbandry systems the human-animal-contact is reduced what can result in different handling problems. Beside the important fact of a high risk of injuries for the human and cattle, the stress in the animals is elevated and the time for catching and fixation is increased (Boissy and Bouissou, 1988). Reduced animal efficiencies, like lower growth rates and financial success are possible consequences (Tulloh, 1961b). For every husbandry system suitable animals are required. Beside the production traits, also functional traits, which include health characteristics as well as fertility, calving ease, efficiency of feed utilization, milkability, docility and temperament (Groen et al., 1997, Dempfle et al., 1991), are important for an effective production and a safe handling (Mathiak, 2002). An orientation from only the production output per animal to an improvement of the functional traits, with integration in breeding programs, will also support the consumer acceptance of animal products (Groen et al., 1997).

In this work different non-invasive biomarkers for behaviour traits in beef and dairy cows will be discussed. After the literature overview with information's about temperament and behaviour of cattle, tests of temperament, biomarkers for diverse behaviour traits and stress parameters, the infrared thermography as one method for the diagnose of welfare, pain, disease and stress will be evaluated in a literature review in chapter III. In the following chapter IV, one important behavioural trait, the maternal ability with potential biomarkers for it, will be explained on the basis of a practical experiment with German Simmental (beef) and German Black Pied cattle. Thereby different behavioural and physiological parameters serve as parameters for maternal ability and stress in the cows. Chapter $\mathrm{V}$ exemplifies the docility of the breeds Charolais and German Simmental (beef) by miscellaneous biomarkers, amongst others the hormone testosterone. Chapter VI gives a general discussion about the study's and the subjects and completes with a general conclusion. 


\section{CHAPTER II}

\section{INTRODUCTION TO THE LITERATURE}

\subsection{TEMPERAMENT OF CATTLE}

Specified as the behavioural response of the animal to the humans handling, the temperament (Burrow, 1997, Fordyce et al., 1988) in cattle differs inter alia in animals of different breeds (Hoppe et al., 2010, Gauly et al., 2001, Gauly et al., 2002, Fordyce et al., 1988), sex (Gauly et al., 2001, Gauly et al., 2002, Mathiak, 2002) and age (Fordyce and Goddard, 1984). An alternative definition of temperament was given by Kilgour (1975) who defined temperament as an unique behavioural characteristic of an animal compared to other species members, resulting from it's physical, nervous and hormonal organization. The term is variously used to explain the simpleness to drive, approach, yard, weight, milk or treat the animal in the case of injury or for routine health management and how it practice for example maternal behaviour. The temperament can be evaluated in standardised test situations by scoring the behaviour (Morris et al., 1994). German Simmental cattle are more difficult to handle compared with the breed German Angus (Mathiak, 2002, Gauly et al., 2001). Female animals show themselves with a more difficult temperament (Mathiak, 2002) as well as younger animals that had less experience in handling routine (Fordyce and Goddard, 1984). Another influence on the temperament is given by environmental effects like the contact of the handler to the animals and the management system (Le Neindre et al. 1995). Aggressive behaviour, which is a seriously risk for the handler, can be suppressed by earlier handling of the animal. Non-handled cows can supposable be frightened due to the vicinity of the human, after less adaption to the human and his handling and therefore try to attack (Boivin et al., 1992, Boissy and Bouissou, 1988). If the animals can be handled safe and easily, they are called to have for the management system an appropriate and therefore a good temperament (Grandin, 1993). For management procedures like weighing, docile animals can be handled in a shorter working time compared with animals of a more excitable temperament (Grandin, 1994). The animal's response on 
humans handling can reach from calm to afraid. Flight or aggressions are other response possibilities of the animal to handling (Burrow, 1997). A good temperament is also expressed by a small flight distance of the animal against the human (Morris et al. 1994). Also the flight speed can declare about the animal's temperament. A good temperament is given if the animal shows a slowly flight speed, a poor temperament is given in the case of a fast flight speed (Burrow and Dillon, 1997).

Irritable temperaments in cattle can be a main problem in the handling of the animals (Mathiak, 2002). If an animal shows an agitated behaviour in a handling session, this behaviour can be persistent over the time and can make the decision easy about leaving the animal in the flock or culling it (Grandin, 1993). Some traits of the temperament in cattle offer medium high heritability's (Mathiak, 2002, Le Neindre et al. 1995) and can therefore be used for breeding (Gauly et al. 2001). Several parameters of different behaviour test are presented with their low to medium high heritability's in Table 1. Due to these facts calm and docile animals are needed for every husbandry system particularly for extensive systems where a lot of accidents with animals occur (Dänzer, 1996). Beside the possibility to breed calm and docile animals, also conscious positive contacts by the farmers to their animals will help to get a well human-animal-relationship (Hamm, 2003). Fear memories of the animal should therefore be avoided and the effect of the habituation to the human and the service facilities will help to get calm and docile animals. It is also important that the stockmen are trained and understand the behaviour of cattle in handling procedures (Grandin, 1998). According to Grommers (1987) the relation to the animal is mainly dependent on the behaviour of the stockman, who influences this relation by his personality and professionalism. Another advantage of a good temperament in cattle is furthermore the better quality of products, like the meat quality (Voisinet et al., 1997) and the higher milk production (Kovalcikova and Kovalcik, 1982). Moreover a good temperament has a positive effect on the average daily weight gain, the health and a low plasma cortisol level (Fell et al., 1999). 
Table 1: Heritability's with standard errors of different behavioural parameters of the tethering test, chute test, separation and restraint test and the maternal ability.

\begin{tabular}{|c|c|c|c|c|}
\hline Behaviour test & Parameter & Breed & $h^{2} \pm S E$ & References \\
\hline Tethering test & Calf score & German Simmental & $\begin{array}{c}0.06 \pm 0.06-0.10 \pm \\
0.06 \\
0.17 \pm 0.15-0.29 \pm \\
0.12\end{array}$ & Mathiak, 2002 \\
\hline Chute test & Weighing score & German Simmental & $\begin{array}{c}0.18 \pm 0.09-0.43 \pm \\
0.11 \\
0.05 \pm 0.10-0.30 \pm \\
0.12\end{array}$ & Mathiak, 2002 \\
\hline \multirow{6}{*}{$\begin{array}{l}\text { Separation and } \\
\text { restraint test }\end{array}$} & Separation time & German Simmental & $\begin{array}{c}0.02 \pm 0.05-0.03 \pm \\
0.05 \\
0.16 \pm 0.07-0.38 \pm \\
0.22\end{array}$ & Mathiak, 2002 \\
\hline & $\begin{array}{l}\text { Score pre- } \\
\text { handling }\end{array}$ & German Simmental & $\begin{array}{c}0.11 \pm 0.07-0.13 \pm \\
0.11 \\
0.17 \pm 0.12-0.35 \pm \\
0.21\end{array}$ & Mathiak, 2002 \\
\hline & & German Angus & $\begin{array}{c}0.18 \pm 0.07-0.61 \pm \\
0.17\end{array}$ & Mathiak, 2002 \\
\hline & score nanaling & German Simmental & $\begin{array}{c}0.52 \pm 0.20-0.55 \pm \\
0.15\end{array}$ & Mathiak, 2002 \\
\hline & $\begin{array}{l}\text { Flight speed } \\
\text { score }\end{array}$ & $\begin{array}{c}\text { Bos indicus } \times \text { Bos } \\
\text { taurus }\end{array}$ & 0.50 & $\begin{array}{l}\text { Burrow and } \\
\text { Corbet, } 2000\end{array}$ \\
\hline & Flight distance & Sahiwal x Brahman & $\begin{array}{c}0.32 \pm 0.14-0.70 \pm \\
0.23\end{array}$ & $\begin{array}{c}\text { Fordyce et al., } \\
1996\end{array}$ \\
\hline Maternal ability & $\begin{array}{l}\text { Maternal ability } \\
\text { score }\end{array}$ & $\begin{array}{l}\text { Hereford, Angus, Red } \\
\text { Poll, Charolais }\end{array}$ & $0.06 \pm 0.01$ & $\begin{array}{l}\text { Buddenberg et al., } \\
1986\end{array}$ \\
\hline
\end{tabular}




\subsection{TESTS OF TEMPERAMENT FOR CATTLE}

The temperament of animals can be assessed by different behavioural tests, which analyses the temperament qualitative or quantitative. It is distinguished between tests with or without the limitation of movement of the animal (Burrow, 1997). Crush test, flight-speed-test (Hoppe et al., 2010). If the behaviour tests are implemented on farms for the identification of difficult animals, the procedure should include different situations in the production process and occur in an early stage of the animal's life, with a low impact of previous human-animal-contacts. It also must be considered, that the test are effective, have only a moderate costs and are safe for the human (Urban, 2007).

\subsubsection{Tests with the limitation of movement of the animal}

In tests with the limitation of movement, characteristic traits like the activity of movement before and/or during the fixation, vocalisations, escape attempt, defecation and urination are recorded (Mathiak, 2002). An example for these kinds of tests is the "chute test", where the animal's behaviour during a weighing process is evaluated with the help of scoring systems (Morris et al., 1994, Grandin, 1993, Tulloh, 1961a). A possible time for the chute test is the age of 5 month (Glenske, 2010). The chute test is described in chapter 5.2.2.2. These tests with limitation of movement can also occur during the fixation in headgates like in the feed fence or treatment stations (Grandin, 1993, Fordyce et al., 1982). Furthermore, the "fixation test" belong the category of the tests with the limitation of movement. For this test the animals are fixed with a rope at the head for a previous determined time, while their behavioural reactions are recorded with a scoring system (Mathiak, 2002, Gauly et al., 2002, Boissy and Boissou, 1988). These tests help to identify animals that are difficult to handle in fixation processes (Urban, 2007). A possible age for the fixation test is in the age of 5 weeks (Plachta, 2009).

\subsubsection{Tests without the limitation of movement of the animal}

For these kinds of tests the animals can move freely in a relatively huge area with or without humans. On the one hand these tests show the fear against humans on the other the curiosity against unfamiliar humans, objects and situations (Urban, 2007). 
In "contact avoidance and approach tests", the human only took part of the test passive. In this test the animal is standing in an area with a moving or stationary human or an unfamiliar object like a plastic ball. Amongst other parameters the time the animal need to approach or contact to the human or object and the number approach-withdrawal times are served as an evaluation method for the temperament (Lyons et al., 1988).

The "open-field-test" is used to examine the behaviour of an animal in a new situation, isolated from its flock. The animal is brought to a confined area where different behavioural parameters, like the latency to enter the arena, the locomotor activity and the sniffing number (Boissy and Bouissou, 1988).

Another test in this category is the test of "flight distance". Thereby a human is coming up to the animal and eventually tries to touch it. The possible distance of approaching to the animal until it is moving away from the handler is measured (Purcell et al. 1988, Boissy and Bouissou 1988). The flight distance is used as an extent for the habituation of the animals to the humans handling (Urban, 2007).

With the "flight speed test", the time of the animal is measured, which it needs to cover a special distance, for example after leaving the chute to move to the pasture (Burrow, 1997). Beside the possibility of giving flight speed scores, the time of the flight speed can also recorded electronically with an infrared photo sensor (Burrow et al., 1988). Also for this test it must be considered, that previous handling will influence the test results and lead to a more slowly flight speed (Urban, 2007).

In the "separation- and restraint test" the behaviour of the animal to the direct handling of a human is measured. The reaction of the animal is recorded, when the handler is separating it from his flock and tries to get close to it for restrain it in a corner and touch it (Le Neindre et al., 1995, Mathiak, 2002). This test can occur shortly after weaning in an age of seven month (Plachta, 2009). The separation- and restraint test is described in detail in chapter 5.2.2.1.

For information about the maternal ability the behaviour of the cow can be tested by routine handling procedures with the newborn calf. For example the maternal behaviour can be evaluated with a scoring system from 0-5 ( $0=$ calm cow, $5=$ dangerous cow) during tagging the newborn calf (Morris et al., 1994). More information about maternal behaviour tests are given in chapter 4.2.2.1.

For all kinds of test when the reaction of the animal to handling is measured, it must be considered, that a good docility of animals can result from previous experiences 
with humans and not only describe the genetic nature of the animal. Furthermore, the handler can have an effect of the animal's behaviour due to his personality and appearance (Mathiak, 2002).

\subsection{BIOMARKER}

Although biomarkers have gained popularity in the last years, the definition of the term is varying a lot. They can be defined as a biological response to chemicals, which gives a dimension of exposure, whereby the biological response ranges from a molecule to a community structure or the structure of ecosystems (Peakall, 1994). According to Fung et al. (2000) the term biomarker can be defined easiest as a molecule which indicated an alteration in physiology from normal, whereupon a more practical definition would include the clinical utility of the molecule. Thereby, a biomarker can reflect a disease state and can utilized for the diagnosis and monitoring of a disease as well as for its therapy. In all clinical fields these biomarkers are required (Fung et al., 2000). The definition that fittest the best for this study, was given by the "Biomarkers Definitions Working Group" of the National Institutes of Health: A biological marker (biomarker) is "a characteristic that is objectively measured and evaluated as an indicator of normal biological processes, pathogenic processes, or pharmacologic responses to a therapeutic intervention" (Atkinson et al., 2001).

\subsubsection{Non-invasive biomarker}

From the wide range of used biomarkers today, the use of some non-invasive biomarkers is described here. In many scientific disciplines it is searched for noninvasive biomarkers for umpteen diseases, stress or behaviour.

In cancer research, Zhang et al. (2012) developed salivary biomarkers for the detection of lung cancer. These mRNA biomarkers could differentiate lung cancer patients from healthy control persons (Zhang et al., 2012). Saliva-based biomarkers offer many advantages as a clinical diagnostic tool: They are non-invasive, easy to collect, they afford cost -effective screens and don't cause a lot anxiety in the patients. As telltale molecules they monitor the health status and disease onset, as well as treatment responses (Wong, 2006, Zhang et al., 2012). The neurosciences are another field where biomarkers can be searched. Polta et al. (2013) discovered in 
an animal-model the rapid eye movement sleep as an objective and viable noninvasive biomarker for the posttraumatic stress disorder and further trauma-related psychiatric disorders after traumatic events. Ellmore et al. (2010) found that a reduced putamen volume can be a structural biomarker for REM sleep behaviour disorder and reflect a model of neurodegeneration that prefigure the development of Parkinson's disease. An interesting experiment for gynecology was done by Tegethoff et al. (2011), who detected the fetal steroid dehydroepiandrosterone as a biomarker for intrauterine stress response to maternal stress. The concentration of dehydroepiandrosterone in infant nails was significantly higher if the mothers had stressful life events during pregnancy (Tegethoff et al., 2011). In the scientific field of endocrinology Behrends et al. (2010) found the behavioural biomarker mate calling in frogs to be sensitive for detecting antiandrogenic modes of action, which can contribute for the sensitive assessment of antiandrogenic endocrine disrupting chemicals. Important research in behavioural ecology was done by Thompson et al. (2009) who validated the C-peptide of insulin as a biomarker for evaluating individual and seasonal variation in energetic condition, as well as the costs of processes like reproduction and immune function. In a study about behavioural disorders in dogs the participation of the serotonin $5-\mathrm{HT} 2 \mathrm{~A}$ receptor was evaluated with Single Photon Emission Computed Tomography and the serotonin 2A receptor-selective radiopharmaceutical. Imaging with this radioligand helped to assess the involvement of the receptor in the complex mechanisms of anxious or aggressive behaviour. As a valid biomarker in differentiating the behavioural disorders, the 5HT-2A binding index of the right frontal cortex appears was identified (Vermeire et al., 2011).

\subsection{STRESS PARAMETERS}

Also the stress parameters which are described here are belonging to the biomarkers and partially to the non-invasive biomarkers, but are placed here in an own subitem for better clarity.

Cattle can show their agitation in several ways: By snuffling, tail and head movements, vocalisations, running, jittering and kicking. This agitation can happen in different situations, for example during waiting for feed or milking, in a conflict of decision, at the underrun of the flight distance and during a fight (Hamm, 2003, KileyWorthington and De la Plain, 1983, Grandin and Deesing, 1998). 
Beside the documentation of these stress expressions, there are several parameters to measure the stress of animals:

If an animal can control the situation, the stress level is lower than in the case of restraint (Weiss 1972). Therefore, remote, non-invasive techniques for assessment of physiological changes e.g. related to stress are often preferred over more invasive procedures. The infrared camera acquires real time temperature data without contact to the animal, requiring no need for restraint and contact (Steward et al., 2005). Due to this, the animals' stress caused by handling procedures themselves is reduced (Alam and Dodson 1986). Measurement of heart rate variability (HRV) provides a more accurate representation of stress, compared with the heart rate $(\mathrm{HR})$, due to more accurate demonstration of cardiac activity. In contrast, with HR only the net effect of interrelation between different divisions of nervous system, so metabolic and emotional responses can be shown (Marchant-Forde et al., 2004). An alternative method is the measurement of the cortisol level in saliva (Negrao et al., 2004), milk (Fukasawa and Tsukada 2010) urine (Pol et al., 2002) and faeces (Palme et al., 1999). For these measurements, the different, species and medium specific time-lags have to be considered. For example, the time-lag for cortisol to reach saliva in dairy calves is approximately 10 minutes (Hernandez 2004), and with faecal cortisol it has to be considered, that the time of the production was e.g. in ruminants approximately 12 hours earlier (Mostl et al., 2002). Other blood parameters that potentially provide information about temperament are the levels of lactate, glucose and nonesterified fatty acids (Cafe et al., 2011). According to Stewart et al. (2005) and Stewart et al. (2007), there is a requirement for more noninvasive and reliable possibilities to measure stress. A summary of the common parameters in literature to measure the animals stress, as well as their advantages and disadvantages, is given in Table 2. 
Table 2: Common parameters for animals stress with their respective advantages and disadvantages.

\begin{tabular}{|c|c|c|c|}
\hline Stress parameter & Advantages & Disadvantages & References \\
\hline $\begin{array}{l}\text { Heart rate/ heart rate } \\
\text { variability }\end{array}$ & valuable for welfare questions of short-time studies & $\begin{array}{l}\text { less data storage, equipment in some cases difficult to } \\
\text { fixate reliably on the animal }\end{array}$ & $\begin{array}{l}\text { Von Borell et al. (2007), Marchant-Forde } \\
\text { et al. (2004), Broom (1993) }\end{array}$ \\
\hline Infrared thermography & $\begin{array}{l}\text { non-invasive, no/minimal restraint \& minimal contact, } \\
\text { additional application in veterinary and human } \\
\text { medicine in detection of diseases, simple usage }\end{array}$ & $\begin{array}{l}\text { influencing factors: weather conditions, time after } \\
\text { milking/ruminating/feeding/lying, } \quad \text { ultradian/circadian } \\
\text { rhythms; necessity of clean/dry hair coat }\end{array}$ & $\begin{array}{l}\text { Stewart et al. (2005), Alam and Dobson } \\
\text { (1986), Palmer (1981) }\end{array}$ \\
\hline Cortisol- plasma/serum & usual assessment for stress & $\begin{array}{l}\text { invasive, influenced measurement due to restraint and } \\
\text { handling, circadian rhythms, interference of activity } \\
\text { level/reproductive status/social rank }\end{array}$ & $\begin{array}{l}\text { Müller et al. (2013), Stewart et al. (2005), } \\
\text { Alam and Dobson (1986), Fischer et al. } \\
\text { (2002), Bell et al. (1991), Mulleder et al. } \\
\text { (2003), Becker et al. (1984) }\end{array}$ \\
\hline
\end{tabular}

Cortisol- saliva

minimally invasive, no trained person required, specific time lags, circadian rhythms, interference of Negrao et al. (2004), Hernandez (2004), significantly correlated with serum cortisol activity level/reproductive status/social rank

Kirschbaum and Hellhammer (1989),

Fisher et al. (2002), Bell et al. (1991),

Mulleder et al. (2003), Stewart et al. (2005), Cook et al. (1996)

Cortisol- faeces/urine

useful measurement for chronic stress,non-invasive, no restraint \& catheterisation, minimal contact

convenient sampling, non-invasive, no restraint \& no/minimal contact, easy habituation for cows

Cortisol- milk

Remote systems (for expedient in fundamental studies for detecting acute example implanted stress response caused by management practices radio transmitters for

HRV,

temperature)

$$
\text { body }
$$

specific, large time lags, not suitable for judgement of Mostl et al. (2002), Palme et al. (1999), short-term events, circadian rhythms, interference of Fisher et al. (2002), Bell et al. (1991), activity level/reproductive status/social rank

Mulleder et al. (2003), Stewart et al. (2005), Pol et al. (2002)

circadian rhythms,

interference of activity Fukasawa and Tsukada (2010), Fisher et level/reproductive status/social rank, available only in al. (2002), Bell et al. (1991), Mulleder et al. lactating animals (2003), Stewart et al. (2005)

inexpedient for evaluation of animals stress on farm, need Champion et al. (1997), Lefcourt and of surgery or other manipulations, in parts need of carrying Adams (1998), Stewart et al. (2005)

equipment, thus causes changed behaviour and

physiology, partly disruption of normal behaviour pattern,

because animals cannot be released back to their herd 


\section{REFERENCES}

Alam, M.G.S., Dobson, H., 1986. Effect of Various Veterinary Procedures on PlasmaConcentrations of Cortisol, Luteinizing-Hormone and Prostaglandin-F2-Alpha Metabolite in the Cow. The Veterinary Record 118, 7-10.

Atkinson, A.J., Colburn, W.A., DeGruttola, V.G., DeMets, D.L., Downing, G.J., Hoth, D.F., Oates, J.A., Schooley, R.T., Spilker, B.A., Woodcock, J., Zeger, S.L., 2001. Biomarkers Definitions Working Group, Biomarkers and surrogate endpoints: Preferred definitions and conceptual framework. Clinical Pharmacology \& Therapeutics. 69, 89-95.

Becker, B., Christenson, R., Ford, J., Manak, R., Nienaber, J., Hahn, G., Deshazer, J., 1984. Serum cortisol concentrations in gilts and sows housed in tether stalls, gestation stalls and individual pens. Annales De Recherches Veterinaires 15, 237-242.

Boissy, A., Boissou, M.F., 1988. Effects of early handling on heifer's subsequent reactivity to humans and to unfamiliar situations. Applied Animal Behaviour Science 20, 259-273.

Boivin, X., Le Neindre, P., Chupin, J.M., 1992: Establishment of cattle-human relationships. Applied Animal Behaviour Science 32,325-335.

Broom, D.M., 1993. Assessing the welfare of modified or treated animals. Livestock Production Science 36, 39-54.

Buddenberg, B.J., Brown, C.J., Johnson, Z.B., Honea, R.S, 1986. Maternal behaviour of beef cows at parturition. Journal of Animal Science 62, 42-46

Burrow, H.M., 1997. Measurement of temperament and their relationship with performance traits of beef cattle. Animal Breeding Abstracts 65, 478-195.

Burrow, H.M., Dillon, R.D., 1997. Relationships between temperament and growth in a feedlot and commercial carcass traits of Bos indicus crossbreds. Australian Journal of Experimental Agriculture 3, 407-411.

Burrow, H.M., Seifert, G.W., Corbet, N.J., 1988. A new technique for measuring temperament in cattle. Australian Society of Animal Production 17,154-157.

Café, L.M., Robinson, D.L., Ferguson, D.M., Geesink, G.H., Greenwood, P.L., 2011. Temperament and hypothalamic-pituitary-adrenal axis function are related and combine to affect growth, efficiency, carcass, and meat quality traits in Brahman steers. Domestic Animal Endocrinology 40, 230-240.

Champion, R.A., Rutter, S.M., Penning, P.D., 1997. An automatic system to monitor lying, standing and walking behaviour of grazing animals. Applied Animal Behaviour Science 54, 291-305. 
Cook, N.J., Schaefer, A.L., Lepage, P., Jones, S.M., 1996. Salivary vs serum cortisol for the assessment of adrenal activity in swine. Canadian Journal of Animal Science 76, 329-335.

Dänzer, D., 1996. Mit Fleischrindern Geld verdienen. Dlz Agrarmagazin, Sonderheft 6 , BIV Verlagsgesellschaft mbH München.

Dempfle, L., Jaitner, J., Reinsch, N., 1991. Zucht auf Sekundärmerkmale. Wie wichtig sind die "zweitrangigen" Zuchtmerkmale wie Fruchtbarkeit oder Krankheitshäufigkeit tatsächlich? Tierzüchter 43, 160-162.

Ellmore, T.M., Hood, A.J., Castriotta, R.J., Stimming, E.F., Bick, R.J., Schiess, M.C., 2010. Reduced volume of the putamen in REM sleep behaviour disorder patients. Parkinsonism \& Related Disorders 16, 645-649.

Fordyce, G., Goddard, M.E., 1984. Maternal influence on the temperament of Bos indicus cross cows. Australian Society of Animal Production 15, 345-348.

Fordyce, G., Dobt, R.M., Wythes, J.R., 1988. Cattle temperaments in extensive beef herds in northern Queensland. 1. Factors affecting temperament. Australian Journal of Experimental Agriculture 28, 683-687.

Fordyce, G., Howitt, R.G., Holroyd, R.G., O’Rourke, P.K., Enwistle, K.W., 1996. The temperament of Brahman-Shorthorn and Sahiwal-Shorthorn beef cattle in the dry tropics of northern Queensland. 5. Scrotal circumference, temperament, ectoparasite resistance, and the genetics of growth and other traits in bulls. Australian Journal of Experimental Agriculture 36, 9-17.

Fukasawa, M., Tsukada, H., 2010. Relationship between milk cortisol concentration and the behavioral characteristics of postpartum cows introduced to a new group. Animal Science Journal 81, 612-617.

Fung, E.T., Wright, G.L., Dalmasso, E.A., 2000. Proteomic strategies for biomarker identification: progress and challenges. Current opinion in molecular therapeutics 2, 643-650.

Gauly, M., Mathiak, H., Hoffmann, K., Erhardt, G., 2001. Difference in temperament of beef cattle regarding breed and sex. Deutsche Tierärztliche Wochenschrift, $108,206-210$.

Gauly, M., Mathiak, H., Erhardt, G., 2002. Genetic background of behavioural and plasma cortisol response to repeated short-term separation and tethering of beef calves. Journal of Animal Breeding and Genetics, 119, 379-384. 
Glenske, K., 2010. Molekulargenetische Charakterisierung von Genen und Chromosomenabschnitten im Zusammenhang mit Verhalten bei Kälbern der Rassen Dt. Angus und Dt. Fleckvieh. Inaugural-Dissertation zur Erlangung des Grades eines Dr. med. vet. beim Fachbereich Veterinärmedizin der JustusLiebig-Universität Gießen.

Grandin, T., 1993. Behavioural agitation during handling of cattle is persistent over time. Applied Animal Behaviour Science 36,1.

Grandin, T., 1994. Solving livestock handling problems. Veterinary Medicine 89, 989990.

Grandin, T., 1998. Review: Reducing handling stress improves both productivity and welfare. The Professional Animal Scientist 14, 1-10.

Grandin, T., Deesing, M.J., 1998. Genetics and behavior during handling, restraint and herding. In: Grandin, T. (Ed.): Genetics and the behavior of domestic animals. Academic press, San Diego, USA.

Groen, A.F., Steine, T., Colleau, J-J, Pedersen, J., Pribyl, J., Reinsch, N., 1997. Economic values of dairy cattle breeding with special reference to functional traits. Report of an EAAP-working group. Livestock Production Science 49, 121.

Grommers, F.J., 1987. Stockmanship. What is it? In: Seabrook, M.F. (Edit.): Agriculture. The role of stockman in livestock productivity and management. Proceedings of a seminar in the Community programme for coordination of agricultural research, 16th-17th December 1986, Brussel, 11-18.

Hamm, F., 2003. Ethologische und physiologische Untersuchungen zu Mensch-TierInteraktionen in der extensiven Mutterkuhhaltung und der anschließenden Bullenmast. Dissertation zur Erlangung des Doktorgrades der Fakultät für Agrarwissenschaften der Georg-August-Universität Göttingen. Georg-AugustUniversität Göttingen

Hernandez, C., 2004. Effects of Social Separation on Cortisol, Milk Yield and Composition, Udder Health and Behaviour in Dairy Cattle. Swedish University of Agricultural Sciences, Skara

Hoppe, S., Brandt, H.R., König, S., Erhardt, G, Gauly, M., 2010. Temperament traits of beef calves measured under field conditions and their relationships to performance. Journal of Animal Science, 88, 1982-1989.

Kiley-Worthington, M., Plain, S. de la , 1983. The behaviour of beef suckler cattle. Birkenhäuser Verlag, Basel.

Kilgour, R.J., 1975. The open-field test as an assessment of the temperament of dairy cows. Animal Behaviour 23, 615-624. 
Kirschbaum, C., Hellhammer, D.H., 1989. Salivary cortisol in psychobiological research - an overview. Neuropsychobiology 22, 150-169.

Kovalcikova, M., Kovalcik, K., 1982. Relationship between parameters of the open field test of cows and their milk production in loose housing. Applied Animal Ethology 9, 121-129.

Lefcourt, A.M., Adams, W.R., 1998. Radiotelemetric measurement of body temperature in feedlot steers during winter. Journal of Animal Science 76, 18301837.

Le Neindre, P., Trillat, G., Sapa, J., Menissier, F., Bonnet, J.N., Chupin, J.M., 1995. Individual differences in docility in limousin cattle. Journal of Animal Science 73, 2249-2253.

Lyons, D.M., Price, E.O., Moberg, G.P., 1988. Individual differences in temperamet of domestic dairy goats: constancy and change. Animal Behaviour 36, 1323-1333.

Marchant-Forde, R.M., Marlin, D.J. Marchant-Forde, J.N., 2004. Validation of a cardiac monitor for measuring heart rate variability in adult female pigs: accuracy, artefacts and editing. Physiology \& Behavior 80, 449-458.

Mathiak, H., 2002. Genetische Parameter von Merkmalen des Temperaments und der Umgänglichkeit bei den Rassen Dt. Angus und Dt. Fleckvieh. Dissertation zur Erlangung des Doktorgrades am Fachbereich Agrarwisssenschaften, Ökotrophologie und Umweltmanagement der Justus-Liebig-Universität Gießen.

Morris, C.A., Cullen, N.G., Kilgour, R., Bremner, K.J., 1994. Some genetic factors affecting temperament in Bos Taurus cattle. New Zealand Journal of Agricultural Research 37, 167-175.

Mostl, E., Maggs, J.L., Schrotter, G., Besenfelder, U., Palme, R., 2002. Measurement of cortisol metabolites in faeces of ruminants. Veterinary Research Communications 26, 127-139.

Mulleder, C., Palme, R., Menke, C., Waiblinger, S., 2003. Individual differences in behaviour and in adrenocortical activity in beef-suckler cows. Applied Animal Behaviour Science 84, 167-183.

Müller, S., Lehnert, K., Seibel, H., Driver, J., Ronnenberg, K., Teilmann, J., Van Elk, C., Kristensen, J., Everaarts, E., Siebert, U., 2013. Evaluation of immune and stress status in harbour porpoises (Phocoena phocoena): can hormones and mRNA expression levels serve as indicators to assess stress? BMC Veterinary Research 9,145.

Negrao, J.A., Porcionato, M.A., de Passille, A.M., Rushen, J., 2004. Cortisol in saliva and plasma of cattle after ACTH administration and milking. Journal of Dairy Science 87, 1713-1718. 
Palme, R., Robia, C., Messmann, S., Hofer, J., Mostl, E., 1999. Measurement of faecal cortisol metabolites in ruminants: a non-invasive parameter of adrenocortical function. Wien. Tierärztliche Monatsschrift 86, 237-241.

Peakall, D.B., 1994. The role of biomarkers in environmental assessment (1). Introduction. Ecotoxicology 3, 157-160.

Plachta, C., 2009. Untersuchungen zum Temperament von Dt. Angus und Dt. Fleckvieh Rindern sowie deren reziproken Kreuzung anhand verschiedener Testverfahren unter besonderer Berücksichtigung von Kreuzungseffekten. Inaugural-Dissertation zur Erlangung des Grades eines Dr. med. vet. beim Fachbereich Veterinärmedizin der Justus-Liebig-Universität Gießen.

Pol, F., Courboulay, V., Cotte, J.P., Martrenchar. A., Hay, M., Mormede, P., 2002. Urinary cortisol as an additional tool to assess the welfare of pregnant sows kept in two types of housing. Veterinary Research 33, 13-22.

Polta, S.A., Fenzl, T., Jakubcakova, V., Kimura, M., Yassouridis, A., Wotjak, C.T., 2013. Prognostic and symptomatic aspects of rapid eye movement sleep in a mouse model of posttraumatic stress disorder. Frontiers in behavioral neuroscience, 7,60 .

Purcell, D., Arave, C.W., Walters, J.L., 1988, Relationship of three measures of behavior to milk production. Applied Animal Behaviour Science 21, 307-313.

Stewart, M., Webster, J.R., Schaefer, A.L., Cook, N.J., Scott, S.L., 2005. Infrared thermography as a non-invasive tool to study animal welfare. Animal Welfare 14, 319-325.

Stewart, M., Webster, J.R., Verkerk, G.A., Schaefer, A.L., Colyn, J.J., Stafford, K.J., 2007. Non-invasive measurement of stress in dairy cows using infrared thermography. Physiology \& Behavior 92, 520-525.

Tegethoff, M., Raul, J.-S., Jamey, C., Khelil, M.-B., Ludesd, B., Meinlschmidtb, B., 2011. Dehydroepiandrosterone in nails of infants: A potential biomarker of intrauterine responses to maternal stress. Biological Psychology 87, 414-420.

Thompson, M.E., Muller, M.N., Wrangham, R.W., Lwanga, J.S., Potts, K.B., 2009. Urinary C-peptide tracks seasonal and individual variation in energy balance in wild chimpanzees. Hormones and behavior 55, 299-305.

Tulloh, N.M., 1961a. Behaviour of cattle in yards: I. Weighing, order and behaviour before entering scales. Animal Behaviour 9, 25-30.

Tulloh, N.M., 1961b. Behaviour of cattle in yards: II. A study of temperament. Animal Behaviour 9, 25-30. 
Urban, C., 2007. Untersuchungen zum genetischen Hintergrund von Temperament und Umgänglichkeit bei Mutterkühen und Kälbern der Rassen Dt. Angus und Dt. Fleckvieh anhand der Validierung von geeigneten Testverfahren. InauguralDissertation zur Erlangung des Grades eines Dr. med. vet. beim Fachbereich Veterinärmedizin der Justus-Liebig-Universität Gießen.

Vermeire, S., Audenaert, K., De Meester, R., Vandermeulen, E., Waelbers, T., De Spiegeleer, B., Eersels, J., Dobbeleir, A., Peremans, K., 2011. Neuro-imaging the serotonin $2 A$ receptor as a valid biomarker for canine behavioural disorders. Research in veterinary science, $91,465-472$.

Voisinet, B.D., Grandin, T., OConnor, S.F., Tatum, J.D., Deesing, M.J., 1997. Bos indicus cross feedlot cattle with excitable temperaments have tougher meat and a higher incidence of borderline dark cutters. Meat Science, 46, 367-377.

Von Borell, E., Langbein, J., Despres, G., Hansen, S., Leterrier, C., Marchant-Forde, J., Marchant-Forde, R., Minero, M., Mohr, E., Prunier, A., Valance, D., Veissier, I., 2007. Heart rate variability as a measure of autonomic regulation of cardiac activity for assessing stress and welfare in farm animals - A review. Physiology \& Behavior 92, 293-316.

Weiss, J.M., 1972. Psychological Factors in Stress and Disease. Scientific American 226, 104-113

Wong, D.T., 2006. Salivary diagnostics powered by nanotechnologies, proteomics and genomics. The Journal of the American Dental Association 137, 313-321.

Zhang, L., Xiao, H., Zhou, H., Santiago, S., Lee, J.M., Garon, E.B., Yang, J., Brinkmann, O., Yan, X., Akin, D., Chia, D., Elashoff, D., Park, N.H., Wong, D., 2012. Development of transcriptomic biomarker signature in human saliva to detect lung cancer. Cellular and molecular life sciences 69, 3341-3350. 


\title{
CHAPTER III
}

\section{THERMOGRAPHY IN ANIMAL RESEARCH FOR THE ASSESSMENT OF STRESS AND DISEASES}

\author{
Katrin Geburt $^{\mathrm{a}}$ *, Uta König von Borstel ${ }^{\mathrm{a}}$, Matthias Gauly ${ }^{\text {ab }}$ \\ ${ }^{a}$ Georg-August-Universität Göttingen, Department of Animal Science, Livestock Production Systems, \\ Albrecht-Thaer-Weg 3, 37075 Göttingen, Germany \\ ${ }^{\mathrm{b}}$ present address: Faculty of Science and Technology, Universitätsplatz 5 - piazza Università, $5 \mathrm{I}$ \\ 39100 Bozen-Bolzano, Italy \\ * Corresponding author: khille@gwdg.de
}

Keywords: Thermography, Animal welfare, Stress, Diseases, Temperature

\section{ABSTRACT}

Recently, the use of thermal imaging has gained popularity in various disciplines of animal science. This review article provides an overview about infrared thermography (IRT) related to welfare, stress, pain, diseases and inflammation, focusing on livestock. The usefulness of IRT differs for the diverse diseases and infections or other purposes. While a good suitability was attested for detection of virus infections, usability of IRT for detection of diseases of the locomotor system and udder infections is often limited to a supplementary tool. For the detection of diverse diseases by IRT, different reliabilities can be found in literature, in which sensitivity and specificity are strongly depending on the cut-off value, the time of measuring in clinical or post-clinical stage and the decision if all or only the maximum temperatures are included in the evaluation. IRT cannot be considered as a panacea and should also not be used as the sole technique, but it can provide a good, non-invasive 
assistance for many areas of animal research, and practical issues, for example for the detection of (heat) stress and diseases.

\subsection{INTRODUCTION}

The technique of IRT found many applications in human medicine in a plenty of disciplines, for example in breast cancer detection (Joro et al., 2008), angiology (Szabo et al., 2000), sports medicine and rehabilitation (Badza et al., 2012). These applications have soon been extended to animal research. The availability of affordable equipment may be one of the reasons for this rise, and numerous studies have since been released about the use of thermography in research with laboratory and farm animals

At the beginning the operating mode of thermographic spectroscopy is described. Some physiological general stress responses of the animals' body allow for the usage of IRT to measure stress. Today IRT is a useful tool to assess welfare and stress in animals. Compared with typical methods. for stress measurement like the usage of heart rate (HR) (Von Borell et al., 2007), respiratory rate (Eigenberg et al., 2000), blood cortisol (Alam and Dobson 1986) or implanted radio-transmitters (Lefcourt and Adams, 1998), IRT has the advantage to be non-invasive with no or minimal need to contact and restrain the animal (Alam and Dobson 1986, Stewart et al., 2005a). The usage of IRT for the identification of heat stress, stress caused by pain, as well as psychological stress will be explained in this review. Another important field of application of IRT is the detection of diseases and inflammations. This application area is also in connection with the previous, due to the stress which is caused by diseases. One focus is placed on IRT for the recognition of febrile diseases like Foot and Mouth Disease Virus (FMDV), but also non-febrile diseases like lameness diagnoses and inflammations, with an emphasis on mastitis.

Beside all the opportunities of IRT, thermal imaging is limited by several animal related and environmental factors, which can influence the results of the technique. The informative value of IRT data of the bodies' surface can be influenced by factors, such as the ambient temperature (Franze et al., 2012, Alsaaod and Buescher 2012), the distance to the animal (Johnson et al., 2011), sunlight, wind (Palmer 1981, Turner 1991), dirt and moisture of animals coat (Palmer 1981), as well as by rhythmicity of 
body temperature (Bitman et al., 1984, Berry et al., 2003). The review also points to these factors and draws a relation to the influence on the IRT results.

\subsection{THERMOGRAPHIC SPECTROSCOPY}

Thermographic spectroscopy is the graphic representation of the temperature on surfaces (Turner 2001). Every (living or dead) object emits electromagnetic radiation (heat), whose wavelength is correlated to its surface temperature. For ambient temperature, the maximum of the radiation intensity is typically at wavelength in the infrared $(\sim 10 \mu \mathrm{m})$, which is longer than the wavelength of visible light $(0.4-0.7 \mu \mathrm{m})$ (Kleiber 1975). The technique of IRT measures the intensity of the emitted infrared (heat) radiation typically in the range of $8-14 \mu \mathrm{m}$ in order to determine the surface temperature. Even small temperature alterations of $0.1^{\circ} \mathrm{C}$ can be detected by IRT (Stewart et al., 2005a).

Up to $60 \%$ of the heat losses of humans and animals occur as infrared radiation from the body surface. The temperature of the surface is mainly influenced by the blood flow. This is why IRT is a well-known method in medicine for the non-contact detection of the blood flow via the emitted (heat) radiation (Turner 2001). As a reaction of stress, the hypothalamic-pituitary-adrenocortical (HPA) axis is activated, resulting in the production of adrenocorticotropic hormone $(\mathrm{ACTH})$ and thereby cortisol is produced. The cortisol is spread via blood circulation and reaches the organs, where it is needed for coordination of brain and bodily functions as well as for the handling of stress, regeneration and adaptation (Munck et al., 1984). The technique of IRT can be utilized to detect the effects of stress via the measurement of the change of the animal's body surface temperature, as the blood flow through peripheral vessels mainly affects the temperature of the extremities (Hsieh et al. 1990). Changes in the blood flow caused by stress will also modify the radiated heat, which is lost from the animal (Stewart et al., 2005a). The increase in blood circulation of skeleton and brain and the resulting better supply of oxygen is also important in the case of special events, such as the appearance of predators. Thereby, the heart rate increases and the breathing deepen. The liver releases glycogen for the muscles, and the catecholamines adrenalin as well as noradrenalin are delivered by the adrenal medulla (Sambraus 1991). 


\subsection{APPLICATIONS OF IRT TO ASSESSMENT OF ANIMAL WELFARE}

\subsubsection{Assessment of the heat stress and the general stress response}

\subsubsection{Heat stress}

In an experiment of Paim et al. (2013) heat stress of four different sheep breeds was tested by IRT. Half of the animals of this extensive study were housed inside, while the others were housed in an outside paddock. Thermographic images were taken in four-hour-intervals over three days of different parts of the body in order to measure the heat stress during the day and cold stress during the night. Paim et al. (2013) suggested infrared thermography to be a good technique to evaluate the animal's response to its environment.

The welfare of outdoor housed dairy cows exposed to wet and cold climate conditions was studied by Webster et al. (2008) by evaluating different stress measurements of the Holstein Friesian cows under harsh weather conditions. Cows were housed for one week either indoors or outside under continuous exposure to wind and rain at a median temperature of $3.4^{\circ} \mathrm{C}$. Thermographic images were recorded daily, in addition to the collection of faeces and blood samples. The behaviour and core body temperature were also observed. Behavioral and physiological adaptations to the outside climate conditions were found for the outdoor housed cows, their stress axis was activated and they showed reduced welfare. This was shown by less time lying, lower orbital and dorsal temperatures, the internal body temperature showed stronger amplitudes, the mean body temperature was $0.07^{\circ} \mathrm{C}$ higher than in indoor cows, higher concentrations of faecal and plasma cortisol levels as well as non-esterified fatty acids while the number of total white blood cells was lower. (Webster et al., 2008). Earlier, Zahner et al. (2004) studied the ability of cows in open stables in western central Europe to adapt to the predominant climatic conditions. The lactating dairy cows (Brown Swiss, Holstein Friesian, Red Holstein X Swiss Simmental) of four different Swiss farms were observed in winter, spring and summer for five weeks. Tested parameter were skin temperature measured with a temperature sensor, body surface temperature of udder, leg and thigh measured with IRT, rectal temperature, heart rate, cortisol in milk and lying behaviour. Separately for days and nights, the temperature humidity index (THI) was 
calculated based on air temperature and relative air humidity. Significant effects of THI were found for body surface temperature and skin temperature for day and night. There was also a significant effect of THI on lying behaviour, rectal temperature and milk cortisol during the day. Most parameters showed differences between the farms. Zahner et al. (2004) concluded that there are stronger thermoregulatory responses to climatic conditions during the day compared to the night. However, the capacity of the animals to adapt to the conditions was not overcharged.

In recent studies Zhao et al. (2013) report that infrared thermography is suitable to evaluate the feather coverage of laying hens and the resulting heat loss in the birds. Compared to a traditional feather scoring, infrared thermography was found to be more suitable for an objective and quantitative evaluation of feather coverage (Zhao et al., 2013).

Veissier et al. (2000) tested nociception by pointing a $\mathrm{CO}_{2}$ laser on the caudal aspect of the metatarsi of calves. For the experiments, the legs of Holstein calves were shaved and irradiated with the $\mathrm{CO}_{2}$ laser. Analyses by IRT showed that the animals were lifting their legs when the skin temperature reached $45-55^{\circ} \mathrm{C}$. In the second part of the experiment, the response latencies to different power settings were tested to assess validity of the method. In most cases, the animals responded by legkicking. At the higher power settings, the calves showed lower latencies for tailflicking and leg-lifting. The repeatability of the method was also tested with high power settings in nine measurements. There were small alterations in response latencies. The effect of response latencies to the ambient temperature was examined. No effect on the response latencies were found at ambient temperatures of $16-27^{\circ} \mathrm{C}$, but larger response latencies were observed at $7^{\circ} \mathrm{C}$. Veissier et al. (2000) concluded that IRT is as a useful method to measure nociception in cattle as no animal fixation and close contact is necessary. In order to get reliable results of response latency, it is recommendable to take at least three consecutive measures (Veissier et al., 2000).

\subsubsection{Stress caused by pain}

Different parts of the body can be studied by IRT to estimate the effect of various events, which can influence the animal health, stress and behaviour (Stewart et al., 2005a). One example is the possibility to measure the dorsal surface temperature. Cook and Schaefer (2002) measured the stress response of mature wapiti with two 
analgesic methods during cutting their velvet antler. The same was assessed by Cook et al. (2005) in elk and reindeer. The animals included one control group without any analgesic method. The heart rate, respiration rate, white blood cell and cortisol levels were measured as well as the dorsal surface temperature. Thermographic pictures were recorded before and after the removal of the velvet antler. It was found an increase of radiated heat in the dorsal surface area and an increase of the eye temperature after removing the velvet antler (Cook et al., 2005, Cook and Schaefer, 2002).

Stewart et al. (2008a) tested the alteration of the eye temperature, the HRV and the behaviour after disbudding Holstein-Friesian calves. The maximum eye temperature was measured by IRT at the medial posterior palpebral border of the lacrimal caruncle and the lower eyelid. The parameters were measured for 40 minutes after the treatments in a control group and groups with or without local anaesthetic and disbudding or sham disbudding. Same was done by Stewart et al. (2009), who only gave accessory nonsteroidal anti-inflammatory drugs to a part of the animals. For calves without local anesthetics and anti-inflammatory drugs, HR showed a more pronounced increase compared with other treatment groups and stayed elevated for 3 hours. The HRV did not change between the treatments around the time of dehorning, but later after 2-3hours. In the group with local anesthetic, the eye temperature dropped down after 2-3h after dehorning probably because of pain when the effect of local anesthetic declined (Stewart et al., 2009). In the study of Stewart et al. (2008a) some of the disbudded calves were given an ACTH or saline injection after one week. In the disbudded calves without local anesthetic the eye temperature dropped immediately and significantly after disbudding. The drop in disbudded calves with local anaesthetic was not significant. In both disbudded groups, the eye temperature increased five minutes after the treatment and stayed over the baseline for the test period and the heart rate as well as the physical activity increased. After the injection of ACTH, the eye temperature stayed unmodified. Due to this, Stewart et al. (2008) supposed that the hypothalamus-pituitary-adrenal axis (HPA) is not responsible for changes in eye temperature after disbudding. It was suggested that the drop in eye temperature is released by vasoconstriction because of an acute sympathetic response to pain. This eye temperature drop was consistent with other studies, where animals were stressed or frightened. The region regulating the blood flow should be specific for the species. The heart rate frequency and eye 
temperature together are a good non-invasive index for pain and more direct than HPA activity alone (Stewart et al., 2008a).

Eicher et al. (2006) evaluated IRT and behavioural indicators of chronic pain or sensitivity after tail docking. Holstein Friesian heifers with an intact tail were tested and compared to animals that were subjected to a neonatal tail-docking. Neutral, hot and cold packs were placed on the underside of the tails. During the procedure, the animals were videotaped. Before and after the test, IRT images were taken. Heifers with a docked tail showed higher surface temperature changes in the test, which is an indicator for sensitivity alterations. Docked heifers also had higher temperatures on the underside compared with the top of the tail before and after the test. A behavioural indicator of stress in these animals was the higher stomping activity after placing the cold pack on the tail (Eicher et al., 2006).

According to a study by Stewart et al. (2010), the combined use of infrared thermography, HR and HRV provides information about responses by the autonomic nervous system after acute pain. Bull calves were divided into one control group, one group which was subjected a surgical castration, one group with sham handling and local anesthesia and one group with surgical castration and local anesthesia. The eye temperature measured by infrared thermography, increased during the first 20 minutes after the surgical castration with local anesthesia and increased even more after surgical castration without local anesthesia. A small eye temperature increase could also be detected in the control group. Similar results were registered for cortisol level and heart rate (Stewart et al., 2010).

Giansella et al. (2010) studied the effects of rumenocentesis on performance and health. Dairy cows were subjected to a rumenocentesis or sham procedure. Before and four times after the procedure, the skin temperature in this body region was collected using IRT. Blood samples for immunologic response were taken and milk yield and rectal temperature was measured. It was found that the skin temperature measured by IRT increased about $1^{\circ} \mathrm{C}$, but returned to the normal value $48 \mathrm{~h}$ after the rumenocentesis. From the results, Giansella et al. (2010) concluded that rumenocentesis has a minimal harmful effect on cow welfare.

Mc Greevy et al. (2012) used IRT to test, if double bridles and nosebands, which are sometimes used in equestrian disciplines to avoid the opening of the horses' mouth, affect welfare of horses. The temperature of the eyes and the facial skin was measured by IRT in horses wearing a double bridge, either with or without a 
cavesson noseband. The noseband was fixed by a taper gauge as a spacer beside the mandible or at the nasal planum. Horses with double bridles and nosebands, which were fixed with and without taper gauge, showed an increase of eye temperatures. Probably because of reduced vascular perfusion the facial skin of the horses was cooler when the nosebands were tighter. Therefore, Mc Greevy et al. (2012) supposed that there are physiological stress responses of horses, which are wearing double bridles and close nosebands, but their findings were based on five animals. Because of welfare reasons, nosebands which are affecting jaw movement should be reviewed (Mc Greevy et al., 2012).

To evaluate hot-iron and freeze branding in beef cattle, Schwartzkopf-Genswein and Stookey (1997) conducted a study in which they compared the duration and degree of developed inflammation using IRT. The thermal camera was used to assess discomfort and tissue damage in heifers. Previously the mixed breed animals were were clipped at the side and subjected to a freeze or hot-iron branding. Before and after branding, thermal images of the branding area and a control area were recorded. After either branding procedure, branded areas were warmer than the control areas; therefore, tissue damage can be assumed for both methods. However, compared to the freeze branding, the hot-iron branding areas stayed warm for a longer time. Thus, Schwartzkopf-Genswein and Stookey (1997) suspected that hotiron branding generated more discomfort and tissue damage in the animals.

Stubsjoen et al. (2009) wanted to work out if HRV and IRT can discover moderate pain of sheep. Ewes were subjected to a harmful ischaemic stimulus by the practice of a forelimb tourniquet, the stimulus together with an analgesic or only the application of an analgetic. They documented the behaviour, HRV and maximum eye temperature for one hour, including a baseline, the procedure phase and a postprocedure phase. Stubsjoen et al. (2009) observed that HRV tended to decrease in the stimulus group without analgesic, but that it increased from day one to day three. For all treatments, the eye temperature was decreasing during the procedures, on the two last days more than on the first test day. Between day one and three, the vocalization and lip licking decreased. Although based on a limited sample size, the authors concluded that compared to HRV, IRT is a less sensitive method to detect moderate or mild pain in sheep (Stubsjoen et al., 2009).

Vianna and Carrive (2005) found, that the temperatures in paws and tails of fearconditioned rats decrease as a fear response. Prior to testing, the rats were fear- 
conditioned with a shock generator. During the foot-shock session, a thermographic camera took pictures of the animals. While the temperature in paws and tails decreased, the temperature in the eyes, back and head increased. Vianna and Carrive (2005) suggested that fear evokes a cutaneous vasoconstriction in paws and tails in rats. The rats prepare a fight and flight response. In the case of injury, they can reduce blood losses in displayed parts of the body (Vianna and Carrive 2005).

\subsubsection{Psychological stress}

Stewart et al. (2007) tested if the assessment of eye temperature by infrared thermography is a possibility to detect stress. They examined dairy cattle in six different treatments for stimulation of the stress axis. The treatments consisted of a control group with saline application, one with ACTH treatment, two with different doses of Bovine Corticotropin-Releasing Hormone ( $\mathrm{bCRH}$ ), one with epinephrine application and one group with social isolation. All the cows were subjected once to every treatment. Before, during and after the treatments, blood samples were taken and core body temperatures as well as eye temperature were collected. The eye temperature measured by IRT increased after ACTH and saline application, but there was no general, significant increase after exogenous stimulation of the HPA activity or a decrease after the application of epinephrine. The increase after repetition of the catheterization in the second week suggests that the animals anticipated a procedure which stresses them and thus resulted in changes of the eye temperature. Although only six animals were studied, these results, suggest that an involvement of cognitive component is necessary for changing eye temperature (Stewart et al., 2007).

Valera et al. (2012) compared the stress assessment by using IRT at the eye with the common stress measurement by salivary cortisol in jumping horses. They tested horses three hours before, immediately after and three hours after jumping events on three subsequent days and observed that infrared thermography can be used as efficient method to measure stress at horse jumping events (Valera et al., 2012).

Transport stress also causes variations in skin and body temperature. According to Costa (2009), IRT brings up the advantage of an easy measurement of the temperature of living animals under special housing conditions or during slaughter (Costa, 2009).

Stewart et al. (2005b) tested IRT of the eye as a possible method for measuring stress in dairy cattle. The cows were exposed to psychological stress by social 
isolation and were given an injection of ACTH or saline solution for the control group. The increase in cortisol and ACTH concentrations showed that the stress axis was stimulated. The eye temperature increased after and prior to the treatments, which indicates an effect of handling stress or prior activity. After social isolation, the eye temperatures decreased and then increase again, which suggests a sympathetic response caused by psychological stress. During the isolation test, the increase of eye temperature and cortisol concentration was not significant for the first time, but both parameters showed a significant increase when tested for the second time. This indicates that the cows expected the procedure causing a higher stress level. According to Stewart et al. (2005b) IRT of eye temperatures involves some psychological components, so that IRT should be capable to detect acute sympathetic responses and also HPA activity.

According to Stewart et al. (2008b) infrared thermography is also a non-invasive, useful tool to assess dread of pain or fear caused by handling procedures in cattle. In one experiment they tested crossbred heifers for fear responses and measured the maximum eye temperature before and after the treatment. One group was startled by a short waving of a plastic bag; the other group was hit on the rump by a plastic tube. After both treatments, the eye temperature dropped down rapidly and returned to the baseline afterwards. In another experiment of the same study, crossbred bulls were tested for fear or pain responses. Some animals got an electric prod and some animals were startled like in the first experiment, but additionally including shouting. Here, the eye temperatures dropped also but returned later to the baseline after the electric prod (Stewart et al., 2008b).

Warriss et al. (2006) measured in an extensive study the stress of pigs at slaughtering using IRT amongst other measurements. The mean ear temperature of pigs slaughtered in a commercial abattoir was determined. Significant correlations were found between the mean temperatures of the blood lost by the pigs at exsanguination, and the mean temperature of the ear. Furthermore, positive correlations were found between the mean blood temperature and the serum cortisol and between the mean ear temperature and serum creatine kinase as well. Warriss et al. (2006) deduced that pigs with higher temperatures were more stressed.

Monkey emotions were studied by Kuraoka and Nakamura (2011), measureing nasal skin temperatures with IRT. Rhesus monkeys (Macaca mulatto) were presented with videos displaying sounds from conspecifics showing different emotions and 
expressions. Afterwards, the nasal skin temperature was recorded. The results showed significant decreases of the nasal skin temperature after threatening stimuli. Especially the combination of a vocalization together with a facial expression resulted in a strong nasal temperature decrease. Kuraoka and Nakamura (2011) concluded that the nasal skin temperature is one indicator of emotional status in monkeys.

In the case of an avian disease outbreak or at the end of laying hens' laying period, depopulation of the whole barn with carbone dioxide $\mathrm{CO}_{2}$ is suggested as a humane and quick depopulation method for poultry. Turner et al. (2012) tested the physiologic response of the chicken using this method. For the recording of electrocardiographs, electroencephalographs, activity and body temperature, they implanted telemetric transmitters in spent laying hens. The animals were placed in a sealed barn and killed by $\mathrm{CO}_{2}$.inhalation. Hens were observed by IRT along with ambient temperature, $\mathrm{O}_{2-}$ and $\mathrm{CO}_{2}$-concentrations. Within two minutes and at $\mathrm{CO}_{2}$ concentration of 18$20 \%$, the monitored hens lost consciousness after mild to moderate head shaking, muscle contraction and gasping. The brain death followed in less than five minutes. While there were welfare advantages for catching and transporting of the animals, the financial costs for this $\mathrm{CO}_{2}$ depopulation are greater compared to other slaughter techniques. Turner et al. (2012) proposed that results of their study should be used for developing national protocols for poultry depopulation with $\mathrm{CO}_{2}$

The temperature reply to positive stress in laying hens was studied by Moe et al. (2012). The temperature change of the comb was measured after giving a conditioned signal related to the hen's food as a stimulus for positive emotional status during feeding the hens with mealworms. The hens comb showed an average temperature drop about $1.5^{\circ} \mathrm{C}$, which was interpreted as a peripheral vasoconstriction that is similar to the emotional fever caused by negative emotional status. Moe et al. (2012) guesses, that the decreased peripheral temperature reflects the emotional excitement.

\subsubsection{Assessment of local changes due to diseases}

\subsubsection{Febrile diseases}

Rainwater-Lovett et al. (2009) proved that IRT can be used for identifying FMDV in dairy cattle. The maximal foot temperatures were recorded of directly inoculated, contact, vaccinated and healthy animals. The cut-off value of $34.4^{\circ} \mathrm{C}$ was established to detect infected cattle before and after clinical signs appeared. $50 \%$ of the contact 
and $58 \%$ of directly infected animals reached the maximal foot temperature before foot vesicles appeared. Possibly because of the vaccine protection, $24 \%$ of the vaccinated cows showed high temperatures above the cut-off value. In clinical stage of foot-and- mouth-disease a sensitivity (SE) of $79.5 \%$ and a specificity (SP) of $87.5 \%$ could be detected. In the post-clinical stage SE and SD changed to $78.1 \%$ and $88.4 \%$. It was concluded that IRT can assist in quickly identifying potentially FMDV infected cattle during FMDV outbursts. Rainwater-Lovett et al. (2009) also recommended performing more studies for the use of this technology to perceive cows with sub-clinical infections or mild clinical signs. Based on previous studies in which IRT was used to detect infected animals with FMDV, Gloster et al. (2011) wondered if the variation of temperatures in hoofs and eyes is not too great to detect animals in early stages of disease. Therefore, IRT over five month in healthy cattle was done, to test how body temperatures vary under ambient temperatures and with time. The eye temperature as an alternate for core body temperature and the coronary band temperature, a place where foot and mouth disease develops, were collected. The temperature of the eyes displayed the core body temperature well, because they did not differ a lot with changing ambient temperature. Based on these findings IRT was suggested to be a good indicator of fever. Under the climatic conditions of the United Kingdom, the temperatures of the hoofs vary about $26^{\circ} \mathrm{C}$ with the ambient temperature and also the activity of the animals prior to the measurements influenced the results. Therefore, a period of adaptation should be allowed before the measurements start. Due to the influence of the ambient temperature, Gloster et al. (2011) concluded that the practice of taking threshold hoof temperature is a proper indicator of early FMDV.

Schaefer et al. (2004) tested the possibility of IRT as an early prediction method for Bovine Virus Diarrhea Virus (BVDV). A part of the Angus-Hereford crossed calves were infected with BVDV while some animals were kept as an uninfected control group. The temperature sensitivity of the eye, nose, ear and dorsal surface temperature before and after an infection was compared. Clinical scores were given and biological measurements such as cortisol levels were determined. It was found that measuring the eye temperature is the best method for an early detection of an infection with BVDV. Changes in the eye temperature appeared some days up to one week before laboratory tests showed indications of an infection and before clinical scores were changed (Schaefer et al., 2004). 
The usability of IRT for an early detection of Bovine respiratory disease complex (BRD) was also examined by Schaefer et al. (2007) using weaned calves in a large study. The results indicated that IRT could discover diseased animals some days to one week before clinical symptoms appeared (Schaefer et al., 2007). In a recent study, Schaefer et al. (2012) tested again the use of IRT as a prediction method to identify calves with BRD. Calves which were exposed to transportations and auctions were tested for three weeks for BRD by using clinical scores, hematology, serum cortisol levels, core temperature and IRT. Compared to negative tested animals with a temperature of $34.9 \pm 0.22^{\circ} \mathrm{C}$, the true positive tested calves had with $35.7+/-0.35$ ${ }^{\circ} \mathrm{C}$ increased temperatures. According to Schaefer et al. (2012), biometric data for animals' health could be received automatically and non-invasively using an IRT system, which was installed at the water station.

Dunbar and Mac Carthy (2006) investigated the usability of IRT to identify rabiesinfected raccoons. Most of the experimentally infected raccoons (Procyon lotor) developed clinical signs. Images with IRT of the animals were taken twice a day. When the animals developed clinical signs, their surface temperature of the nose began to increase. Significant nose temperature differences were found contrary to the IRT monitored thermal temperature of the eye and the body temperature measured by implants, where no differences existed between the days. Due to the increased nose temperatures in clinically infected raccoons, IRT could be used to identify animals in an infectious stage (Dunbar and Mac Carthy, 2006).

Ellison et al. (2012) tested IRT for the identification of bats, which were inoculated with the bat rabies virus. In the experiment, big brown bats were infected with the virus and were tested together with control animals for temperature changes. Thermographic facial images were recorded one day before up to three weeks after infection. A temperature decrease of $4.6^{\circ} \mathrm{C}$ was found for $62 \%$ of the infected bats. Ellison et al. (2012) suggested that IRT has the potential to identify infected animals. Loughmiller et al. (2001) assessed the relation between the mean body surface temperature of pigs measured by IRT and the ambient temperature. Furthermore, the possibility of using IRT in identifying febrile animals infected with Actinobacillus pleuropneumoniae was judged using crossbred barrows. A part of the pigs were kept in an environmental chamber with a temperature range of $10-32^{\circ} \mathrm{C}$ and thermal images were taken in order to establish the temperature relationship. Noninoculated pigs and pleuropneumonia-inoculated nonfebrile and febrile pigs were subjected to 
IRT and rectal temperature measurement for two hours before and 18 hours after infection. The results showed a significant correlation between the mean body surface temperature and the ambient temperature. Thus, IRT can be taken to account for the ambient temperature. Furthermore, Loughmiller et al. (2001) concluded that IRT is successful in detecting changes in the radiant heat production and mean body surface temperature in febrile pigs.

Dewulf et al. (2003) surveyed IRT as an alternative method for detecting fever and forecast the rectal temperature by the body surface temperature of pigs. Belgian native breed pigs were tested on 45 successive days. Thermal images were collected from their feet, ear, anus and side and were compared to the daily measured rectal temperatures. Rectal temperatures and body surface temperatures showed significant correlations for the most parts of the body. However, it was not possible to make reliable predictions of the rectal temperature, so Dewulf et al. (2003) suggested that IRT cannot be regarded as an adequate alternative to discover fever in pigs. Similarly, Sikoski et al. (2007) assessed the relationship between rectal temperature and IRT measurements of the face axillary region, shoulder and abdomen of cynomolgus macaques (Macaca fascicularis) but could not detect any significant correlations. It was supposed that the larger area considered in IRT measurements give room for more measurement errors compared to rectal temperatures. Alternatively, the excessive amount of fur in these monkeys compared to animals of other studies may have influenced the results (Sikoski et al., 2007). In contrast, Johnson et al. (2011) suggested IRT to be a suitable additional tool for measuring body temperature in ponies as they found significant correlations between temperatures measured via IRT and via microchip as well as temperatures measured rectally in ponies subjected to an equine herpes virus vaccine. At a cutoff temperature of $>38.6^{\circ} \mathrm{C}$, when all measurements of the ponies were used, the SE of detection of febrile animals was $44 \%$ while SP was $98 \%$. The SE increased to $74.6 \%$ and the SP decreased to $92.3 \%$, when only maximum temperatures of an animal per day were used. With a lowered cutoff value of $38^{\circ} \mathrm{C}$, SE increased to $91.5 \%$ and SP declined to $84.6 \%$. Although measurements were also influenced by sunlight and distances between camera and animal, Johnson et al. (2011) highlighted that the noninvasive and remote technique of IRT has advantages over conventional methods as it is well accepted by the animals. 


\subsubsection{Non-febrile diseases}

Arenas et al. (2002) proved the possibility of IRT to detect sarcoptic mange. The Spanish ibex (Capra pyrenaica) were observed with conventional binoculars to identify lesions evoked by mange. IRT was achieved and the results judged as positive or negative. Afterwards, the animals were killed and the distances to the ibexes were measured. Mite detections were performed in routine laboratory diagnosis. The results showed that observations by conventional binoculars are a more specific and more sensitive method for the detection of mange compared to IRT, whose SE decreased with greater distances $>100 \mathrm{~m}$ (Arenas et al., 2002).

Vadlejch et al. (2010) used IRT for detecting temperature changes in different parts of the body after infection of rabbits with oocytes of Eimeria intestinalis. They measured the ocular surface, rectal and ear temperature of inoculated and noninoculated animals. A significant drop of all temperatures could be measured after the inoculation. Vadlejch et al. (2010) could also assess a medium negative correlation in ocular surface, ear and rectal temperature two days after infection.

The diagnostic usefulness of IRT in horses with sinonasal disease was tested by Holzer et al. (2010). All horses of this study underwent an endoscopic, clinical and radiographic examination of oral cavity or respiratory tract. In nine of the horses, the head was also investigated using computer tomography (CT). Thermographic images were recorded from a distance of 1.5 meters from the sides and in front of the heads in order to get the surface temperatures of the left and right maxillary sinuses. The mean temperatures and the temperatures of the opposite side were calculated. No significant correlations occurred between the clinical, radiographic, endoscopic and thermographic results. Therefore, Holzer et al. (2010) saw only limited utility in IRT to detect this disease.

In a study by Allmers et al. (2005), the suitability of IRT for routine measurements of temperature patterns was tested in healthy horses. At nine different target regions of the forelimbs the surface temperature was measured one time before and one time after a treatment with a cooling gel. Before the cooling treatment, the temperatures of the left and right leg were similar to each other. After application of the cooling gel to one leg, the expected decrease in temperature was found in the treated leg. Allmers et al. (2005) affirmed the method to be suitable for equine practitioners to measure temperature differences. 
A comparison of the diagnostic tools radiography, thermography and ultrasonography was performed by Cetinkaya and Demirutku (2012), who analysed the lameness of horses with different degrees of lameness. After a clinical examination consisting of inspection and palpation, the cleaned legs of the horses were investigated with IRT and compared to ultrasonographic and radiographic images of the legs taken afterwards. For this purpose, horses were kept in a closed environment without air circulation. The technique of IRT could uncover increased temperatures of $0.5-1.5^{\circ} \mathrm{C}$ in injured regions. The different methods were evaluated and it was concluded that IRT is a useful appendage for lameness evaluation, when combined with other methods. Temperature increases about $1^{\circ} \mathrm{C}$ could be detected via IRT noninvasively and practicably, while palpation is not easily performable. IRT could help to diagnose lameness in acute cases better than in chronic cases (Cetinkaya and Demirutku, 2012) and helps to detect the inflamed tissue (Eddy et al., 2001). Also in an extensive study by Weil et al. (1998), IRT was proven for lameness diagnosis in horses. Horses which suffered from lameness in the distal forelimb and lameness free horses took part in the study. Thermography was used to calculate temperature differences between the concerning part of the leg and the symmetrically corresponding part of the other forelimb. A significant temperature difference in the forelimbs was only found in horses suffering from lameness, except from horses suffering from periostitis and laminitis. Weil et al. (1998) concluded that IRT can detect lameness-caused changes in skin temperature, but for a reliable diagnosis, a clinical examination with additional procedures is necessary.

According to Turner (1991) IRT increases the accuracy of lameness diagnosis and is therefore a useful aid for clinical evaluation of lameness. By this method temperature changes can be detected earlier than with routine physical examination. For lameness evaluation, thermography suggests valuable information about the intensity of damage, the position of pain and efficiency of treatment. The method also provides unique information about joint diseases, tendon damage, long bone injuries, vertebral column diseases, muscle strains (Turner, 2001) stress injuries, laminitis, stress fractures (Turner, 1991) and generally of the conditions of the foot (Turner, 2001). IRT is a great complementary method together with radiographic and clinical examination. So it can be used in addition to imaging techniques such as scintigraphy and ultrasonography (Turner, 1991). 
Um et al. (2005) performed a study in which they subjected dogs to an induced chronic arthritis. Half of the animals were treated with acupuncture and evaluated the treatment with IRT. The complete Freund's adjuvant, which induced chronic arthritis, was extruded in the left knee joint of the mixed-breed dogs. The skin temperature difference between the knee joints was measured by IRT in the following three weeks of observation. The skin temperature of the animals treated once a week with acupuncture turned back to base value after three weeks, while the temperature difference in the non-treated animals remained high. Um et al. (2005) regarded IRT as a good possibility to evaluate the treatment of chronic induced arthritis in dogs, but the very limited sample size of eight animals must be noted in this study.

One study in veterinary surgery was performed by Infernuso et al. (2010). These authors investigated the possibility to differentiate between stifles with cruciate ligament ruptures and healthy stifles in dogs using IRT. Thermographic images of healthy adult Labrador Retrievers and of dogs with cranial cruciate ligament rupture were taken shorn and unshorn, one hour after clipping. Cruciate ligament rupture was additionally attested by surgery. After image analysis, Infernuso et al. (2010) could determine that IRT had a success rate of $75-85 \%$ to diagnose cruciate ligament ruptures in dogs. For a successful thermographic evaluation of the stifle, it was not necessary to clip the hair. Infernuso et al. (2010) concluded IRT to be suitable to detect cranial cruciate ligament deficiency when a rupture is assumed, but the laxity of the stifle is not evident.

The aim of the experiments performed by Alsaaod and Buescher (2012) was to explore IRT as a noninvasive method for early detecting foot pathologies such as lesions of hind limbs associated with lameness in dairy cows. The temperature changes in the coronary band of cows were measured before and after claw trimming and compared to visually detected abnormalities of the claws. Analyses between preand post- trimming data showed significant temperature differences of the coronary band for cows without and with lesions. Threshold values could be established to ascertain temperature differences between claws with and without lesions. For the detection of hoof lesions, a SE of $85.7 \%$ and SP of $55.9 \%$ before claw trimming, and a SE of $80.0 \%$ and SP of $82.9 \%$ after trimming, could be achieved. Alsaaod and Buescher (2012) concluded also that the surface temperature increased at lame limbs. Stokes et al. (2012) tested IRT as a diagnostic method for foot lesions, especially in the presence of digital dermatitis (DD) in dairy cattle. In the case of claw 
horn lesions, increased temperatures at the coronry band were expected. Cows with and without DD were examined in a crush. Thermal images were taken from all dirty, cleaned and also raised foot at the pastern. No significant temperature difference was found between feet with DD and other claw or skin lesions, regardless of whether the claw was trimmed, clean or dirty. However, IRT was found to be reliable in detecting foot lesions with associated increased temperatures (Stokes et al., 2012). The suitability of IRT for detection of different diseases, the site of measurement at the animal and the detected temperature difference, are shown in Table 3. 
Table 3: Usability of IRT for detection of Foot and Mouth Disease Virus (FMDV), Bovine Virus Diarrhea Virus (BVDV), Bovine Respiratory Disease Complex (BRD), Rabies, Lameness, Chronic Arthritis, Cranial cruciate ligament rupture, Hoof lesions and Mastitis

\begin{tabular}{|c|c|c|c|c|c|}
\hline Disease & Usefulness IRT & $\begin{array}{l}\text { Site of IRT } \\
\text { measurement }\end{array}$ & Temperature difference $\left({ }^{\circ} \mathrm{C}\right)$ & Reference & Type of animal \\
\hline FMDV & yes (foot) & foot, (eye) & $\begin{array}{l}4.7^{\circ} \mathrm{C} \text { to preclinical stage }(30.1+/-4.1 \text { to } 34.8+/- \\
3.4), 7.2^{\circ} \mathrm{C} \text { to clinical stage }(37.3+/-3.4)\end{array}$ & $\begin{array}{l}\text { Rainwater-Lovett et al. } \\
\text { (2009) }\end{array}$ & dairy cattle \\
\hline BVDV & yes (eye) & $\begin{array}{l}\text { eye, nose, ear, } \\
\text { hooves, back, } \\
\text { side }\end{array}$ & $\begin{array}{l}\text { eye: earliest and less variable difference, } 2.6^{\circ} \mathrm{C} \\
+/-0,15 \text { until day } 10 \text { post infection; nose: } 3.5^{\circ} \mathrm{C} \text {; } \\
\text { ear: } 3.9^{\circ} \mathrm{C} \text {; side: } 1.9^{\circ} \mathrm{C} \text {; dorsal: } 1.8^{\circ} \mathrm{C}\end{array}$ & Schaefer et al. (2004) & beef calves \\
\hline BRD & yes (eye) & $\begin{array}{l}\text { eye, nose, ear, } \\
\text { hooves, back, } \\
\text { side }\end{array}$ & $\begin{array}{l}0.8^{\circ} \mathrm{C} \text { between healthy and infected calves }(34.9 \\
+/-0.22 \text { to } 35.7+/-0,35)\end{array}$ & Schaefer et al. (2012) & beef calves \\
\hline Rabies & $\begin{array}{l}\text { yes (nose, in } \\
\text { clinical stage) }\end{array}$ & $\begin{array}{l}\text { eye, nose, body } \\
\text { surface }\end{array}$ & $\begin{array}{l}8.4^{\circ} \mathrm{C} \text { preinoculation to clinical stage }(22.0+/-0.9 \\
\text { to } 30.4+/-3.5)\end{array}$ & $\begin{array}{l}\text { Dunbar and Mac } \\
\text { Carthy, } 2006\end{array}$ & $\begin{array}{l}\text { racoons } \\
\text { (Procyon lotor) }\end{array}$ \\
\hline Rabies & yes & facial & $\begin{array}{l}62 \% \text { infected animals showed }-4.6^{\circ} \mathrm{C}+/-2.5 \text { to } \\
\text { the baseline }\end{array}$ & Ellison et al. (2012) & $\begin{array}{l}\text { big brown bats } \\
\text { (Eptesicus } \\
\text { fuscus) }\end{array}$ \\
\hline Lameness & $\begin{array}{l}\text { yes, useful addition } \\
\text { for lameness } \\
\text { evaluation }\end{array}$ & legs & increase of $0.5-1.5^{\circ} \mathrm{C}$ in injured regions & $\begin{array}{l}\text { Cetinkaya and } \\
\text { Demirutku, } 2012\end{array}$ & horses \\
\hline $\begin{array}{l}\text { Chronic } \\
\text { Arthritis }\end{array}$ & yes & knee joint & increase of $0,3^{\circ} \mathrm{C}$ & Um et al. (2005) & dogs \\
\hline $\begin{array}{l}\text { Cranial } \\
\text { cruciate } \\
\text { ligament } \\
\text { rupture }\end{array}$ & yes & stifle & no significant temperature difference & Infernuso et al. (2010) & dogs \\
\hline Hoof lesions & yes & $\begin{array}{l}\text { claw (coronary } \\
\text { band region and } \\
\text { skin above) }\end{array}$ & $\begin{array}{l}1.64+/-0.95 \text { pre-trimming, } 2.18+/-1.37 \text { post- } \\
\text { trimming }\end{array}$ & $\begin{array}{l}\text { Alsaaod and Buescher } \\
(2012)\end{array}$ & dairy cattle \\
\hline
\end{tabular}




\begin{tabular}{|c|c|c|c|c|c|}
\hline Disease & Usefulness IRT & $\begin{array}{l}\text { Site of IRT } \\
\text { measurement }\end{array}$ & Temperature difference $\left({ }^{\circ} \mathrm{C}\right)$ & Reference & Type of animal \\
\hline Mastitis & yes & udder & $\begin{array}{l}\text { n.s. between udder quarters, but strong } \\
\text { correlation with California Mastitis Test }\end{array}$ & Colak et al. (2008) & dairy cattle \\
\hline Mastitis & yes & udder & $\begin{array}{l}\text { mastitic quarters } 2.35^{\circ} \mathrm{C} \text { higher than healthy } \\
\text { quarters }\end{array}$ & Polat et al. (2010) & dairy cattle \\
\hline Mastitis & $\begin{array}{l}\text { no early } \\
\text { identification tool } \\
\text { for induced } \\
\text { mastitis, not closely } \\
\text { related to mastitic } \\
\text { signs, local signs } \\
\text { were seen before }\end{array}$ & udder & $1-1.5^{\circ} \mathrm{C}$ & Hovinen et al. (2008) & dairy cattle \\
\hline Mastitis & $\begin{array}{l}\text { successfull } \\
\text { detection of } \\
\text { changes in udder } \\
\text { temperature, not } \\
\text { useful for } \\
\text { promising early } \\
\text { mastitis }\end{array}$ & udder & $2-3^{\circ} \mathrm{C}$ & Pezeshki et al. (2011) & dairy cattle \\
\hline
\end{tabular}




\subsection{INFLAMMATIONS}

In a study by Spire et al. (1999), the feasibility of IRT was examined to detect inflammation in cattles' ears caused by contaminated growth promotant implants. Yearling crossbred beef steers with clean and contaminated ear implants and nonimplanted control animals were enrolled in the study. For the experimental period of three weeks, thermal images of the caudal and rostral surface of the cattle were taken at four different parts of the ear. The results indicated significant temperature differences between control animals and ears with contaminated implants. Moreover, a higher contrast in ear temperature of control and contaminated ears was observed when the ambient temperatures were low. Spire et al. (1999) concluded that IRT can identify abscesses in beef cattle induced by contaminated growth promotants.

The possibility of IRT to detect inflamed leg joints of fattening pigs was tested by Savary et al. (2008). To get baseline temperatures of diverse parts of the body, healthy pigs were examined with IRT. Thermal images of both body sides were taken from pigs, which were supposed to have an inflamed leg joint. For the analyses, it was differentiated between target and reference regions. In both regions, the measured skin temperature increased with ambient temperature. Due to the fact that up to $38 \%$ of the measurements of anatomic symmetrical body parts of healthy pigs showed large temperature differences, IRT seemed not to be a reliable method to diagnose inflamed leg joints. The same was seen for reference and target regions. Only $9.5 \%$ of leg joints with evidenced acute inflammation could be detected by IRT, while $10 \%$ of the legs from healthy pigs were detected as inflamed. Savary et al. (2008) concluded that IRT alone is not suitable to diagnose joint inflammation in pigs.

The use of IRT as an automatic health monitoring system was tested in Holstein Friesian cows in an extensive study by Franze et al. (2012). The thermal camera was placed in the milking parlor and images were taken at every milking. The researchers detected that cows with healthy udders had significantly different temperatures of rear udder quarters compared with cows with udder diseases. By applying daily IRT tests, SP of around $70 \%$ and SE of around $30 \%$ for mastitis of rear udder quarters, unspecific mastitis and latent infections could be detected (Franze et al., 2012). 
The use of IRT as an early detection method for subclinical mastitis was tested in a study by Colak et al. (2008). California Mastitis test and IRT of each quarter was performed in Holstein and Brown Swiss cows. The results presented a strong correlation between the California mastitis score and the skin surface temperature. Because IRT was sensitive enough to detect changes in skin surface temperature due to mammary gland infection, it is proposed as an excellent noninvasive detecting method, which can help to realize early treatments of mastitis (Colak et al., 2008). In a similar study, Polat et al. (2010) compared the ability detect subclinical mastitis based on IRT results with that of the California mastitis test and the somatic cell count. One day before the test, lactating Brown Swiss cows were subjected to a health inspection to eliminate the possibility of diseases other than subclinical mastitis. An udder palpation and milk test was utilized. To minimize external influences before the test, the dairy cows were placed in a room not receiving sunshine to adapt to the same conditions. The udder skin surface temperature was determined using IRT and the somatic cell count was measured. The results showed strong positive correlations between the udder skin surface temperature and the California mastitis test as well as with the somatic cell count. The skin surface temperature of mastitic quarters was about $2.35^{\circ} \mathrm{C}$ higher than the healthy quarters. SP and SE of IRT were similar compared to California mastitis test. Polat et al. (2010) concluded that IRT is a quick and noninvasive tool, which is sensitive enough to detect udder skin temperature changes caused by subclinical mastitis. They promote the technique for mastitis detection making an early treatment possible (Polat et al., 2010). The suitability of IRT for early detection of mastitis was moreover tested by Hovinen et al. (2008). The left forequarters of healthy Holstein Frisian and Finnish Ayrshire cows in late lactation were experimentally inoculated with Escherichia coli endotoxin. For a period of five days, udder temperature detected by IRT and rectal temperature was measured and local signs of the udder, milk appearance and systemic signs of the cow were observed. The first local and systemic signs appeared two hours post inoculation. However, an increase in udder temperature and rectal temperature was first seen four hours post inoculation. Electrical conductivity and somatic cell count also increased after the same time span. For detecting temperature changes of $1-1.5^{\circ} \mathrm{C}$ on udder skin caused by clinical mastitis, IRT was a suitable tool. Contrary to the studies before, Hovinen et al. (2008) do not advised IRT to be an early identification tool of cows with induced clinical mastitis due to the fact 
that udder temperature was closely related to rectal temperature, but not to the mastitis signs, which appeared earlier. It must be noted, that only a few animals were involved in the study. According to Hovinen et al. (2008), IRT of the udder is a possible tool for detection of febrile diseases. Thus, a thermal camera in the milking parlor can be useful (Hovinen et al., 2008). Pezeshki et al. (2011) also subjected dairy cows to intramammary infections with Escherichia coli to prove IRT for the detection of changes in udder skin surface temperature. After parturition, the left quarters of primiparous cows were inoculated. Thermografic images were taken from the udder of the Holstein Friesian cows afterwards and milk and blood samples were gathered before and after the application. The results showed changes in prostaglandin, somatic cell count, basophils, tumor necrosis factor-alpha, milk potassium und sodium concentrations. Thermography could detect changes in udder skin temperature of $2-3^{\circ} \mathrm{C}$. Local signs of mastitis and rectal temperature increase occurred before the peak of udder skin temperature. Like Hovinen et al. (2008), Pezeshki et al. (2011) suggested IRT not to be an early detection method for mastitis.

\subsection{FACTORS INFLUENCING RESULTS OBTAINED BY THERMAL IMAGING}

In human medicine thermography can be done under controlled environmental factors. This is generally not or only to a limited extent the case in veterinary medicine (Cetinkaya and Demirutku 2012). This is a reason why there are plenty of factors that potentially influence the results of IRT. When using IRT as a tool for stress measurement these limitations need to be regarded (Stewart et al., 2005a).

\subsubsection{Internal (animal related) factors}

Circadian rhythms such as the time following lying, ruminating, feeding, milking and exercise exert influence on the results of infrared thermography (Stewart et al., 2005a, Colak et al., 2008, Berry et al., 2003). In a study by Bitman et al. (1984), the rhythmicity of body and udder temperatures was evaluated for Holstein cows in early and late lactation. Thermistors were implanted in the peritoneal cavity and the right front quarter of the udder, which documented the temperature every $1.4 \mathrm{~min}$ for five days. The ambient temperatures were recorded for reference. The examination revealed a clear 
correlation between body and udder temperature. For most cows, a 24-hours-rhythm with two daily troughs with an amplitude of $1.25^{\circ} \mathrm{C}$ and an ultradian rhythm with a nearly 90 min period and an amplitude of $0.41^{\circ} \mathrm{C}$ appeared. This repetitive pattern suggests a control mechanism of heat production and heat loss. Bitman et al. (1984) recommended a consideration of rhythmicity of body and udder temperature in research on mastitis. $A$ circadian rhythm of the udder temperature was also found by Berry et al. (2003). The udder temperature of healthy multiparous Holstein Frisian cows with cleaned quarters was analyzed using IRT. To get knowledge about the pattern and magnitude of udder temperature variation, the within-day and daily variation was measured. The results showed a significant rise of udder temperature after the daily exercise period of the cows. A clear circadian rhythm was detected after observing the within-day udder temperature. Berry et al. (2003) found out that parameters of environmental temperature together with the previous daily temperature of the udder enables with high accuracy the prediction of current udder temperature. The minor difference between current and predicted temperature makes the detection of an inflammation possible. Berry et al. (2003) ascertained that measurements of IRT combined with ambient temperature can be used for early monitoring of mastitis in dairy cows.

Rosenmeier et al. (2012) studied the coronary band temperatures with IRT in healthy horses, which were tested every hour from 8 AM to 10 PM for four days. IRT pictures were taken from all legs and ambient and rectal temperatures were recorded. The temperature of the coronary band followed a diurnal pattern and showed correlations with the ambient temperature. Rosenmeier et al. (2012) established that the coronary band temperature can vary among the legs and during the day. This has to be regarded for the use of temperatures of the coronary band as an indicator for laminitis or other clinical research (Rosenmeier et al. 2012). The time of the day had also a clear influence on the surface temperature in the study of Franze et al. (2012). The temperatures measured by IRT were $0.2-0.4 \mathrm{~K}$ higher in the evening compared to the morning (Franze et al., 2012).

Wrenn et al. (1958) found that body temperature in dairy cows varied with their physiological state. The body temperature of dairy cows was tested with a rectal thermometer in combination with infrared thermography observations. The body temperature was at the lowest point just before estrus while it is high at estrus. For ovulation, the temperature is low again and high for the luteal phase. A decline of body 
temperature was found immediately before parturition (Wrenn et al., 1958). Nikkhah et al. (2005) wanted to ascertain the possibility of IRT to detect differences in hoof temperature in two lactating stages of dairy cows. This should be related to the appearance of underrun heels and sole hemorrhages. For these indicators of laminitis, the hooves of Holstein Frisian cows were examined once in early/midlactation and one time in late lactation. Temperature difference was calculated of the coronary band and a control region above this. Cows in the early/midlactation $(<=200$ days in milk (DIM)) showed higher coronary band temperatures and temperature differences compared to cows in late lactation (>200 DIM). Sole hemorrhages occurred more often in early/midlactating cows. In contrast cows in late lactation showed more often underrun heels than cows in early lactation stage (Nikkhah et al. 2005). Alsaaod and Buescher (2012) tested IRT as a tool to detect hoof lesions. They detected that surface temperatures of the skin, the coronary band at the hind limbs and the temperature difference between both were significantly lower in healthy cows > 200 DIM compared with healthy cows <= 200 DIM (Alsaaod and Buescher 2012). Also Colak et al. (2008) supposed an influence of the physiological state and production level on udder temperature in dairy cows. Furthermore the animals' coat should be clean, because dirt changes the conductivity and emissivity, and moisture contributes to heat loss (Palmer 1981).

\subsubsection{External (environmental) factors}

Franze et al. (2012) tested IRT as an automatic health monitoring method for dairy herds. With correlations about 0.6 , the results presented a great influence of the ambient temperature on the surface skin temperature. Similar results were found by Alsaaod and Buescher (2012), who assumed that the ambient temperature is positively correlated with the temperatures of the coronary band and the skin. The effects of factors such as relative humidity, air pressure, wind speed and cleanliness were claimed as negligible in these studies (Franze et al., 2012). This statement is in contrast to other authors: It is not possible to obtain reasonable results from the infrared camera outside a stable with exposure to sunlight or wind (Palmer, 1981). A possible effect on the surface skin temperature of the udder through the humidity of the skin and environment is assumed by Colak et al. (2008). To get exact results, thermographic images must be taken in a draft-free and temperature-controlled space. To avoid 
heating of the skin, this research area should be sheltered from sunlight and the hair should have an even length (Turner, 1991).

The intraobserver reproducibility of ocular thermography in healthy humans was examined by Klamann et al. (2012). They checked eyes with an ocular surface-oriented thermographic camera. One examiner measured the ocular surface temperature over a period of ten seconds with three repetitions. Due to the high intraclass correlation coefficient for mean, minimum and maximum temperatures, it is suggested that IRT could offer new options for examining the ocular surface physiology (Klamann et al., 2012).

Table 4 shows factors that influence the measured results by IRT.

Table 4: Internal and external factors influencing IRT measurements

\begin{tabular}{|c|c|c|c|}
\hline Internal factor & Influcence on measurement & Reference & Type of animal \\
\hline $\begin{array}{l}\text { Circadian/ultradian rhythms } \\
\text { of body/udder temperature }\end{array}$ & Mastitis research & $\begin{array}{l}\text { Bitman et al. (1984), } \\
\text { Berry et al. (2003) }\end{array}$ & Dairy cows \\
\hline $\begin{array}{l}\text { Diurnal/between leg } \\
\text { variation of coronary band } \\
\text { temperature }\end{array}$ & Laminitis research & $\begin{array}{l}\text { Rosenmeier et al. } \\
\text { (2012) }\end{array}$ & Horses \\
\hline Lactation stage & $\begin{array}{l}\text { Coronary band temperature, } \\
\text { Sole hemorrhages }\end{array}$ & $\begin{array}{l}\text { Nikkhah et al. (2005), } \\
\text { Alsaaod and Buescher } \\
\text { (2012) }\end{array}$ & Dairy cows \\
\hline Dirty/ wet coat & $\begin{array}{l}\text { Conductivity/emissivity, heat } \\
\text { loss }\end{array}$ & Palmer (1981) & Dairy cows \\
\hline Exercise & Rise of udder temperature & Berry et al. (2003) & Dairy cows \\
\hline External factor & Influcence on measurement & Reference & Type of animal \\
\hline Ambient temperature & $\begin{array}{l}\text { Surface skin temperature, } \\
\text { coronary band }\end{array}$ & $\begin{array}{l}\text { Franze et al. (2012), } \\
\text { Alsaaod and Buescher } \\
\text { (2012) }\end{array}$ & Dairy cows \\
\hline Sunlight & Heating of the skin & $\begin{array}{l}\text { Palmer (1981), Turner } \\
\text { (1991) }\end{array}$ & Dairy cows \\
\hline Humidity & $\begin{array}{l}\text { Conductivity/emissivity, heat } \\
\text { loss }\end{array}$ & Colak et al. (2008) & Dairy cows \\
\hline Wind/draft & Cooling of the skin & Turner (1991) & Dairy cows \\
\hline Distance to the animal & Biassed measurement result & Johnson et al. (2011) & Ponies \\
\hline
\end{tabular}




\subsection{CONCLUSION}

In research of farm animals IRT has potential for application in welfare assessment as well as for the detection of stress and pain. Possible application areas of IRT are the evaluation of the animals' response to its environment and the adaptation to outside climate conditions. Also stress caused by pain, especially at disbudding, tail docking, cattle branding or surgical castration, can be detected by IRT. For these applications IRT is used as a sole or an additional tool. The measurement of psychological stress by IRT performed well at horse jumping events or slaughtering of pigs. Good opportunities are also offered for the early identification of different diseases like FMDV, BVDV or BRD. The opinions differ for the usability of IRT for the detection of fever. Similarly for sinonasal diseases limited usage of the technique is seen. In lameness diagnoses IRT should mostly be a suitable appendage. For mastitis, IRT was in the majority of cases seen as a valuable early detection method. Infrared thermography is able to be a good assistance for many parts of animal research but generally should not be used as the sole technique. It must be considered that especially in farm animal research plenty of factors can influence the measurements obtained by this technique and confine the informative value of IRT. 


\section{REFERENCES}

Alam, M. G. S., Dobson, H., 1986. Effect of Various Veterinary Procedures on Plasma-Concentrations of Cortisol, Luteinizing-Hormone and Prostaglandin-F2Alpha Metabolite in the Cow. Veterinary Record 118, 7-10.

Allmers, E., Hollenberg, C., Heldt, S., Meyer, W., 2005. Routine use of an infrared thermometer in measuring the body surface temperature pattern of horse limbs. Tieräerztliche Praxis Ausgabe Grosstiere Nutztiere 33, 181-187.

Alsaaod, M., Buscher, W., 2012. Detection of hoof lesions using digital infrared thermography in dairy cows. Journal of Dairy Science 95, 735-742.

Arenas, A. J., Gomez, F., Salas, R., Carrasco, P., Borge, C., Maldonado, A., O'Brien, D.J., Martinez-Moreno, F.J., 2002. An evaluation of the application of infrared thermal imaging to the tele-diagnosis of sarcoptic mange in the Spanish ibex (Capra pyrenaica). Veterinary Parasitology 109, 111-117.

Badza, V., Jovancevic, V., Fratric, F., Roglic, G., Sudarov, N., 2012. Possibilities of thermovision application in sport and sport rehabilitation. Vojnosanitetski Pregled 69, 904-907.

Becker, B., Christenson, R., Ford, J., Manak, R., Nienaber, J., Hahn, G., Deshazer, J., 1984. Serum cortisol concentrations in gilts and sows housed in tether stalls, gestation stalls and individual pens. Annales De Recherches Veterinaires 15, 237-242.

Bell, M. E., Wood, C.E., Kellerwood, M., 1991. Influence of reproductive state on pituitary-Adrenal activity in the ewe. Domestic Animal Endocrinology 8, 245254.

Berry, R. J., Kennedy, A.D., Scott, S.L., Kyle, B.L., Schaefer,A.L., 2003. Daily variation in the udder surface temperature of dairy cows measured by infrared thermography: Potential for mastitis detection. Canadian Journal of Animal Science 83, 687-693.

Bitman, J., Lefcourt, A., Wood, D.L., Stroud, B., 1984. Circadian and ultradian temperature rhythms of lactating dairy. Journal of Dairy Science 67, 1014-1023.

Broom, D. M., 1993. Assessing the welfare of modified or treated animals. Livestock Production Science 36, 39-54.

Cetinkaya, M.A., Demirutku, A., 2012. Thermography in the assessment of equine lameness. Turkish Journal of Veterinary \& Animal Sciences 36, 43-48.

Colak, A., Polat, B., Okumus, Z., Kaya, M., Yanmaz, L.E., Hayirli, A., 2008. Early Detection of Mastitis Using Infrared Thermography in Dairy Cows. Journal of Dairy Science 91, 4244-4248. 
Cook, N. J., Schaefer, A.L., 2002. Stress responses of wapiti (Cervus elaphus canadensis) to removal of velvet antler. Canadian Journal of Animal Science, 82: $11-17$.

Cook, N. J., Schaefer, A.L., Lepage, P., Jones,S.M., 1996. Salivary vs serum cortisol for the assessment of adrenal activity in swine. Canadian Journal of Animal Science 76, 329-335.

Cook, N.J., Schaefer, A.L., Webster, J.R., Matthews, L.R., Suttie, J.M., 2005. Stress and pain assessment of velvet antler removal from Elk (Cervus elaphus canadensis) and Reindeer (Rangifer tarandus). Online Journal of Veterinary Research 9, 24-36.

Costa, L. N. 2009. Short-term stress: the case of transport and slaughter. Italian Journal of Animal Science 8, 241-252.

Dewulf, J., Koenen, F., Laevens, H., De Kruif, A., 2003. Infrared thermometry is not suitable for the detection of fever in pigs. Vlaams Diergeneeskundig Tijdschrift 72, 373-379.

Dunbar, M. R., MacCarthy, K.A., 2006. Use of infrared thermography to detect signs of rabies infection in raccoons (Procyon lotor). Journal of Zoo and Wildlife Medicine 37, 518-523.

Eddy, A. L., Van Hoogmoed, L.M., Snyder, J.R., 2001. The role of thermography in the management of equine lameness. Veterinary Journal 162, 172-181.

Eicher, S. D., Cheng, H.W., Sorrells, A.D., Schutz, M.M., 2006. Short communication: Behavioral and physiological idicators of sensitivity or chronic pain following tail docking. Journal of Dairy Science 89, 3047-3051.

Eigenberg, R. A., Hahn, G.L., Nienaber, J.A., Brown-Brandl, T.M., Spiers,D.E., 2000. Development of a new respiration rate monitor for cattle. Transactions of the Asae 43, 723-728.

Ellison, J.A., Johnson, S.R., Kuzmina, N., Gilbert, A., Carson, W.C., Vercauteren, K.C., Rupprecht, C.E., 2013. Multidisciplinary approach to epizootiology and pathogenesis of bat rabies viruses in the United States. Zoonoses and public health 60, 46-57.

Fisher, A. D., Verkerk, G.A., Morrow, C.J., Matthews, L.R., 2002. The effects of feed restriction and lying deprivation on pituitary-adrenal axis regulation in lactating cows. Livestock Production Science 73, 255-263.

Franze, U., Geidel, S., Heyde, U., Schroth, A., Wirthgen, T., Zipser, S., 2012. Investigation of infrared thermography for automatic health monitoring in dairy cows. Züchtungskunde 84, 158-170. 
Gianesella, M., Morgante, M., Stelletta, C., Ravarotto, L., Giudice, E., Van Saun, R.J., 2010. Evaluating the Effects of Rumenocentesis on Health and Performance in Dairy Cows. Acta Veterinaria Brno 79, 459-468.

Gloster, J., Ebert, K., Gubbins, S., Bashiruddin, J., Paton, D.J., 2011. Normal variation in thermal radiated temperature in cattle: implications for foot-andmouth disease detection. Bmc Veterinary Research 7.

Guida, M., Tommaselli, G.A., Palomba, S., Pellicano, M., Moccia, G., Di Carlo, C., Nappi, C., 1999. Efficacy of methods for determining ovulation in a natural family planning program. Fertility and sterility 72 , 900-904.

Hsieh, J.C., Chan, K.H., Lui, P.W., Lee, T.Y., 1990. Clinical application of infrared thermography in diagnosis and therapeutic assessment of vascular ischemic pain. Ma zui xue za zhi = Anaesthesiologica Sinica 28, 493-501.

Holzer, K., Rijkenhuizen, A.B.M., Simhofer, H., 2010. Thermographic imaging in the diagnosis of equine sinonasal disease. Pferdeheilkunde 26, 168-172.

Hovinen, M., Siivonen, J., Taponen, S., Hanninen, L., Pastell, M., Aisla, A.M., Pyorala, S., 2008. Detection of Clinical Mastitis with the Help of a Thermal Camera. Journal of Dairy Science 91, 4592-4598.

Infernuso, T., Loughin, C.A., Marino, D.J., Umbaugh, S.E., Solt, P.S., 2010. Thermal Imaging of Normal and Cranial Cruciate Ligament-Deficient Stifles in Dogs. Veterinary Surgery 39, 410-417.

Johnson, S. R., Rao, S., Hussey, S.B., Morley, P.S., Traub-Dargatz, J.L., 2011. Thermographic Eye Temperature as an Index to Body Temperature in Ponies. Journal of Equine Veterinary Science 31, 63-66.

Joro, R., Laaperi, A.L., Dastidar, P., Soimakallio, S., Kuukasjarvi, T., Toivonen, T., Saaristo, R., Jarvenpaa, R., 2008. Imaging of breast cancer with mid- and longwave infrared camera. Journal of medical engineering \& technology 32, 189197.

Kirschbaum, C., Hellhammer, D.H., 1989. Salivary cortisol in psychobiological research- An overview. Neuropsychobiology 22, 150-169.

Klamann, M.K.J., Maier, A.K.B., Gonnermann, J., Klein, J.P., Pleyer, U., 2012. Measurement of Dynamic Ocular Surface Temperature in Healthy Subjects Using a New Thermography Device. Current Eye Research 37, 678-683.

Kleiber, M., 1975. The fire of life. RE Krieger Publishing Company: Huntington, New York, USA.

Kuraoka, K., Nakamura, K., 2011. The use of nasal skin temperature measurements in studying emotion in macaque monkeys. Physiology \& Behavior 102, 347-355. 
Lefcourt, A. M., Adams, W.R., 1998. Radiotelemetric measurement of body temperature in feedlot steers during winter. Journal of Animal Science 76, 18301837.

Loughmiller, J. A., Spire , M.F., Dritz, S.S., Fenwick, B.W., Hosni, M.H., Hogge, S.B., 2001. Relationship between mean body surface temperature measured by use of infrared thermography and ambient temperature in clinically normal pigs and pigs inoculated with Actinobacillus pleuropneumoniae. American Journal of Veterinary Research 62, 676-681.

McGreevy, P., Warren-Smith, A., Guisard, Y., 2012. The effect of double bridles and jaw-clamping crank nosebands on temperature of eyes and facial skin of horses. Journal of Veterinary Behavior-Clinical Applications and Research 7, 142-148.

Moe, R.O., Stubsjoen, S.M., Bohlin, J., Flo, A., Bakken, M., 2012. Peripheral temperature drop in response to anticipation and consumption of a signaled palatable reward in laying hens (Gallus domesticus). Physiology \& Behavior 106, 527-533.

Mulleder, C., Palme, R., Menke, C., Waiblinger, S.,. 2003. Individual differences in behaviour and in adrenocortical activity in beef-suckler cows. Applied Animal Behavior Science 84, 167-183.

Munck, A., Guyre, P.M., Holbrook, N.J., 1984. Physiological Functions of Glucocorticoids in Stress and their Relation to Pharmacological Actions. Endocrine Reviews 5, 25-44.

Nikkhah, A., Plaizier, J.C., Einarson, M.S., Berry, R.J., Scott, S.L., Kennedy, A.D., 2005. Short communication: Infrared thermography and visual examination of hooves of dairy cows in two stages of lactation. Journal of Dairy Science 88, 2749-2753.

Paim, T. D., Borges, B.O., Lima, P.D.T., Gomes, E.F., Dallago, B.S.L., Fadel, R., de Menezes, A.M., Louvandini, H., Canozzi, M.E.A., Barcellos, J.O.J., McManus, C., 2013. Thermographic evaluation of climatic conditions on lambs from different genetic groups. International Journal of Biometeorology 57: 59-66.

Palmer, S., 1981. Use of the portable infrared thermometer as a means of measuring limb surface temperature in the horse. American Journal of Veterinary Research 42, 105-108.

Pezeshki, A., Stordeur, P., Wallemacq, H., Schynts, F., Stevens, M., Boutet, P., Peelman, L.J., De Spiegeleer, B., Duchateau, L., Bureau, F., Burvenich, C., 2011. Variation of inflammatory dynamics and mediators in primiparous cows after intramammary challenge with Escherichia coli. Veterinary Research 42. 
Polat, B., Colak, A., Cengiz, M., Yanmaz, L.E., Oral, H., Bastan, A., Kaya, S., Hayirli, A., 2010. Sensitivity and specificity of infrared thermography in detection of subclinical mastitis in dairy cows. Journal of Dairy Science 93, 3525-3532.

Rainwater-Lovett, K., Pacheco, J.M., Packer, C., Rodriguez, L.L., 2009. Detection of foot-and-mouth disease virus infected cattle using infrared thermography. Veterinary Journal 180, 317-324.

Rosenmeier, J. G., Strathe, A.B., Andersen, P.H., 2012. Evaluation of coronary band temperatures in healthy horses. American Journal of Veterinary Research 73, 719-723.

Sambraus, H.H., 1991. Nutztierkunde. Ulmer, Stuttgart.

Savary, P., Hauser, R., Ossent, P., Jungbluth, T., Gygax, L., Wechsler, B., 2008. Evaluation of infrared thermography as a method for diagnosing inflammation of the leg joints in fattening pigs. Deutsche Tierarztliche Wochenschrift 115, 324329.

Schaefer, A.L., Cook, N., Tessaro, S.V., Deregt, D., Desroches, G., Dubeski, P.L., Tong, A.K.W., Godson, D.L., 2004. Early detection and prediction of infection using infrared thermography. Canadian Journal of Animal Science 84, 73-80.

Schaefer, A.L., Cook, N.J., Church, J.S., Basarab, J., Perry, B., Miller, C., Tong, A.K.W., 2007. The use of infrared thermography as an early indicator of bovine respiratory disease complex in calves. Research in Veterinary Science 83, 376384.

Schaefer, A. L., Cook, N.J., Bench, C., Chabot, J.B., Colyn, J., Liu, T., Okine, E.K., Stewart, M., Webster, J.R., 2012. The non-invasive and automated detection of bovine respiratory disease onset in receiver calves using infrared thermography. Research in Veterinary Science 93, 928-935.

Schwartzkopf-Genswein, K.S., Stookey, J.M., 1997. The use of infrared thermography to assess inflammation associated with hot-iron and freeze branding in cattle. Canadian Journal of Animal Science 77, 577-583.

Sikoski, P., Banks, M.L., Gould, R., Young, R.W., Wallace, J.M., Nader, M.A., 2007. Comparison of rectal and infrared thermometry for obtaining body temperature in cynomolgus macaques (Macaca fascicularis). Journal of Medical Primatology 36, 381-384.

Sinai, I., Jennings, V., Arevalo, M., 1999. The TwoDay algorithm: A new algorithm to identify the fertile time of the menstrual cycle. Contraception 60, 65-70. 
Spire, M.F., Drouillard, J.S., Galland, J.C., Sargeant, J.M., 1999. Use of infrared thermography to detect inflammation caused by contaminated growth promotant ear implants in cattle. Journal of the American Veterinary Medical Association $215,1320-1324$.

Stewart, M., Webster, J.R., Schaefer, A.L., Cook, N.J., Scott, S.L., 2005a. Infrared thermography as a non-invasive tool to study animal welfare. Animal Welfare 14, 319-325.

Stewart, M., Webster, J., Verkerk, G., Colyn, J., Schaefer, A., 2005b. Infrared thermography as a non-invasive measure of stress in dairy cows. Journal of Animal Science 83, 374-374.

Stewart, M., Webster, J.R., Verkerk, G.A., Schaefer, A.L., Colyn, J.J., Stafford, K.J., 2007. Non-invasive measurement of stress in dairy cows using infrared thermography. Physiology \& Behavior. 92: 520-525.

Stewart, M., Stafford, M.J., Dowling, S.K., Schaefer, A.L., Webster, J.R., 2008a. Eye temperature and heart rate variability of calves disbudded with or without local anaesthetic. Physiology \& Behavior 93: 789-797.

Stewart, M., Schaefer, A., Hale, D.B., Colyn, J., Cook, N.J., Stafford, K.J., Webster, J.R., 2008b. Infrared thermography as a non-invasive method for detecting fearrelated responses of cattle to handling procedures. Animal Welfare 17, 387-393.

Stewart, M., Stookey, J.M., Stafford, K.J., Tucker, C.B., Rogers, A.R., Dowling, S.K., Verkerk, G.A., Schaefer, A.L., Webster, J.R., 2009. Effects of local anesthetic and a nonsteroidal antiinflammatory drug on pain responses of dairy calves to hot-iron dehorning. Journal of Dairy Science 92, 1512-1519.

Stewart, M., Verkerk, G.A., Stafford, K.J., Schaefer, A.L., Webster, J.R., 2010. Noninvasive assessment of autonomic activity for evaluation of pain in calves, using surgical castration as a model. Journal of Dairy Science 93, 3602-3609.

Stokes, J.E., Leach, K.A., Main, D.C.J., Whay, H.R., 2012. An investigation into the use of infrared thermography (IRT) as a rapid diagnostic tool for foot lesions in dairy cattle. Veterinary Journal 193, 674-678.

Stubsjoen, S. M., Flo, A.S., Moe, R.O., Janczak, A.M., Skjerve, E., Valle, P.S., Zanella, A.J., 2009. Exploring non-invasive methods to assess pain in sheep. Physiology \& Behavior 98: 640-648.

Szabo, T., Fazekas. L., Geller, L., Horkay, F., Merkely, B., Gyongy, T., Juhasz-Nagy, A., 2000. Cardiothermographic assessment of arterial and venous revascularization - Safely evaluating bypass graft patency using IR imaging. leee Engineering in Medicine and Biology Magazine 19, 77-82. 
Turner, T.A., 1991. Thermography as an aid to the clinical lameness evaluation. Veterinary Clinics of North America-Equine Practice 7, 311-338.

Turner, T. A., 2001. Diagnostic thermography. Veterinary Clinics of North AmericaEquine Practice 17, 95.

Turner, P.V., Kloeze, H., Dam, A., Ward, D., Leung, N., Brown, E.E.L., Whiteman, A., Chiappetta, M.E., Hunter, D.B., 2012. Mass depopulation of laying hens in whole barns with liquid carbon dioxide: Evaluation of welfare impact. Poultry science 91, 1558-1568.

Um, S.W., Kim, M.S., Lim, J.H., Kim, S.Y., Seo, K.M., Nam, T.C., 2005. Thermographic evaluation for the efficacy of acupuncture on induced chronic arthritis in the dog. Journal of Veterinary Medical Science 67, 1283-1284.

Vadlejch, J., Knizkova, I., Makovcova, K., Kunc, P., Jankovska, I., Janda, K., Borkovcova, M., Langrova, I., 2010. Thermal profile of rabbits infected with Eimeria intestinalis. Veterinary Parasitology 171: 343-345.

Valera, M., Bartolome, E., Sanchez, M.J., Molina, A., Cook, N., Schaefer, A., 2012. Changes in Eye Temperature and Stress Assessment in Horses During Show Jumping Competitions. Journal of Equine Veterinary Science 32, 827-830.

Veissier, I., Rushen, J., Colwell, D., De Passille, A.M., 2000. A laser-based method for measuring thermal nociception of cattle. Applied Animal Behavior Science $66,289-304$.

Vianna, D.M.L., Carrive, P., 2005. Changes in cutaneous and body temperature during and after conditioned fear to context in the rat. European Journal of Neuroscience 21, 2505-2512.

Von Borell, E., Langbein, J., Despres, G., Hansen, S., Leterrier, C., Marchant-Forde, J., Marchant-Forde, R., Minero, M., Mohr, E., Prunier, A., Valance, D., Veissier, I., 2007. Heart rate variability as a measure of autonomic regulation of cardiac activity for assessing stress and welfare in farm animals - A review. Physiology \& Behavior 92, 293-316.

Warriss, P. D., Pope, S.J., Brown, S.N., Wilkins, L.J., Knowles, T.G., 2006. Estimating the body temperature of groups of pigs by thermal imaging. Veterinary Record 158, 331-334.

Webster, J.R., Stewart, M., Rogers, A.R., Verkerk, G.A., 2008. Assessment of welfare from physiological and behavioural responses of New Zealand dairy cows exposed to cold and wet conditions. Animal Welfare 17, 19-26.

Weil, M., Litzke, L.F., Fritsch, R., 1998. Diagnostic validity of thermography in equine lameness. Tierärztliche Praxis Ausgabe Großtiere Nutztiere 26, 346-354. 
Wrenn, T. R., Bitman, J., Sykes, J.F., 1958. Body temperature variations in dairy cattle during the estrus cycle and pregnancy. Journal of Dairy Science 41, 1071-1076.

Zahner, M., Schrader, L., Hauser, R., Keck, M., Langhans, W., Wechsler, B., 2004. The influence of climatic conditions on physiological and behavioural parameters in dairy cows kept in open stables. Animal Science 78, 139-147.

Zhao, Y., Xin, H., Dong, B., 2013. Use of infrared thermography to assess laying-hen feather coverage. Poultry science 92, 295-302. 


\title{
CHAPTER IV
}

\section{VALIDITY OF PHYSIOLOGICAL BIOMARKERS FOR MATERNAL BEHAVIOR IN COWS \\ - A COMPARISON OF BEEF AND DAIRY CATTLE}

\author{
Katrin Geburt ${ }^{a}$, Morten Friedrich ${ }^{a}$, Marion Piechotta ${ }^{b}$, Matthias Gauly ${ }^{\text {ac }}$ \\ Uta König von Borstel *a
}

\footnotetext{
${ }^{a}$ Georg-August-Universität Göttingen, Department of Animal Science, Livestock Production Systems, Albrecht-Thaer-Weg 3, 37075 Göttingen, Germany

${ }^{\mathrm{b}}$ University of Veterinary Medicine Hannover, Bischofsholer Damm 15, 30173 Hannover, Germany ${ }^{c}$ present address: Faculty of Science and Technology, Universitätsplatz 5 - piazza Università, $5 \mathrm{I}$ 39100 Bozen-Bolzano, Italy

*Corresponding author: koenigvb@gwdg.de; +49 551395602
}

Published at Physiology \& Behavior 139 (2015) 361-368

Keywords: Maternal behavior, Cattle, Thermography, Oxytocin, Cortisol, Heart Rate.

\begin{abstract}
The objectives of the present study were to evaluate the suitability of potential biomarkers for maternal ability in cattle, and in addition to test the hypothesis that dairy cows have a less pronounced motherliness than beef cows. Therefore, maternal behavior of 20 Simmental beef-type (S) and 20 German Black Pied (dairytype) Cattle (BP) was assessed on the 2 nd and again on the 3rd day of the calf's life. Measurements included the frequency of interactions between cow and calf, the cow's willingness to defend her calf, the overall maternal behavior, saliva cortisol, saliva oxytocin, heart rate, and thermal images of the eye (ET). Mixed model analysis revealed that BP had significantly $(P<0.05)$ higher oxytocin $(88.6 \pm 9.2$ vs. $62.8 \pm$
\end{abstract}


$9.2 \mathrm{pg} / \mathrm{ml}$ saliva) and cortisol ( $1.3 \pm 0.1 \mathrm{vs} .1 .0 \pm 0.1 \mathrm{ng} / \mathrm{ml}$ saliva) levels, but lower heart rates $(80.0 \pm 2.0$ vs. $95.8 \pm 2.0 \mathrm{bpm})$ than $S$ cows. Simmental (beef) cows showed more defensive behavior ( $3.5 \pm 0.2$ vs. $2.7 \pm 0.2$ scores), but fewer total interactions between cow and calf ( $8.1 \pm 1.4$ vs. $13.8 \pm 1.4$ ), compared to BP (dairy). However, with the exception of heart rate and overall maternal behavior, breed differences tended to diminish from the 2 nd to the 3 rd day of the calf's life. Repeatabilities ranged from $9 \pm 23 \%$ (ET) to $77 \pm 7 \%$ (maternal behavior measured on a visual analogue scale), and correlations between physiological parameters and behavior differed between breeds and were generally at a low level. In conclusion, beef cows do not seem to be per se more maternal compared to dairy cows, and the assessed parameters are of limited use as biomarkers for maternal behavior.

\subsection{INTRODUCTION}

The establishment of a strong maternal bond with the calf, nursing, attention and protection from potential predators are key features of maternal behavior (Grandinson, 2005). Therefore, maternal behavior can be defined as the cow's care for the calf, which includes social interactions, provision of milk, as well as protection from danger. Good maternal behavior is considered to be one of the main components of maternal success, i.e. the survival and growth of the offspring. The capability to give birth to a calf and to rear it without human assistance is particularly important in extensive production systems, as commonly used in beef 
production. However, also in intensive production systems with increasing sizes of production units and less time for observations by stockmen, the importance of maternal ability is undisputable (Grandinson, 2005). On the other hand, a too strong maternal behavior results in several negative aspects. Handling of the calf can be greatly complicated due to highly protective cows that may attack the handler. With such aggressive cows, routine handling procedures such as marking the calf for identification, pose a risk of injury to the human or calf (Urban, 2007). Factors influencing maternal behavior include the cow's breed (Hoppe et al., 2008), parity (Vanheede et al., 2001), the sex of the calf as well as its birth weight (Stehulova et al., 2013).

However, in dairy cattle, calves are routinely separated from their dams immediately after birth for management purposes as well as for protection of the calf from infections. For example, calves that suckled colostrum from their dams rather being bottle-fed are at a higher risk to suffer from severe diarrhea (Svensson et al., 2003). Thus, in contrast to beef cattle, due to the early separation of dairy cow and calf after parturition, a strong long-term maternal ability is not required in dairy production, and may have been diminished due to relaxed selection pressure during centuries of calf rearing by humans (Le Neindre, 1989). Indeed, Hopster et al. (1995) observed only limited responses of multiparous dairy cows to removal of their calves. We therefore hypothesized that beef cows exhibit stronger maternal behavior than dairy cattle when kept under similar husbandry conditions.

In addition to this breed comparison, the aim of the present study was to detect potential biomarkers that might later be used as indicators for maternal behavior and/or stress for use in breeding programs. Maternal behavior is facilitated by various hormonal changes. For example in different mammalian species, physiological parameters related to stress, such as ACTH or corticosterone, are reduced during motherhood (Neumann, 2005). Also, oxytocin has been shown to reduce fearfulness (Neumann, 2005), and perhaps more importantly to induce social bonding as well as to activate maternal behavior (Von Borell et al., 2007, Kendrick et al., 1987). Oxytocin is released e.g. during teat stimulation while suckling as well as during vaginocervical stimulation as is the case when giving birth (Kendrick et al., 1988 a, b). A relationship between oxytocin levels and maternal and/or bonding behavior has been detected in various species such as cattle (Williams et al., 2001), sheep (Kendrick et al., 1987), rats (Pedersen and Prange, 1979), and primates (Boccia et al., 2007), 
including humans (Uvnas-Moberg et al., 1990). We therefore hypothesized that saliva oxytocin levels either alone or in combination with parameters indicative of tress may serve as a biomarker for maternal behavior in cattle.

\subsection{MATERIAL AND METHODS}

\subsubsection{Animals and housing}

Each 20 cows with their calves of the breeds German Simmental (beef) (S), located on the research farm Relliehausen of the University Gottingen, and German Black Pied Cattle (BP), located on the research farm Frankenhausen of the University Kassel, both central Germany, were tested. On both farms, cows had regular access to pasture, but were brought prior to calving into the stable and were kept for the test period individually. For this purpose, BP were brought into separate calving boxes, while with the $S$ cows for the duration of the test a box was partitioned from the group box. In both cases, animals were housed on straw-bedding for calving and the test period, and the respective test cows could always see the remaining herd members and also had the possibility to interact via tactile contact with the other animals of the herd through the partition. Animals of both research farms were exposed to similar levels of daily contact with humans during routine management procedures for at least one month prior to calving. However compared to $S$ cows, prior to the dry period, multiparous BP cows were used to additional, more intensive contact with humans during milking twice daily. The following information was collected from the calvings prior to the tests: difficulty of birth (scored 0 (no assistance needed) to 2 (dystocia, intense assistance required)), parity class (primiparous or multiparous), sex of calf and weight of calf.

\subsubsection{Test procedures}

\subsubsection{Behavioral observations}

The tests were performed on the second and again on the third day of the calf $s$ life. In the beginning of the test, cow and calf were observed for $1 \mathrm{~h}$ in their box and all apparent cow-calf interactions were documented. Each interaction (see Table 5) was counted towards the frequency of "cow-calf-interaction" (CCI). 
In the second part of the test, the calf was tethered with a halter and rope for 2 min according to Mathiak (2002). The corresponding "calf score" (CS) (Table 5) was used to assess the behavior of the calf during tethering.

The behavior of the cow during handling and tying her calf was evaluated by different scores for the cow's motherliness, docility and will to protect her calf: For the maternal ability a modified "Motherliness score" (MS) by Hoppe et al. (2008), modified according to (Buddenberg et al., 1986, Morris et al., 1994) was used (Table 5). The same behavior was evaluated with a different method, based on a $15 \mathrm{~cm}$ visual analogue scale. Due to potentially different, underlying motivations for social interactions with the calf and preparedness to defend the calf, the cow's aggressiveness was also assessed separately from the overall behavior score by means of the "defense score" (DS). The parameter "Total Motherliness" (Mtotal) was composed of the mean of $\mathrm{CCl}$ and a transformed DS. The DS was transformed such that the highest possible value for DS (i.e. 5) was matched to the maximum value obtained for $\mathrm{CCl}$ (i.e. 39). An overview of the different parameters and their description is given in Table 5. Additionally, the time of testing (morning, mid-day, afternoon, evening) was recorded as it was, due to practical reasons, not possible to conduct all tests at the same time of the day. 
Table 5: List and description of behavioral parameters assessed during the test.

\begin{tabular}{|c|c|c|}
\hline Parameter & Information & Description \\
\hline $\begin{array}{l}\text { Cow-calf- } \\
\text { interaction } \\
\text { (CCI) }\end{array}$ & $\begin{array}{l}\text { Maternal } \\
\text { behavior without } \\
\text { human contact }\end{array}$ & $\begin{array}{l}\text { Every interaction in the observation period ( } 1 \mathrm{~h}) \text { : } \\
\text { Quantity of licking (each bout counted as one } \\
\text { interaction irrespective of the duration), } \\
\text { vocalisations, shifting of the body position to } \\
\text { facilitate sucking, nose-calf-contact, defense } \\
\text { against other cows }\end{array}$ \\
\hline
\end{tabular}

Calf score (CS) Docility of the calf

Motherliness score (MS)
Maternal behavior during the handling period of the calf
Behavior of the calf during tethering (2min). Scores: $1=$ calf is quiet, moves rarely with the rope not or only partially tensioned, $2=$ uneasy, frequently moving with tensioned rope, $3=$ nervous, partly strong movements with heavy pulling of the rope, $4=$ fighting against the fixation with vigorous movements

Behavior of the cow during tethering the calf. Scores: $1=$ cow shows no interest in her calf being handled, $2=$ stands quietly, watching her calf, is attentive and observes the situation, $3=$ restless, moving, vocalizes, concentrating only on her calf, $4=$ nervous, shows strong movements, handler only feels safe when cow is observed, $5=$ aggressive / furious, attacks or attempts to attack and has to be prevented from further attacking the handler
Maternal ability Maternal be- Maternal behavior on a $15 \mathrm{~cm}$ visual analogue (MaS)

Defence score (DS) and 15 (cow vigorously attacks the handler) havior during the handling period of the calf

\section{Defence} readiness of the cow scale with the endpoints 0 (cow is perfectly calm)

Will to protect and defend the calf. Scores: $1=$ cow is only concentrating on her own activity, $2=$ observing the situation, $3=$ standing beside the calf, try to screen the calf from the handler, $4=$ anxious $/$ nervous, $5=$ threat $/$ attack attempt

Total motherliness (Mtotal)
Whole maternal ability
Whole maternal ability consisted of maternal interactions (CCl) and the weighted defence (DS) of the calf 


\subsubsection{Physiological measurements}

Directly after tethering of the calf and the corresponding behavior observation of the cow, the cow was fixated to allow for collection of the following physiological parameters: eye temperature, saliva cortisol, saliva oxytocin and heart rate (HR). In addition, two weeks before the first calving in $\mathrm{S}$ and BP occurred, cows of each breed were fixed for the collection of baseline values for eye temperature, saliva cortisol and HR.

Thermal images were acquired with the infrared camera "ThermoPro ${ }^{\text {TM }}$ TP8", distributed by the company "InfraMedic", 64546 Morfelden, Germany. Pictures were taken of the eyes, standing distally at a distance of 1 to $1.5 \mathrm{~m}$ to the cow. Maximum and mean temperatures were obtained from the software "Exam Professional 5.7, InfraMedic GmbH, 2011".

Heart rate was measured using a Polar RS $800 \mathrm{CX}$ heart rate monitor by Polar, Kempele, Oy, Finland, and mean HR was calculated for the two minute measuring period

For saliva collection, swabs were placed under the cow's tongue until they were soaked with saliva. Samples were collected using Salivette $\AA$ (REF 51.1534) sampling tubes by Sarstedt AG \& Co., 51588 Nürnberg, Germany. For each hormone (oxytocin and cortisol) one saliva sample was collected.

\subsubsection{Cortisol and oxytocin analyses}

After sampling, saliva was stored for one day in the fridge at $4{ }^{\circ} \mathrm{C}$. Samples were then centrifuged at $2000 \mathrm{rpm}$, at $18{ }^{\circ} \mathrm{C}$ for $20 \mathrm{~min}$ in a Megafuge $1.0 \mathrm{R}$, Heraeus Instruments, Schütt Labortechnik, 37079 Gottingen, Germany. Centrifuged saliva was stored at $-20^{\circ} \mathrm{C}$ in a freezer until further processing.

Cortisol was analyzed using a "Cortisol free in saliva ELISA DES6611" by Demeditec Diagnostics GmbH, 24145 Kiel (Germany) test kit. The Microliterwell was coated with a polyclonal anti-cortisol antibody. For the enzyme conjugate cortisol was conjugated to horseradish peroxidase. The analytical sensitivity of the assay represents 0.014 $\mathrm{ng} / \mathrm{ml}$. The range of the assay covers $0-30 \mathrm{ng} / \mathrm{ml}$. The intra-assay variability is 5.9 $6.8 \%$, the inter-assay variability $53-9.4 \%$. In order to reach higher concentrations of oxytocin, the saliva samples for oxytocin analyses were concentrated via freezedrying before analyses. For freeze-drying a Lyophilisator, Typ ALPHA 1-12, from the company Christ, 37520 Osterode am Harz, was used. The oxytocin ELISA Kit, 
Catalog No. ADI-900-153 by ENZO® Life Sciences, ENZO Life Sciences (ELS) AG, $\mathrm{CH}-4415$ Lause/Switzerland was used for oxytocin analyses. The microtiter plate was coated with a goat anti-rabbit IgG (Catalog No. 80-0060), the oxytocin antibody (Catalog No. 80-1494) consisted of a rabbit polyclonal antibody to oxytocin. Sensitivity of the assay was $11.7 \mathrm{pg} / \mathrm{ml}$ (range 15.6-1.0000 pg/ml), with a standard deviation of $9.1 \%$ (intra-assay) and $14.5 \%$ (inter-assay) for low oxytocin concentration (21.4 and $19.3 \mathrm{pg} / \mathrm{ml}$ ).

\subsubsection{Statistical analysis}

The statistical analysis of the data was performed using the SAS 9.3 program, SAS Institute Inc. Cary, North Carolina 27513-2414, USA. To achieve a Gaussian distribution, cortisol values and the observations recorded on the visual analogue scale (MaS) were log10-transformed. The remaining variables (eye temperature, HR, oxytocin levels, and behavior scores) approximately followed a normal distribution and were thus not transformed. A mixed model accounting for repeated observations per cow was used to assess significance of the fixed effects breed (S or BP) and repetition (baseline measurement [if applicable], 1st or 2nd observation) as well as their interaction. The fixed factors time of testing, ease of calving, sex of calf and parity class, as well as the covariable calf weight were likewise tested for significance. Variance components from the mixed model analysis were used to calculate repeatabilities and their standard errors according to e.g. Falconer (1984) and Roberts and Strom (2006), respectively. In addition, a regression with a stepwise selection procedure was used to calculate the coefficient of determination, i.e. the amount of variance explained in behavioral parameters by the most influential physiological parameter and the combination of the three physiological parameters $\mathrm{HR}$, oxytocin, and cortisol. Due to technical problems with the infrared camera, only a limited number of observations $(n=38)$ were available for eye temperature, and therefore, this parameter was excluded from the regression analysis. The procedure "CORR" was used to calculate the Pearson correlation coefficients between the different behavioral and physiological parameters within and across breeds. 


\subsection{RESULTS}

For the parameters oxytocin, heart rate, cow-calf-interaction and defense score significant breed differences were found, as shown in Figure 1 and Figure 2. Significant differences between the measurements were found for cortisol, HR and the behavioral parameters $\mathrm{CCl}$, Mtotal and MaS (Figure 1 and Figure 2). However, for oxytocin, HR, DS and Mtotal, the interaction between breed and measurement was significant. With the exception of the DS and the MS, the intensity of behavior decreased from the first to the second measurement in the dairy cows, while the change was not significant in the beef cows (Figure $1 \mathrm{a}-\mathrm{d}$ ). Similarly, oxytocin levels tended to decrease in $\mathrm{BP}$, but not in $\mathrm{S}$, from the first to the second measurement (Figure 2c). After correction for multiple comparisons, the changes from first to second measurement were not significant within breeds for the remaining physiological parameters (Figure 2a-d), indicating that breed is the main factor influencing these physiological measurements. While beef cattle had higher $(\mathrm{P}<$ $0.05) \mathrm{HR}$ than dairy cattle, they had lower $(P<0.05)$ levels of both cortisol and oxytocin.

Within breed, HR did not differ during test situations from baseline measurements, while cortisol levels showed a significant increase from baseline levels at either test in dairy cattle, and tended $(P<0.1)$ to increase in beef cattle (Figure 2a-b). No significant differences $(P>0.1)$ between the breeds or measurements were found for ET (Figure 2d). No significant differences $(P>0.1)$ between breeds and measurements were detected for the calves' behavior (CS; least square means $\mathrm{S}=$ $1.2 \pm 0.05, \mathrm{BP}=1.1 \pm 0.05$, measurement $1 \mathrm{st}=1.2 \pm 0.04$, measurement $2 \mathrm{nd}=1.1 \pm$ 0.04). Similarly, no significant $(P>0.1)$ differences were detected for $M S$ between breeds $(S=2.5 \pm 0.2, \mathrm{BP}=2.1 \pm 0.2)$, measurements $(1 \mathrm{st}=2.4 \pm 0.1,2 \mathrm{nd}=2.3+$ $0.1)$ or their interaction.

Multiparous cows ( $D S=3.2 \pm 0.1$ ) showed stronger protective behavior compared to primiparous cows ( $\mathrm{DS}=2.4 \pm 03 ; \mathrm{P}=0.028)$. The effect of the calfs weight $(+0.06 \pm$ 0.02 DS per additional $\mathrm{kg}$ weight; $\mathrm{P}=0.0147$ ) points out, that cows defended heavier calves more vigorously. Similarly, cows showed that the stronger overall maternal behavior the heavier the calf was $(0.1 \pm 0.04$ Mtotal scores per additional $\mathrm{kg}$ weight). Ease of calving did not $(P>0.1)$ influence any of the assessed parameters.

Mean HR was clearly $(P=0.0002)$ higher for primiparous (least square mean: $98.1 \pm$ $2.9 \mathrm{bpm})$ compared to multiparous ( $85.1 \pm 1.3 \mathrm{bpm})$ cows. Besides the parity of the 
cow, also the calves weight had an influence on HR $(P=0.0450)$. The regression coefficient of $-0.52 \pm 0.25$ indicates that the heavier the calves were, the lower the cows' HRs were. Difficulty at birth did not significantly (all $P>0.1$ ) affect any of the behavioral or physiological parameters.

Repeatabilities for the different parameters (Table 6) ranged from values below $10 \%$ (eye temperature) to values higher than $78 \%$ (motherliness score).

The amount of variance explained in behavioral parameters by the most influential physiological parameter was generally very low, ranging between $\mathrm{R} 2=0.7 \%$ (MS oxytocin) and $\mathrm{R} 2=7.9 \%$ (Cow-calf interactions - oxytocin) for the individual, most influential parameter and between 1.3\% (MS - HR, oxytocin and cortisol) and 15.4\% (cow-calf interactions, HR, oxytocin and cortisol) for the combination all three physiological parameters.

With a few exceptions, behavioral parameters were generally positively correlated with each other as well as with calf weight, but they were negatively correlated with eye temperature and did not correlate across breeds with HR or oxytocin levels (Table 7). Cortisol showed no correlations with any of the other parameters. The within-breed Pearson correlation coefficients for the parameters differ considerably from the across-breed correlations as well as from each other (

Table 8). 


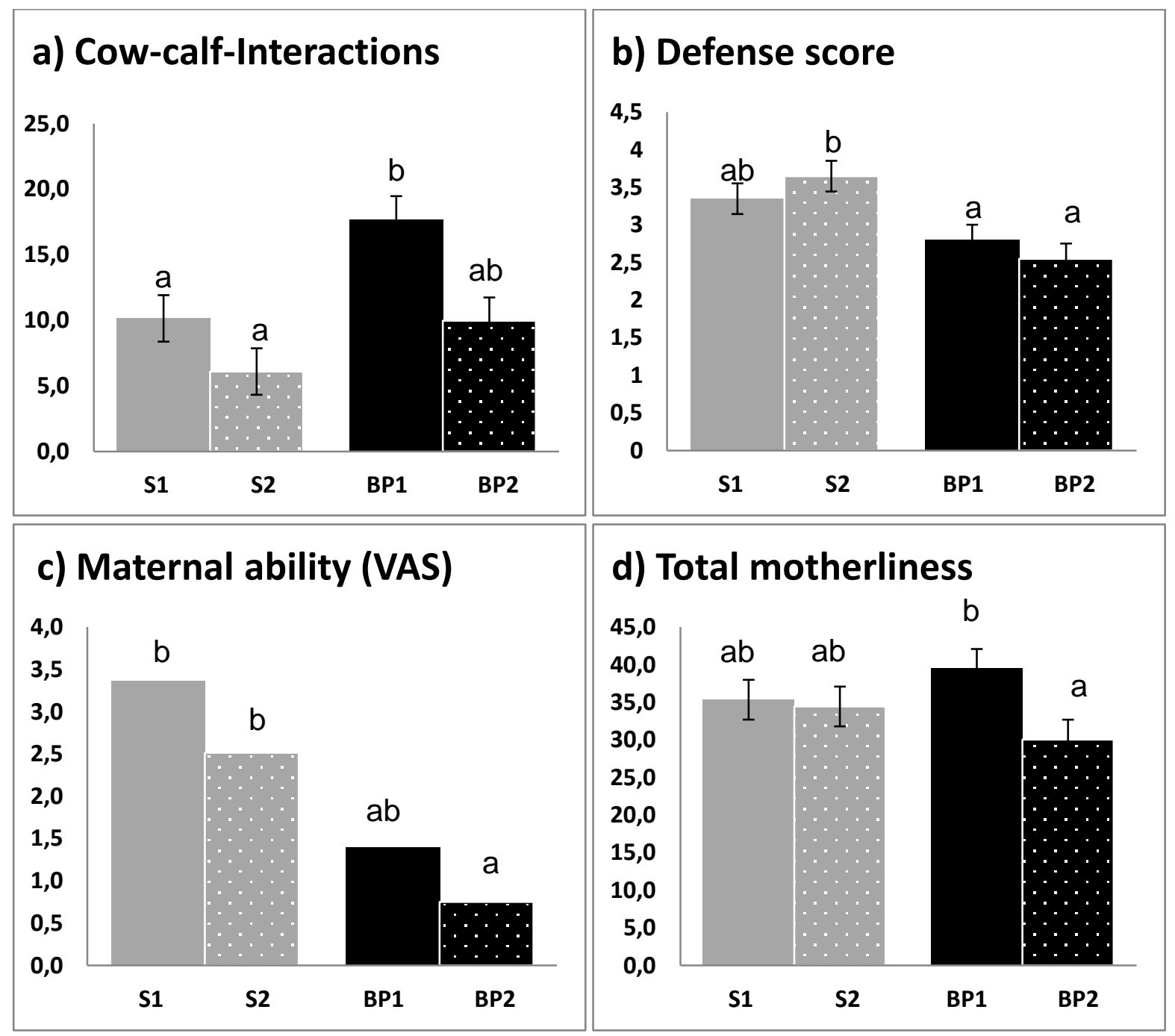

Figure 1 a-d: Effect of breed ( $\mathrm{S}=$ Simmental beef cattle; $\mathrm{BP}=$ Black Pied dairy cattle) and measurement ( 1 = 1st measurement on the second day after parturition; 2 = 2 nd measurement on the third day after parturition) as well as their interaction on the parameters frequency of cow-calf-interaction (a), defense score (b), maternal ability assessed via visual analogue scale (VAS) (c) and total motherliness (d). a,b represent significant differences at $P<0.05$. For the parameter maternal ability re-transformed-values are shown and thus no standard errors are presented. 


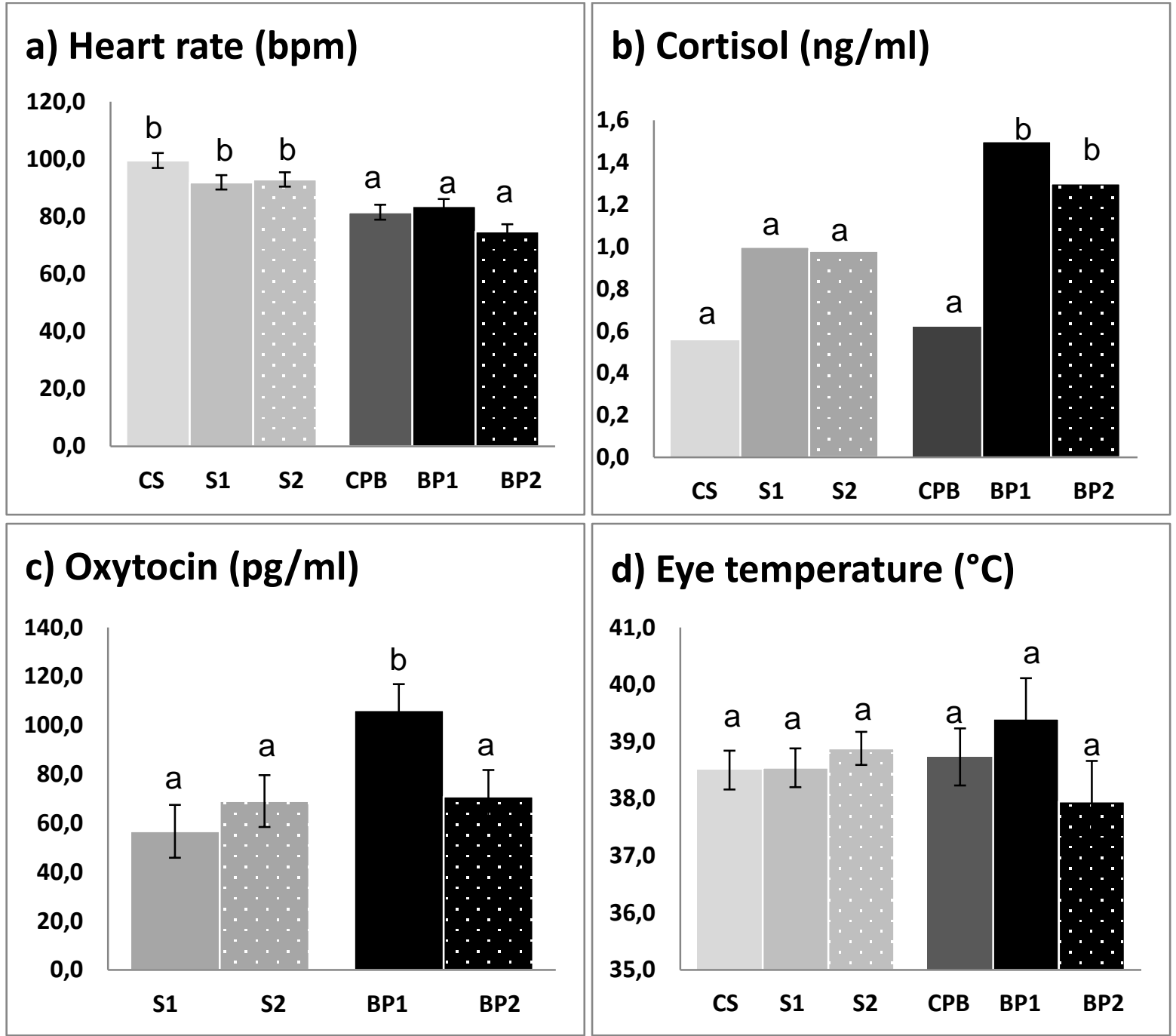

Figure 2 a-d: Effect of breed ( $\mathrm{S}=$ Simmental beef cattle; BP= Black Pied dairy cattle) and measurement $(C=$ Control/baseline value measured 2 weeks before parturition; 1 = 1st measurement on the second day after parturition; 2 = 2nd measurement on the third day after parturition) as well as their interaction on the parameters heart rate (a), cortisol (b), oxytocin(c) and eye temperature (d). a,b represent significant differences at $P<0.05$. For the parameter cortisol re-transformed-values are shown and thus no standard errors are presented. 
Table 6: Repeatability ( \pm Standard Error) of the different parameters across test day (2nd and 3rd day after parturition). VAS = visual analogue scale.

\begin{tabular}{ll} 
Parameter & Repeatability \pm Standard Error \\
\hline Cow-calf-interaction & $19.5 \pm 17.2$ \\
Defence score & $74.8 \pm 7.6$ \\
Motherliness score & $78.7 \pm 6.5$ \\
Total motherliness & $44.4 \pm 14.5$ \\
Maternal ability (VAS) & $77.4 \pm 6.6$ \\
Oxytocin & $48.3 \pm 14.1$ \\
Cortisol & $23.8 \pm 12.1$ \\
Heart rate & $44.7 \pm 10.9$ \\
Eye temperature & $9.0 \pm 23.3$
\end{tabular}

Table 7: Across-breed Pearson correlations coefficients for the parameters cow-calf-interaction (CCI), motherliness score (MS), defense score (DS), total motherliness (Mtotal), maternal ability measured on the visual analogue scale (MaS), heart rate (HR), cortisol (Corti), oxytocin (Oxy), eye temperature (ET), and calf weight (Cw). Significant correlation coefficients are shown above the diagonal and corresponding $p$-values below the diagonal ( $\mathrm{n} . \mathrm{s} .=\mathrm{P}>0.1$ )

CCI MS DS Mtotal MaS HR Corti Oxy ET Cw $\begin{array}{lll}\text { CCl } & 0.77 & 0.29\end{array}$

$\begin{array}{lccccccc}\text { MS } & \text { n.s. } & & 0.78 & 0.57 & 0.89 & -0.47 & 0.34 \\ \text { DS } & \text { n.s. } & <0.0001 & & 0.71 & 0.81 & -0.53 & 0.45 \\ \text { Mtotal } & <0.0001 & <0.0001 & <0.0001 & & 0.49 & -0.62 & 0.37 \\ \text { MaS } & \text { n.s. } & <0.0001 & <0.0001 & <0.0001 & & -0.45 & 0.36 \\ \text { HR } & \text { n.s. } & \text { n.s. } & \text { n.s. } & \text { n.s. } & \text { n.s. } & 0.42 & \end{array}$

Corti n.s. n.s. n.s. n.s. n.s. n.s.

Oxy 0.011 n.s. n.s. n.s. n.s. n.s. n.s.

$\begin{array}{lllllllll}\text { ET } & \text { n.s. } & 0.0177 & 0.0061 & 0.0011 & 0.0238 & 0.0091 & \text { n.s. } & \text { n.s. }\end{array}$

Cw n.s. $\quad 0.0064 \quad 0.0002 \quad 0.003 \quad 0.0039 \quad$ n.s. $\quad$ n.s. $\quad$ n.s. 0.0092 
Table 8: Within-breed Pearson correlations coefficients for the parameters cow-calf-interaction (CCI), motherliness score (MS), defense score (DS), total motherliness (Mtotal), maternal ability measured on the visual analogue scale (MaS), heart rate (HR), cortisol (Corti), oxytocin (Oxy) and eye temperature (ET). Above diagonal: German Black Pied Cattle; below diagonal:

Simmental beef cattle.

\begin{tabular}{|c|c|c|c|c|c|c|c|c|c|}
\hline & $\mathrm{CCl}$ & MS & DS & Mtotal & MaS & HR & Corti & Oxy & ET \\
\hline CCI & & n.s. & $\begin{array}{c}0.40 \\
(0.0110)\end{array}$ & $\begin{array}{c}0.90 \\
(<0.0001)\end{array}$ & n.s. & $\begin{array}{c}0.42 \\
(0.0069)\end{array}$ & n.s. & $\begin{array}{c}0.36 \\
(0.0241)\end{array}$ & $\begin{array}{c}0.38 \\
(0.0625)\end{array}$ \\
\hline MS & n.s. & & $\begin{array}{c}0.75 \\
(<0.0001)\end{array}$ & $\begin{array}{c}0.52 \\
(0.0005)\end{array}$ & $\begin{array}{c}0.90 \\
(<0.0001)\end{array}$ & n.s. & n.s. & n.s. & n.s. \\
\hline DS & n.s. & $\begin{array}{c}0.80 \\
(<0.0001)\end{array}$ & & $\begin{array}{c}0.75 \\
(<0.0001)\end{array}$ & $\begin{array}{c}0.75 \\
(<0.0001)\end{array}$ & n.s. & n.s. & n.s. & n.s. \\
\hline Mtotal & $\begin{array}{c}0.69 \\
(<0.0001)\end{array}$ & $\begin{array}{c}0.67 \\
(<0.0001)\end{array}$ & $\begin{array}{c}0.84 \\
(<0.0001)\end{array}$ & & $\begin{array}{c}0.48 \\
(0.0017)\end{array}$ & $\begin{array}{c}0.32 \\
(0.0435)\end{array}$ & n.s. & $\begin{array}{c}0.38 \\
(0.0180)\end{array}$ & n.s. \\
\hline MaS & n.s. & $\begin{array}{c}0.90 \\
(<0.0001)\end{array}$ & $\begin{array}{c}0.79 \\
(<0.0001)\end{array}$ & $\begin{array}{c}0.63 \\
(<0.0001)\end{array}$ & & n.s. & n.s. & n.s. & n.s. \\
\hline HR & n.s. & n.s. & n.s. & n.s. & n.s. & & $\begin{array}{c}0.39 \\
(0.0031)\end{array}$ & n.s. & n.s. \\
\hline Corti & n.s. & $\begin{array}{c}0.33 \\
(0.0414)\end{array}$ & $\begin{array}{c}0.32 \\
(0.0505)\end{array}$ & n.s. & $\begin{array}{c}0.42 \\
(0.0083)\end{array}$ & n.s. & & n.s. & n.s. \\
\hline Oxy & n.s. & n.s. & n.s. & n.s. & n.s. & n.s. & n.s. & & n.s. \\
\hline ET & $\begin{array}{c}-0.59 \\
(0.0052)\end{array}$ & $\begin{array}{c}-0.48 \\
(0.0263)\end{array}$ & $\begin{array}{c}-0.53 \\
(0.0132\end{array}$ & $\begin{array}{c}-0.64 \\
(0.0016)\end{array}$ & $\begin{array}{c}-0.47 \\
(0.0330)\end{array}$ & $\begin{array}{c}0.44 \\
(0.0161)\end{array}$ & n.s. & n.s. & \\
\hline
\end{tabular}

\subsection{DISCUSSION}

\subsubsection{Breed differences in maternal ability}

Breed differences in maternal behavior could be detected in this study, similar to results by Hoppe et al. (2008), who discovered differences in maternal protective behavior of German Angus and Simmental cows, or Das et al. (2001), who detected a higher maternal ability in Zebu (Bos indicus) than in crossbred (B. indicus $x$ Bos taunts) cattle. Contrary to the hypothesis, beef cows did not express a generally higher maternal ability in the present study. Indeed dairy rather than beef cows showed more frequent interactions with their calves, when allowed to stay together with their calves and when kept under similar husbandry conditions. Although the confounding of breed and location does not allow for a definite conclusion regarding 
breed differences, results of the present study nevertheless show that at least under certain circumstances and with some breeds the assumption of higher maternal ability in beef rather than dairy cattle does not hold. Husbandry conditions were similar for both breeds, thereby minimizing the potential effect of husbandry conditions on aspects of maternal behavior and maternal ability, as shown e.g. in pigs (Damm et al., 2005, Baxter et al., 2011) and sheep (Dwyer, 2006). Also, both beef and dairy cows were accustomed to daily interactions with humans on their respective research farm. Although human-cow contact was more intensive for the dairy cows during lactation, this is not the case during the dry period i.e. for several weeks up until the day of the first test. General conclusions regarding breed type differences (beef or dairy cattle) should nevertheless be seen with caution as Black Pied Cattle may not be highly representative of dairy cattle in general. Black Pied Cattle have been selected less intensively for milk production than, for example, the more common dairy breed Holstein Friesians, with an average recorded milk production of $8.865 \mathrm{~kg}$ milk, compared with $6.711 \mathrm{~kg}$ milk for Black Pied cattle (ADR, 2012). In contrast to results based on $\mathrm{CCl}$ and MaS, the beef cows showed higher levels of defensiveness than the dairy cattle. These results are consistent with our hypothesis based on the assumptions by Le Neindre (1989). However, the contrasting results for breed differences in cow-calf interactions and the willingness to defend the calf against humans highlights the importance of clearly distinguishing these traits, which may be influenced by different motivational factors (maternal interest in the calf versus aggressiveness and/or fear of humans). The dairy cows showed greater interest in their calf and they appeared to be more calm and relaxed and were easier to handle in the specific test situation. According to a study by Hopster et al. (1995), separation of the calf was found not to be a considerable stressor for the dairy cow. After removing the calf three days postpartum, they detected only little behavioral effects, such as vocalizing and physiological changes in the cow. Heart rate rose only in the first minutes after separation and no effects in plasma cortisol were found (Hopster et al., 2008) However, Hopster et al. (2008) only used a rather small number of eight animals and a limited time of 15 min for observation after separation. For a hider species such a short duration of separation is normal and may not be sufficient to reveal differences between breeds, because also in free-ranging beef cows, especially the male calves do not stand always in the vicinity of the cow (Lidfors and Jensen, 1988). In semi-wild Maremma cattle also 
young calves spend most of the day away from the mother in calf groups and were only visited by the cows for suckling or in a situation of danger (Vitale et al., 1986). In contrast, Weary and Chua (2000) determined strong vocal and behavioral responses in Holstein cows after separation of their calves in dependence on the time of the cow-calf-pair spending together after birth. Also in the study by Hudson and Mullord (1977), dairy cows showed strong restlessness and vocalizations after separation from their calves, and Lidfors (1996) showed that rumination, vocalization and activity of Swedish dairy cows were affected for as long as four days after separation from their calves post-partum. In the present study, S cattle had clearly higher HR compared with BP cattle, potentially suggesting a higher stress reaction of the beef cows during the handling of their calves, although this pattern was not reflected by cortisol measurements or eye temperature. The latter has been shown to be a good indicator for stress e.g. in horses (Yamell et al., 2013, Hall et al., 2014).

Contrary to the hypothesis of higher motherliness and therefore higher oxytocin levels in beef cows, $S$ had lower oxytocin levels than BP. Likely, oxytocin is linked stronger to milk ejection than to maternal behavior, which is why dairy cows had overall higher oxytocin levels.

\subsubsection{Differences between first and second measurement}

In both breeds for the majority of parameters of maternal behavior there was a decrease in intensity from the first to the second measurement, indicating a rapid decrease of maternal care from the 2 nd to the $3 r d$ day of the calf $s$ life. The decline of maternal care expressed by $\mathrm{CCl}$, is consistent with the studies by Jensen (2011), Lidfors (1996) and Stehulova et al. (2013), who documented a gradual decrease of maternal grooming, sniffing, licking and nursing of the calf some days postpartum. Compared to behavioral parameters of maternal ability, the physiological stress parameters HR, cortisol level, and eye temperature generally did not show a clearly significant decrease from first to second measurement within breeds, potentially indicating that limited habituation to removal and handling of the calf took place in the cows. However, the increase of these values from baseline to test situation was, with the exception of cortisol in BP cows, likewise not significant, showing that overall the stress induced by the testing procedures was at a low level, which may also explain the limited habituation. 


\subsubsection{Suitability of physiological parameters as biomarkers for maternal ability}

Highest repeatabilities were found for the behavioral parameters MaS and DS, and their values compare well to repeatabilities for other temperament traits (see König von Borstel et al., 2013 for a review). In contrast, the physiological parameters only showed moderate (oxytocin and HR) to low repeatabilities (cortisol, eye temperature), indicating that factors other than those considered in the present analysis greatly influence levels of these parameters. These comparably low repeatabilities for physiological parameters, and in particular for HR are surprising since HR showed moderate repeatability in horses during a temperament test $(r=0.57)$ even though the testing conditions changed over repeated trials (König von Borstel et al., 2012). Indeed, eye temperature seemed to be an entirely irreproducible parameter in this experiment, perhaps owing to the limited number of observations or undetected technical problems with the equipment or large environmental influences such as differences in ambient temperature and solar radiation that could not be controlled for properly.

Based on numerous studies (reviewed e.g. in Lee et al., 2009), a strong link between maternal behavior and oxytocin was hypothesized. Results of the present study regarding relationships of oxytocin with cortisol or maternal behavior contradict results from studies in e.g. pigs (Valros et al., 2004), rhesus macaques (Maestripieri et al., 2009) and humans (Feldmann et al., 2007, Levine et al., 2007), where oxytocin correlated positively with infant-directed behavior (Valros et al., 2004, Maestripieri et al., 2009) and mother-infant attachment (Levine et al., 2007), but exhibited a negative relationship with cortisol levels (Feldmann et al., 2007). Potentially, the strong selection for milk yield in dairy cows considerably changed oxytocin levels, thereby breaking links that may exist in unselected species. However, contrary to this hypothesis, some correlations between oxytocin levels and behavior existed in the dairy cows, but not in the beef cows. It may also be that only specific behavior patterns are closely linked to oxytocin levels, such as e.g. shown for the relationship between kissing the dog and oxytocin levels in human-dog attachment (Handlin et al., 2012). Such relationships, if existent, might have been blurred by the compound behavior traits assessed in the present study. Other studies also failed to consistently detect the expected relationships: oxytocin related rapid induction of maternal behavior could not be confirmed by Bolwerk and Swanson (1984) or Rubin et al. (1983). Based on contradictory findings from different species, and in particular 
different oxytocin-sensitive brain structures, Young et al. (1997) suggested that there is evidence that oxytocin may not play a universal role in eliciting maternal behavior: while in oxytocin knockout mice maternal behavior was not affected, the hormone released at parturition seems to initiate motherliness in other species such as rats. Finally, contradictory findings of different studies may also be the result of different analysis methods. Horvat-Gordon et al. (2005) stated that saliva oxytocin measured by immunological methods may not be an usable biomarker owing to the low levels of oxytocin in saliva. However, in the present study, we avoided this problem by concentrating the samples by freeze-drying. Based on the low correlations and the very low coefficients of determination, none of the physiological parameters of the present study seem to be able to serve either alone or in combination with each other as a satisfactory biomarker for maternal behavior in cattle. Considering the differences in correlations for the different breeds, potentially, certain parameters such as eye temperature may serve as a biomarker within one but not the other breed. However, before a general recommendation can be given, these relationships would have to be confirmed in a larger number of animals per breed.

\subsubsection{Influence of parity and calf weight on behavior and physiological parameters}

Results of the present study showed that multiparous cows were more protective and, based on HR measurements, calmer compared with primiparous cows during handling their calves. These findings of greater vigilance (Florcke et al., 2012) in multiparous rather than primiparous cows are confirmed in the literature, although the present results do not confirm more intensive maternal care (as suggested for cattle and sheep (Vandenheede et al., 2001, Dwyer et al., 2005, Ungerfeld et al., 2011) or lower levels of abnormal maternal behavior (as described by Edwards and Broom (1982) in multiparous cows. Also, considering that HR may reflect stress, results of the present study are rather inconsistent, with some studies suggesting higher levels of stress in response to separation from the calf in multiparous cows (price et al., 1986) while others found no difference between parities (Flower and Weary, 2001).

The observed relationship between offspring birth weight and maternal behavior is known from many species such as sheep (König von Borstel et al., 2011) and may have some adaptive value as smaller offspring may be at greater risk of predation 
(Mappes et al., 1997). In polygynous mammals higher maternal investment in male compared with female progenies was discussed by Clutton-Brock et al. (1981), Stehulova et al. (2013) and Trivers and Willard (1973). Potentially with polygynous species, there are fitness benefits in increasing maternal investment for male offspring, as only the strongest males will later receive a chance to reproduce, while female reproductive success is generally limited and not as closely related to size or strength as it is in males. Male progeny which normally show higher weights, suck more frequently from their mothers and tend to have longer suckling bouts (CluttonBrock et al., 1981). In the present study, several effects for calfs weight but no such relationships between calfs gender and dam behavior were found, perhaps because calf weight rather than calf gender is the more influential parameter.

The lack of a significant influence of difficulty at birth is surprising since it could be expected that this variable relates to pain, which in turn is expected to influence behavior as well as physiological parameters. For example, in women perinatal analgesia influenced the activity of the hypothalamic-pituitary-adrenal axis as late as two days after birth (Handlin et al., 2009). Potentially, the subjective assessment of difficulty at birth in the present study did not very accurately reflect the true pain experienced by the cow, or at least not the pain at the time of testing.

\subsection{CONCLUSIONS}

Results of the present study reveal that beef cows do not generally have a higher motherliness compared to dairy cows. German Black Pied Cattle showed more interactions with their calves, but they were less aggressive towards humans handling their calves, when compared to Simmental beef cattle. The physiological parameters saliva oxytocin, cortisol, heart rate, and eye temperature, considered either alone or in combinations, did not show strong and consistent relationships with maternal behavior, indicating that their use as a biomarker for maternal ability is limited.

\section{Acknowledgments}

Many thanks to the head and staff of the research farms for making this research project possible. This project was funded by the Network of Competence of Agricultural and Nutritional Research "PHENOMICS" of the German Federal Ministry 
of Education and Research (project number: 0315536J).The funders were not involved in study design, collection, analysis or interpretation of data, writing or submission of this article. 


\section{REFERENCES}

Arbeitsgemeinschaft Deutscher Rinderzüchter e.V. ADR, 2012. Statistik 2012. Durchschnittleistungen von MLP-Kühen nach Rassen (Average production of recorded cows by breed). Bonn, Germany: Arbeitsgemeinschaft Deutscher Rinderzüchter.

Baxter, E.M., Jarvis, S., Sherwood, L., Farish, M., Roehe, R., Lawrence, A.B., 2011. Genetic and environmental effects on piglet survival and maternal behavior of the farrowing sow. Applied Animal Behavior Science 130, 28-41.

Boccia, M.L., Goursaud, A.P.S., Bachevalier, J., Anderson, K.D., Pedersen, C.A., 2007. Peripherallyadministered non-peptide oxytocin antagonist, L368,899((R)), accumulates in limbic brain areas: a new pharmacological tool for the study of social motivation in non-human primates. Hormones and Behavior 52, 344-51.

Bolwerk, E.L.M., Swanson, H.H., 1984. Does oxytocin play a role in the onset of maternal-behavior in the rat? Journal of Endocrinology 101, 353-7.

Buddenberg, B.J., Brown, C.J., Johnson, Z.B., Honea, R.S., 1986. Maternal behavior of beef cows at parturition. Journal of Animal Science 62, 42-6.

Clutton-Brock, T.H., Albon, S.D., Guinness, F.E., 1981. Parental investment in male and female offspring in polygynous mammals. Nature 289, 487-9.

Damm, B.I., Pedersen, L.J., Heiskanen, T., Nielsen, N.P., 2005. Longstemmed straw as an additional nesting material in modified Schmid pens in a commercial breeding unit: effects on sow behavior, and on piglet mortality and growth. Applied Animal Behavior Science 92, 45-60.

Das, S.M., Redbo I., Wiktorsson, H., 2001. Behavior of Zebu and crossbred cows in restricted suckling groups. Applied Animal Behavior Science 72, 263-70.

Dwyer, C.A., Lawrence, A.B., 2005. A review of the behavioral and physiological adaptations of hill and lowland breeds of sheep that favour lamb survival. Applied Animal Behavior Science 92, 235-60.

Dwyer, C.M., 2008. Individual variation in the expression of maternal behavior: a review of the neuroendocrine mechanisms in the sheep. Journal of Neuroendocrinology 20, 526-34. 
Edwards, S.A., Broom, D.M., 1982. Behavioral interactions of dairy cows with their newborn calves and the effects of parity. Animal Behaviour 30, 525-35.

Falconer, D.S., 1984. Einführung in die quantitative Genetik (Introduction to quantitative genetics). Stuttgart, Germany: Eugen Ulmer GmbH \& Co.

Feldman, R., Weller, A., Zagoory-Sharon, O., Levine, A., 2007. Evidence for a neuroendocrinological foundation of human affiliation - plasma oxytocin levels across pregnancy and the postpartum period predict mother-infant bonding. Psychological Science 18, 965-70.

Florcke, C., Engle, T.E., Grandin, T., Deesing, M.J., 2012 Individual differences in calf defence patterns in Red Angus beef cows. Applied Animal Behavior Science 139, 203-8.

Flower, F.C., Weary, D.M., 2001. Effects of early separation on the dairy cow and calf: 2. Separation at 1 day and 2 weeks after birth. Applied Animal Behavior Science 70(4), 275-284.

Grandinson, K., 2005. Genetic background of maternal behavior and its relation to offspring survival. Livestock Production Science 93, 43-50.

Hall, C., Kay, R., Yarnell, K., 2014. Assessing ridden horse behavior: professional judgment and physiological measures. Journal of Veterinary Behavior 9, 22-9.

Handlin, L., Jonas, W., Petersson, M., Ejdeback, M., Ransjo-Arvidson, A.-B., Nissen, E., 2009. Effects of Sucking and Skin-to-Skin Contact on Maternal ACTH and Cortisol Levels During the Second Day Postpartum-Influence of Epidural Analgesia and Oxytocin in the Perinatal Period. Breastfeed Medicine 4, 207-20.

Handlin, L., Nilsson, A., Ejdeback, M., Hydbring-Sandberg, E., Uvnas-Moberg, K., 2012. Associations between the psychological characteristics of the human-dog relationship and oxytocin and cortisol levels. Anthrozoos 25, 215-28.

Hoppe, S., Brandt, H.R., Erhardt, G., Gauly, M., 2008. Maternal protective behavior of German Angus and Simmental beef cattle after parturition and its relation to production traits. Applied Animal Behavior Science 114, 297-306.

Hopster, H., Oconnell, J.M., Blokhuis, H.J., 1995. Acute effects of cow-calf separation on heart rate, plasma-cortisol and behavior in multiparous dairy-cows. Applied Animal Behavior Science 1995;44:1-8. 
Horvat-Gordon, M., Granger, D.A., Schwartz, E.B., Nelson, V.J., Kivlighan, K.T.. Oxytocin is not a valid biomarker when measured in saliva by immunoassay. Physiology \& Behavior 84, 445-8.

Hudson, S.J., Mullord, M.M., 1977. Investigations of maternal bonding in dairy-cattle. Applied Animal Ethology 3, 271-6.

Jensen, M.B., 2011. The early behavior of cow and calf in an individual calving pen. Applied Animal Behavior Science 134, 92-9.

Kendrick K.M., Keverne E.B., Chapman C., Baldwin B.A., 1988. Microdialysis measurement of oxytocin, aspartate, gamma-aminobutyric acid and glutamate release from the olfactory-bulb of the sheep during vaginocervical stimulation. Brain Research 442, 171-4.

Kendrick, K.M., Keverne, E.B., Baldwin, B.A., 1987. Intracerebroventricular oxytocin stimulates maternal-behavior in the sheep. Neuroendocrinology 46, 56-61.

Kendrick, K.M., Keverne, E.B., Chapman, C., Baldwin, B.A., 1988. Intracranial dialysis measurement of oxytocin, monoamine and uric-acid release from the olfactory-bulb andsubstantia nigra of sheep during parturition, suckling, separation from lambs and eating. Brain Research 439, 1-10.

König von Borstel, U., 2013. Assessing and influencing personality for improvement of animal welfare: a review of equine studies. CAB Review 8, el-27.

König von Borstel, U., Euent, S., Graf, P., König, S., Gauly, M., 2012. Equine behavior and heart rate in temperament tests with or without rider or handler. Physiology \& Behavior 104, 454-63.

König von Borstel, U., Moors, E., Schichowsk,i C., Gauly, M., 2011. Breed differences in maternal behavior in relation to lamb (Ovis orientalis aries) productivity. Livestock Science 137, 42-8.

Le Neindre, P., 1989. Influence of cattle rearing conditions and breed on social relationshipsof mother and young. Applied Animal Behavior Science 23, 117-27.

Lee, H.J., Macbeth, A.H., Pagani, J.H., Young, I.W.S., 2009. Oxytocin: the great facilitator of life. Progress in Neurobiology 88(2), 127-51. 
Levine, A., Zagoory-Sharon, O., Feldman, R., Weller, A., 2007. Oxytocin during pregnancy and early postpartum: individual patterns and maternal-fetal attachment. Peptides 28, 1162-9.

Lidfors, L., Jensen, P., 1988. Behavior of free-ranging beef cows and calves. Applied Animal Behavior Science 20, 237-47.

Lidfors, L.M., 1996. Behavioral effects of separating the dairy calf immediately or 4 days post-partum. Applied Animal Behavior Science 49, 269-83.

Maestripieri, D., Hoffman, C.L., Anderson, G.M., Carter, C.S., Higley, J.D., 2009. Mother-infant interactions in free-ranging rhesus macaques: relationships between physiological and behavioral variables. Physiology \& Behavior 96, 6139.

Mappes, J., Mappes, T., Lappalainen, T., 1997. Unequal maternal investment in offspring qualityin relation to predation risk. Evolutionary ecology, 11, 237-43.

Mathiak, H., 2002. Genetische Parameter von Merkmalen des Temperaments und der Umganglichkeit bei den Rassen Dt. Angus und Dt. Fleckvieh. [PhD thesis] Germany, University of Gießen.

Morris, C.A., Cullen, N.G., Kilgour, R., Bremner, K.J., 1994. Some genetic factors affecting temperament in Bos taurus cattle. New Zealand Journal of Agricultural Research 37, 167-75.

Neumann, I.D., 2005. Adaptationen der Streßbewältigung peripartum: Sind Oxytocin und Prolactin involviert? Journal für Neurologie, Neurochirurgie und Psychiatrie 6, 16-21.

Pedersen, C.A., Prange, A.J., 1979. Induction of maternal-behavior in virgin rats after intra-cerebroventricular administration of oxytocin. Proceedings of the National Academy of Sciences of the United States of America 76, 6661-5.

Price, E.O., Smith, V.M., Thos, J., Anderson, G.B., 1986. The effects of twinning and maternal experience on maternal-final social relationships in confined beefcattle. Applied Animal Behavior Science 15, 137-46.

Roberds, J.H., Strom, B.L., 2006. Repeatability estimates for oleoresin yield measurements in three species of the southern pines. Forest Ecology and Management 228, 215-24. 
Rubin, B.S., Menniti, F.S., Bridges, R.S., 1983. Intracerebroventricular administration of oxytocin and maternal-behavior in rats after prolonged and acute steroid pretreatment. Hormones and Behavior 17, 45-53.

Stehulova, I., Spinka, M., Sarova, R., Machova, L., Knez, R., Firla, P, 2013. Maternal behavior in beef cows is individually consistent and sensitive to cow body condition, calf sex and weight Applied Animal Behavior Science 144, 89-97.

Svensson, C., Lundborg, K., Emanuelson, U., Olsson, S.-O., 2003. Morbidity in Swedish dairy calves from birth to 90 days of age and individual calf-level risk factors for infectious diseases. Preventive Veterinary Medicine 58, 179-97.

Trivers, R.L., Willard, D.E., 1973. Natural-selection of parental ability to vary sex-ratio of offspring. Science 179, 90-2.

Ungerfeld, R., Hotzel, M.J., Scarsi, A., Quintans, G., 2011. Behavioral and physiological changes in early-weaned multiparous and primiparous beef cows. Animal 5, 1270-5.

Urban, C., 2007. Untersuchungen zum genetischen Hintergrund von Temperament und Umgänglichkeit bei Mutterkühen und Kalbern der Rassen DL Angus und Dt. Fleckvieh anhand der Validierung von geeigneten Testverfahren. [PhD thesis] Germany, University of Gießen

Uvnas-Moberg, K., Widstrom, A.M., Nissen, E., Bjorvell, H., 1990. Personality-traits in women 4 days postpartum and their correlation with plasma-levels of oxytocin and prolactin. Journal of Psychosomatic Obstetrics \& Gynecology 11, 261-73.

Valros, A., Rundgren, A., Spinka, M., Saloniemi, H., Hulten, F., Uvnas-Moberg, K., 2004. Oxytocin, prolactin and somatostatin in lactating sows: associations with mobilisation of body resources and maternal behavior. Livestock Production Science 85, 3-13.

Vandenheede, M., Nicks, B., Desiron, A., Canart, B., 2001. Mother-young relationships in Belgian Blue cattle after a Caesarean section: characterisation and effects of parity. Applied Animal Behavior Science 72, 281-92.

Vitale, A.F., Tenucci, M., Papini, M., Lovari, S., 1986. Social behavior of the calves of semi-wild Maremma cattle, Bos primigenius taurus. Applied Animal Behavior Science 16, 217-31. 
Von Borell, E., Dobson, H., Prunier, A., 2007. Stress, behavior and reproductive performance in female cattle and pigs. Hormones and Behavior 52, 130-8.

Weary, D.M., Chua, B., 2000. Effects of early separation on the dairy cow and calf 1. Separation at 6 h, 1 day and 4 days after birth. Applied Animal Behavior Science 69, 177-88.

Williams, G.L., Gazal, O.S., Leshin, L.S., Stanko, R.L., Anderson, L.L., 2001. Physiological regulation of maternal behavior in heifers: roles of genital stimulation, intracerebral oxytocin release, and ovarian steroids. Biology of Reproduction 65, 295-300.

Yamell, K., Hall, C., Billett, E., 2013. An assessment of the aversive nature of an animal management procedure (clipping) using behavioral and physiological measures. Physiology \& Behavior 118, 32-9.

Young L.J., Winslow J.T., Wang Z.X., Gingrich B., Guo Q.X., Matzuk M.M., 1997. Gene targeting approaches to neuroendocrinology: oxytocin, maternal behavior, and affiliation. Hormones and Behavior 31(3), 221-3. 


\title{
CHAPTER V
}

\section{INFLUENCE OF TESTOSTERONE ON THE DOCILITY OF GERMAN SIMMENTAL AND CHAROLAIS HEIFERS DURING BEHAVIOR TESTS}

\author{
Katrin Geburt ${ }^{a}$, Marion Piechotta ${ }^{\mathrm{b}}$, Uta König von Borstel ${ }^{\text {*a }}$, Matthias Gauly ${ }^{\text {ac }}$ \\ ${ }^{a}$ Georg-August-Universität Göttingen, Department of Animal Science, Livestock Production Systems, \\ Albrecht-Thaer-Weg 3, 37075 Göttingen, Germany \\ ${ }^{\mathrm{b}}$ University of Veterinary Medicine Hannover, Bischofsholer Damm 15, 30173 Hannover, Germany \\ ${ }^{c}$ present address: Faculty of Science and Technology, Universitätsplatz 5 - piazza Università, 5 I \\ 39100 Bozen-Bolzano, Italy \\ * Corresponding author: koenigvb@gwdg.de; +49 551395602
}

Published at Physiology \& Behavior 141 (2015) 164-171

Keywords: Testosterone, Docility, Aggression, Behavior tests, Beef cattle, Temperament, Biomarker.

\begin{abstract}
In beef cows, docility is important for animal welfare reasons, the farmer's and veterinarian's safety as well as for economic reasons. The hormone testosterone is often mentioned in the context with aggressions and docility. The present study tested the hypothesis that higher testosterone levels in beef cows are associated with more aggressive behavior and lower docility during behavior tests. German Simmental (beef) $(n=21)$ and Charolais heifers $(n=20)$ were subjected with one
\end{abstract}


repetition to a chute test as well as a separation and restraint test. Heart rate, thermal images of the eye, saliva cortisol as well as saliva testosterone were collected along with behavioral parameters during the tests. For all physiological and most of the behavioral parameters significant breed differences were detected. Charolais heifers $(0.10 \square 0.01 \mathrm{ng} / \mathrm{ml}$ saliva) had considerably higher testosterone levels compared with Simmental heifers $(0.04 \square 0.01 \mathrm{ng} / \mathrm{ml} ; \mathrm{P}=0.0001)$. Interestingly, the Charolais heifers expressed a higher docility, so across breeds higher levels of testosterone are associated with higher docility. However, all the parameters presumably linked to stress (heart rate, eye temperature, cortisol levels) generally showed stronger correlations to behaviour traits than testosterone (e.g. trait "time in corner" testosterone: $r=0.25$ vs. cortisol: $r=-0.43$ (Fisher's $r$-to-z: $P=0.0985$ ); eye temperature: $r=-0.65 ;(P=0.0005)$ heart rate: $r=-0.60(P=0.003))$. Eye temperature correlated with both heart rate $(r=0.68)$ and cortisol levels $(r=0.62$; both $\mathrm{P}<0.0001)$. Therefore, eye temperature more so than testosterone appears to be a suitable indicator of stress, and as such also an, albeit incomplete, indicator of docility in cattle.

\subsection{INTRODUCTION}

The hormone testosterone is infamously known for its presumed effects on aggressive and sexual behavior. Research shows that besides its relation to reproduction physiology related aspects (Barna and Mezes, 1994, Deen, 2008) the hormone testosterone has indeed an important influence on sexual (Ahmad et al., 1994) as well as general behavior of mammals. For example, according to Gastal et al. (2007) stallion-like behavior, including especially mounting, in mares without ovarian tumors, is a consequence of high ephemeral fluctuation in testosterone. Also according to Beaver and Amoss (1982) high serum testosterone levels can be one reason for masculine and aggressive behavior of mares. Vanheede and Boissou (1993a) subjected rams and ewes to fear-elicting situations and described rams to be less fearful, perhaps as a result of sex-specific differences in hormone levels. Such an influence of testosterone on emotional reactivity has also been shown experimentally (Vanheede and Boissou, 1993b). After testosterone treatments, the fear reactions in ewes in standardized test situations were reduced (Vanheede and Boissou, 1993b). These results are consistent with findings by Gauly et al. (2001a) 
and Mathiak (2002) who described male calves of the breeds German Angus and German Simmental to be calmer in a restrain test compared with female calves. Contrary to this Okuliarova et al. (2007) found that injection of testosterone in Japanese quail eggs provoked increased fearfulness in hatched chicks. Animals of treated eggs showed in a novel environment test decreased locomotor activity, increased defecation and longer latency to leave the start point of the test square (Okuliarova et al., 2007). However, these effects in chicks were only seen in the early ontogeny phase of the animals.

Swansson and Schuster (1987) demonstrated negative effects of testosterone for cooperative social coordination in rats. No impairments of learning were shown in females or males when animals were housed individually. When housed socially the learning aptitude of intact rats as well as castrated rats treated with testosterone was impaired, while it was not impaired in castrated rats that did not receive testosterone treatments (Swansson and Schuster, 1987). Price et al. (2003) discovered a relation of testosterone with aggressive behavior. Aggressiveness of surgically castrated bulls, control bulls and immunocastrated bulls was compared and it was shown that immunocastration with a $\mathrm{GnRH}$ conjugate, which reduced the testosterone level, can significantly reduce aggressive behavior such as sparring and butting in bulls (Price et al., 2003). Van Loo et al. (2001), who analyzed aggressions in group-housed male mice, discovered slightly higher testosterone levels in dominant rather than subordinate mice. Interestingly, they (Van Loo et al., 2001) found a negative correlation between testosterone levels and aggressions, as well as between testes weight and aggressions. They explained these findings by the fact that naturally dominant animals need to be less aggressive to maintain their high dominant status compared with subordinated animals, which permanently have to prove themselves (Van Loo et al., 2001). Plusquellec and Boissou (2001) compared behavioral characteristics of the dairy breed Herens, which is selected for dominance and fighting ability with the none-specialized breed Brune des Alpes. Herens cattle turned out to have higher testosterone levels and lower increases of cortisol after a startle test. The fighting breed also showed lower levels of fear of novel objects, was more tolerant in food competition, less aggressive in undisturbed groups, but more difficult to handle in standardized tests (Plusquellec and Boissou, 2001). Taken together, studies suggest that testosterone levels might serve as a biomarker for certain 
behavior traits, but results regarding the direction of the influence are rather inconclusive.

The aim of the present study was to assess the usefulness of the hormone testosterone in Charolais and Simmental cattle as a biomarker for docility, i.e. the animals' behavioral response to human handling in standardized tests (Burrow, 1997, Fordyce et al., 1988).

\subsection{MATERIALS AND METHODS}

\subsubsection{Animals and housing}

Twenty-one heifers of the breed German Simmental (beef) (average age $10 \pm 1$ months), located on the research farm Relliehausen of the University Göttingen, and 20 Charolais heifers (average age $11 \pm 3$ months) located on a private farm in central Germany, were tested. In addition to age, the animals' birth weights and birth types (single / twin) were known. All animals were housed on pastures in the summer, but they were kept during the test period in their respective group (one group per breed) in a stable on straw.

\subsubsection{Test procedure}

\subsubsection{Behavioral observations}

The chute test (modified from Tulloh (1961)) as an example of a restraint test, as well as a separation-and-restraint test, which is a combination of a restrained and a nonrestrained test, were performed for all animals twice. Testing started with the first chute test, followed by the second chute test one week later. Again each at a distance of one week to the previous test, the first and second separation-andrestraint tests were conducted.

For the chute test, a mobile catching and treatment station ("Priefert Squeeze Chute", Texas Trading), was used. All animals waited in a waiting room and were driven individually through an alleyway with two sliding gates into the treatment station. For the behavioral assessment, a modified scoring system by Grandin (1993) was used. The following behavioral parameters were assessed during the chute test:

The behavior for entering the treatment station was measured with an Entry Score using the following scoring system: 
1 = entering without help,

2 = entering with verbal assistance,

3 = entering with verbal and slight tactile assistance,

4 = intense contact with the animal, required for pushing it

5 = severe problems at entering.

For two minutes the cow was fixed in the head gate and the behavior in the treatment station (Weighing Score) was evaluated with the following scoring system:

$1=$ cow is calm without movement,

2 = excited with movements,

$3=$ nervous and shaking of the treatment station,

4 = agitated with continuous movements and shaking, tries to break the fixation,

5 = very agitated.

While the cow stood in the treatment station, the weight was measured with the integrated scale and the Body Condition Score (Edmonson et al., 1989) was assessed with a scoring system from Score 1 (emaciated) to Score 5 (fat). In addition, the number of movements with the tail during the chute test was recorded. The behavior of the cow for leaving the treatment station (Leaving Score) was measured with the same scale as the entry score. In addition, a Flight and Speed Score, according to Lanier and Grandin 2002) was used to assess the cow's vigor at leaving the treatment station. This scoring system is based on the following scores for the cow's gait when leaving the chute:

1 = walking,

2 = trotting,

3 = running,

4 = jumping.

Furthermore, the behavior of the cow concerning the docility (Docility) during the chute test was evaluated with a visual analogue scale. This scale ranged from $0=$ totally calm to 5 = extremely agitated. Other recorded parameters were the excretion 
of faeces or urine, vocalizations, abnormal behavior like trembling, sitting in the chute or aggressions.

The separation and restraint test was performed as a modified test according to Le Neindre et al. (1995), Mathiak (2002) and Boivin et al. (1992). For the test, a paddock system, constructed of panels by Texas Trading was used. With a maximum time allowance of 180 seconds for separation, a handler moved one animal out of a group of 10 animals from a separation yard $\left(100 \mathrm{~m}^{2}\right)$, through an open gate into the adjoining restraint yard $\left(25 \mathrm{~m}^{2}\right)$, without making physical contact with the animals. Two helpers stood outside the paddock system and documented the animal's behavior as described below. In addition, the handler also evaluated the animal's behavior via the same scoring system. If it was not possible to separate the animal during the above-mentioned time, or if aggressions occurred, the maximum time of $180 \mathrm{~s}$ was recorded as the time to completion, and the animal was separated with the help of a second person. The behavior of the animal was documented according to the following scores (modified according to Le Neindre et al. (1995) and Mathiak (2002)): 1 = calm (standing, unimpressed of the handling, moving only when the handler try to move the animal), 2 = uneasy ( $<10$ steps beside the demanded movement by the handler, looking for herdmates, $<5$ vocalizations), $3=$ nervous $(>10$ steps beside the demanded movement by the handler, searching the herdmates, $>5$ vocalizations), 4 = agitated (animal cannot be separated, tries to escape and move back to the herd, many vocalizations), 5 = very agitated (many attempts to escape and vocalizations, possibly also attempts to attack the handler to get out of the situation). Other observed parameters included the separation time (s), the separation running time (s) (time spent running by the animal during separation), separation success (successful/unsuccessful), aggressions toward the handler (yes/no), vocalization, faeces/urine excretion and attempts to escape.

In the beginning of the restraint test in the pre-handling period, the separated animal was left alone in the restraint yard (Figure 3) for 30 seconds to allow for some habituation to isolation from the group. For the same reason, the handler stood still for the next $30 \mathrm{~s}$ after entering the paddock. In the subsequent handling period the handler attempted to move the animal into one defined corner of the restraint yard, and then to keep it there for $30 \mathrm{~s}$. If this was possible, the handler additionally tried to touch the heifer at the back. In cases of aggressions, or if the confining of the animal in the corner was not successful, the maximum time (180s) was recorded. In case of 
any aggressions during the whole separation and restraint test, testing of that animal would have been terminated. Table 9 gives an overview of all parameters recorded in the restraint test.

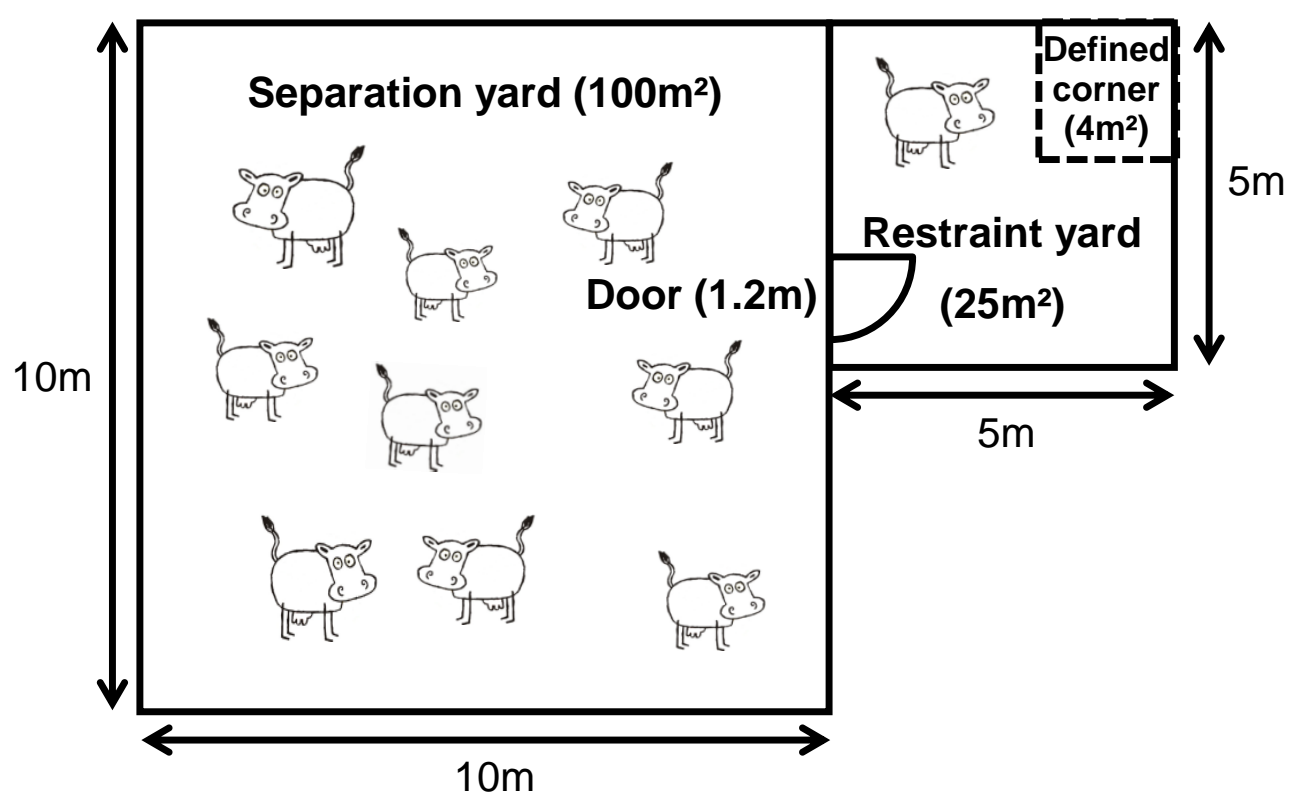

Figure 3: Paddock system for the Separation- and Restraint test (modified according to Mathiak (2002)).

Table 9: List and description of parameters recorded in the restraint test subdivided into the pre-handling and the handling period (modified according to Mathiak (2002)).

\section{Parameter in pre-handling} period (60sec)

Running without person

Running with person

Pre-handling Score

Vocalisation

Faeces / Urine

Parameter in handling period (180 sec)

Time until corner

Handlings run

Time in corner

Try escape

Tolerance touching

Flight distance $(\mathrm{m})$

Aggressions

Handling Score

Vocalisation

Faeces / Urine

\section{Description}

Running time (s) of the cow without a person in the paddock

Running time (s) of the cow in presence of a person in the paddock

Scoring : $1=$ calm, 2 = uneasy, $3=$ nervous, $4=$ agitated, $5=$ very agitated

Utterance of sound via the mouth (yes/no)

Excretion of faeces/urine (yes/no)

\section{Description}

Time (max. $120 \mathrm{~s}$ ) needed until the cow was in the corner

Running time (max. $120 \mathrm{~s}$ ) of the cow until she was in the corner

Time (max. $30 \mathrm{~s}$ ) the cow could be kept in the corner

Attempts to escape (frequency)

Tolerance of touching the cow by the handler (yes/no)

Nearest distance $(m)$ to the cow until she flees

Occurrence of aggressions or aggressive posture (e.g. head lowering)

Scoring: $1=$ calm, $2=$ uneasy, $3=$ nervous, $4=$ agitated, $5=$ very agitated Utterance of sound via the mouth (yes/no)

Excretion of faeces/urine (yes/no) 


\subsubsection{Physiological measurements}

During fixation in the chute test, the following physiological parameters were collected: heart rate, thermal images of the eye, and saliva cortisol as well as saliva testosterone.

Heart rate was measured using a "Polar RS 800 CX" heart rate monitor, while recording the heart rate every 15 seconds for a period of two minutes. Subsequently, the mean heart rate during the two minutes of sampling was calculated.

Thermal images were acquired with the infrared camera "ThermoPro ${ }^{\mathrm{TM}}$ TP8", distributed by the company "InfraMedic", 64546 Mörfelden, Germany. Pictures were taken from the eyes, standing sideways at a distance of $1-1.5 \mathrm{~m}$ to the heifer. Calculations of mean and maximum temperatures were performed with the program "Exam Professional 5.7, InfraMedic $\mathrm{GmbH}, 2011$ ".

Salivette ${ }^{\circledR}$ (REF 51.1534) from Sarstedt AG \& Co., 51588 Nürnberg, Germany, were used for the collection of saliva for testosterone and cortisol analysis. Collection occurred until the swab under the cow's tongue was soaked with saliva.

\subsubsection{Laboratory saliva analyses}

After sampling, the saliva was stored in the fridge at $4^{\circ} \mathrm{C}$ for one day. Samples were centrifuged afterwards at a speed of $2000 \mathrm{rpm}$, in $18^{\circ} \mathrm{C}$ for 20 minutes in a Megafuge ${ }^{\circledR}$ 1.0R, Heraeus Instruments, Schütt Labortechnik, 37079 Göttingen, Germany. Centrifuged saliva was stored at $-20^{\circ} \mathrm{C}$ in a freezer until further processing. Saliva samples for cortisol and testosterone were analyzed by the University of Veterinary Medicine Hannover, 30173 Hannover, Germany. A "Cortisol free in saliva ELISA DES6611" by Demeditec Diagnostics GmbH, 24145 Kiel (Germany), was used. The Microtiterwell was coated with a polyclonal anti-cortisol antibody. For the enzyme conjugate cortisol was conjugated to horseradish peroxidase. The analytical sensitivity of the assay represented $0.014 \mathrm{ng} / \mathrm{ml}$. The range of the assay covered 0 $30 \mathrm{ng} / \mathrm{ml}$. The intra-assay variability contained $5.9-6.8 \%$, the inter-assay variability 5.3-9.4\%. The concentration of testosterone was measured with a self-constructed in-house ELISA of the University of Veterinary Medicine Hannover. The extraction from saliva (200-300 $\mu \mathrm{l}$ ) occurred by a direct enzyme-immunoassay on microtiter plates. A secondary antibody coating technique and horseradish peroxidase was used for the enzyme labelling. The used antiserum was purchased from the Technical University Munich-Weihenstephan, Freising, Germany. The antiserum was 
raised against testosterone with: testosterone $100 \%, 5 \alpha$-dihydrotestosterone $10 \%$, Androstendione $2 \%$, estradiol and progesterone $<0.1 \%$. For a steroid-enzyme conjugate it was used testosterone-3-carboxymethyloxime-horseradish peroxidase. The inter-assay and intra-assay coefficients of variation (CV\%) were calculated by one saliva pool sample. The intra-assay $\mathrm{CV} \%$ was $8.1 \%$, the inter-assay $\mathrm{CV} \%$ amounted to $12.6 \%$. The minimal detectable concentration sustained at $0.2 \mathrm{ng} / \mathrm{ml}$.

This type of non-invasive research is regulated under the German Animal Protection law and does not require a study-specific approval by an ethics committee.

\subsubsection{Statistical analysis}

The statistical analysis of the data was performed using the SAS 9.3 program, SAS Institute Inc. Cary, North Carolina 27513-2414, USA. In order to achieve a Gaussian distribution, the data of the parameters Testosterone, Cortisol, Docility Scale, Separation Time and Separation Run were transformed with log 10. The parameters eye temperature, heart rate and flight distance approximated a Gaussian distribution and were therefore not transformed. Using a mixed model (procedure mixed) the significance of differences between the breeds and repetitions of individual parameters was examined. For most behavior scores (entry score, weighing score, leaving score, separation score, pre-handling score, handling score) as well as the parameters Handling Run, Time until Corner, and Time in Corner a generalized linear mixed model (procedure glimmix) was used, assuming an underlying Poisson distribution. The parameter Flight and Speed Score was converted to a binary parameter (score 0 = walking, score 1 = fast movements), and likewise analyzed with a generalized linear mixed model for binary data. All models included the animal as a random factor and breed, measurement as well as their interaction as fixed factors. Age, weight as well as the physiological parameters (for behavioral parameters as dependent variable only) were tested as covariates but removed from the model, if they were not significant. The procedure "CORR" was used to calculate Pearson correlations between parameters. Fisher's r-to-z test was used to compare significance of differences in magnitude of correlation coefficient between testosterone and all behavioural parameters on the one hand and the remaining physiological parameters and respective behavioural parameters on the other hand. Repeatabilities and their standard errors were calculated from the variance components of the mixed model analyses according to Falconer (1984) and Roberds 
and Strom (2006). Throughout the study, values of $P<0.05$ were considered to indicate significant differences, and values of $\mathrm{P}<0.1$ were considered to indicate a statistical trend.

\subsection{RESULTS}

For every parameter of the chute test and separation and restraint test, except the separation score and flight distance, significant breed differences were observed (Figure $4 \mathrm{a}-\mathrm{d}$ and Figure $5 \mathrm{a}-\mathrm{c}$ ). However, in a few cases, the interaction between breed and measurement was also significant, indicating that breed differences were not consistent across measurements (Figure $4 \mathrm{~b}$, Figure $5 \mathrm{c}$ ).

Significant effects for testosterone were detected for the calving type $(P=0.039)$. Single born animals showed higher testosterone levels compared with twin born animals. Cortisol levels were influenced by the age of the heifer $(P=0.0073)$, with younger animals having higher testosterone levels (value on original scale: -0.01 $\mathrm{ng} / \mathrm{mL}$ per additional month of age; link scale $=-0.08 \pm 0.03$ ). In the chute test, the Charolais heifers were significantly more difficult $(P=0.0316)$ to drive into the chute (score $2.33 \pm 0.24$ vs $1.63 \pm 0.20)$, but also left the chute slower $(P=0.0016$; score $1.00 \pm 0.16$ vs $1.93 \pm 0.21)$ compared with Simmental heifers. For the binary parameter flight and speed score the probability for Charolais to receive score 1 in the test (mean score: $0.94 \pm 0.04)$ was higher $(P=0.0469)$ than for Simmental $(0.72$ \pm 0.09 ). In addition, the animal's weight $(P=0.0082$, value on original scale: -0.003 ; link scale $0.02 \pm 0.01)$ and age $(P=0.0366$; original scale: -0.10 ; link scale $1.04 \pm$ $0.49)$ influenced the flight and speed score, such that heavier and older animals received lower scores.

In the separation- and restraint test the Simmental heifers spent significantly more time running (both $\mathrm{P}<0.0001$ ) compared with the Charolais heifers (separation run: $70.2 \pm 7.8 \mathrm{~s}$ vs $22.5 \pm 8.0 \mathrm{~s}$; handlings run: $76.8 \pm 1.4 \mathrm{~s}$ vs $13.2 \pm 0.6 \mathrm{~s}$ ). The more time animals spent running during separation, the longer it took to separate them $(P<$ 0.0001 , value on original scale: $+1.0 \mathrm{sec}$ per additional sec running; link scale: 0.01 $\pm 0.00036)$. Separation time was shorter with younger animals $(p=0.013 ;+0.79 \mathrm{sec}$ per month of age; transformed value: $-0.10 \pm 0.04$ ). The time spent running during handling was influenced by testosterone $(p=0.0091,+0.003 \mathrm{sec}$ per additional $\mathrm{ng} / \mathrm{ml}$ testosterone; transformed value: $-2.42 \pm 0.88)$ and cortisol levels $(P<0.0001 ;+2.0$ 
sec per additional $\mathrm{ng} / \mathrm{ml}$ cortisol; transformed value: $0.30 \pm 0.03$ ). The pre-handling $(P=0.0321)$ as well as the handling score $(P=0.0161)$ were higher in the Simmental breed (pre-handling score: $1.7 \pm 0.2$ vs $1.1 \pm 0.2$; handling score: $2.1 \pm 0.2$ vs $1.4 \pm$ $0.2)$. More time $(P<0.0001)$ was needed to confine Simmental heifers to the corner (71.7 $\pm 1.4 \mathrm{~s}$ vs $16.0 \pm 0.6 \mathrm{~s}$ ), while the Charolais heifers could be restrained for a longer time $(P<0.0001)$ in the corner $(25.5 \pm 0.8 \mathrm{~s}$ vs $9.1 \pm 0.5 \mathrm{~s})$. The time until the animal was confined in the corner was also the larger the higher the cortisol levels were $(P<0.0001,+0.43 \mathrm{sec}$ per additional $\mathrm{ng} / \mathrm{ml}$ cortisol; value on link scale: $0.13 \pm$ $0.02)$. Animals with a higher heart rate could be restrained for a shorter time in the corner $(\mathrm{P}<0.0001,-0.18 \mathrm{sec}$ per additional beat per minute in heart rate; value on link scale: $-0.02 \pm 0.005$ ). Significant differences between the measurements were only found for cortisol, docility, the handling run and the flight distance (Table 10). None of the tested animals, regardless of the breed, exhibited any aggression during the separation or the handling period. Also no signs for aggressive behavior were observed in the chute test. The repeatability of behavioral and physiological parameters is shown in Table 11. Pearson correlation coefficients between physiological and behavioral parameters of the two tests as well as age are presented in Table 12 a-d. Fisher's r-to-z test revealed that all correlation coefficients between testosterone and the various behavioral parameters were numerically consistently, and for the most part significantly, smaller than the respective correlation coefficients between the other physiological parameters and the respective behavioral parameters (Table $12 \mathrm{a}, \mathrm{b}$ ). 


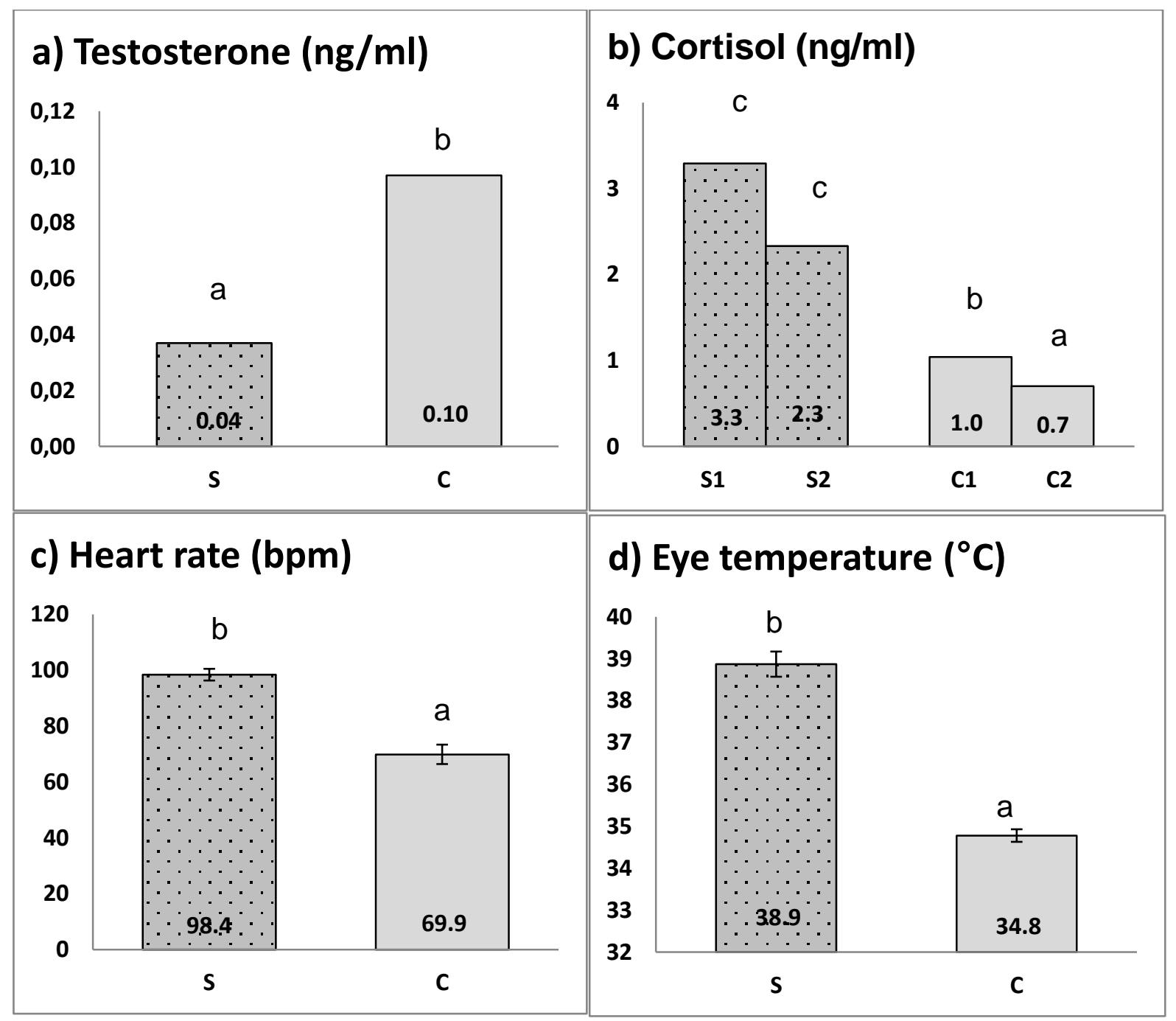

Figure 4: Least square means (heart rate (c) and eye temperature (d)) or re-transformed means (cortisol (b) and testosterone (a)) by breed and their interaction with measurement $\left(1^{\text {st }}\right.$ or $2^{\text {nd }}$ measurement), if applicable, for physiological parameters. Figure $4 \mathrm{a}$ and $\mathrm{b}$ show retransformed values and thus no standard errors are presented. 


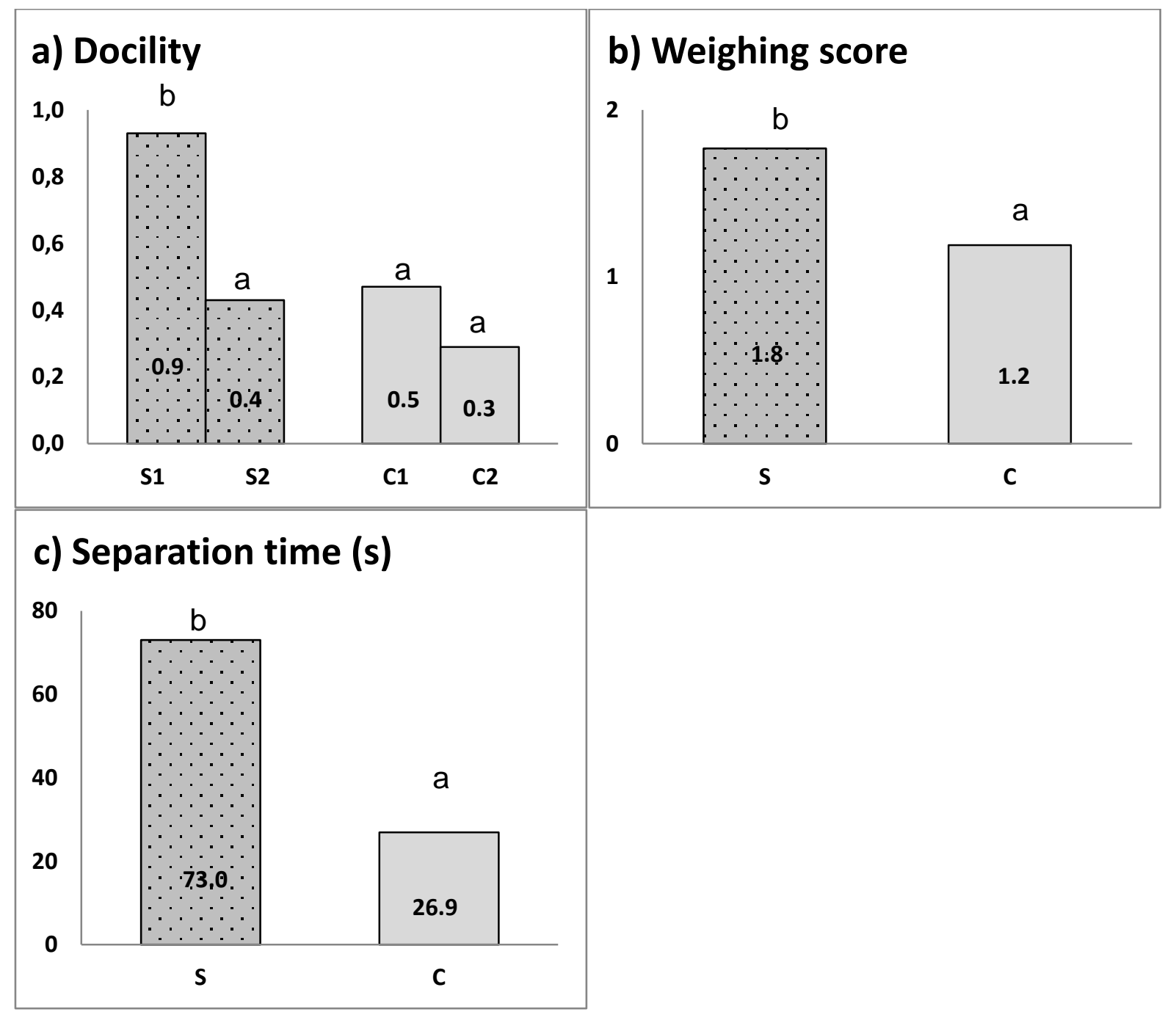

Figure 5: Breed and measurement (if significant; $\mathrm{P}<0.05$ ) differences for behavioral parameters docility (a), weighing score (b) and separation time (c). Different letters (a,b) indicate significant differences $(P<0.05)$. Figures show re-transformed values and thus no standard errors are presented. 
Table 10: Least square means or re-transformed means ( \pm standard errors) and P-values for the measurement (1st and the 2nd measurement) and their interaction with breed (B X M) for all assessed parameters.

\begin{tabular}{lcccc} 
Parameter & $\begin{array}{c}\text { P-value } \\
\text { Measurement }\end{array}$ & $\begin{array}{c}\text { Mean } \\
\text { 1st }\end{array}$ & $\begin{array}{c}\text { Mean } \\
\text { 2nd }\end{array}$ & $\begin{array}{c}\text { P-value } \\
\text { B X M }\end{array}$ \\
\hline Testosterone & 0.2907 & & & 0.3629 \\
Cortisol & $<0.0011$ & $2.2 \pm 0.2$ & $1.5 \pm 0.2$ & 0.7094 \\
Heart rate & 0.0620 & $87.9 \pm 3.4$ & $80.4 \pm 2.0$ & 0.7954 \\
Eye temperature & 0.1226 & & & 0.6835 \\
Entry score & 0.6821 & & & 0.6821 \\
Weighing score & 0.3417 & & & 0.5366 \\
Leaving score & 0.8490 & & & 0.8490 \\
Flight and speed score & 0.9873 & & & 0.2910 \\
Docility & $<0.0001$ & $0.7 \pm 0.1$ & $0.4 \pm 0.1$ & 0.0435 \\
Separation time & 0.1883 & & & 0.0222 \\
Separation run & 0.5020 & & & 0.0142 \\
Separation score & 0.9733 & & & 0.9911 \\
Pre-handling score & 0.9882 & & & 0.7467 \\
Time until corner & 0.0607 & $29.6 \pm 2.4$ & $32.3 \pm 2.5$ & $<0.0001$ \\
Handlings run & 0.0003 & $28.8 \pm 1.1$ & $35.1 \pm 1.1$ & $<0.0001$ \\
Time in corner & 0.2557 & & & 0.0358 \\
Flight distance & 0.0071 & $0.7 \pm 0.1$ & $0.9 \pm 0.1$ & 0.9576 \\
Handling score & 0.5463 & & & 0.1645
\end{tabular}

Table 11: Repeatabilities \pm Standard error (SE) of Gaussian and log-transformed behavioral and physiological parameters.

\begin{tabular}{ll} 
Parameter & Repeatability \pm SE \\
\hline Heart rate & $99.9 \pm 0.01$ \\
Cortisol & $50.6 \pm 13.4$ \\
Testosterone & $10.9 \pm 17.0$ \\
Eye temperature & $90.5 \pm 0.10$ \\
Docility & $55.4 \pm 12.3$ \\
Flight distance & $39.8 \pm 15.2$ \\
Separation time & $13.2 \pm 17.1$ \\
Separation run & $14.5 \pm 17.1$
\end{tabular}


Table 12: Pearson correlation coefficients of a: physiological parameters with the parameters of the chute test and age, $b$ : physiological parameters with the separation and restrain test and age, c: physiological with physiological parameters, $d$ : behavioral parameters of the chute test with the behavioral parameters of the separation and restrain test and age. (Eye temp. = eye temperature; significance values for individual correlation coefficients in brackets; * indicates a significantly (or \# = P $<0.1$ ) larger correlation coefficient compared to the respective correlation coefficient between testosterone and that behavioural parameter; insignificant correlation coefficients were considered to be 0 .)

a)

\begin{tabular}{|c|c|c|c|c|c|c|c|}
\hline & Entry score & $\begin{array}{l}\text { Weighing } \\
\text { score }\end{array}$ & $\begin{array}{c}\text { Tail } \\
\text { movement }\end{array}$ & Leaving score & Flight \& speed score & Docility scale & Age \\
\hline Testosterone & & & & $\begin{array}{l}-0.22 \\
(0.05)\end{array}$ & & & \\
\hline Cortisol & $\begin{array}{l}-0.29^{*} \\
(0.01)\end{array}$ & $\begin{array}{c}0.53^{*} \\
(<0.0001)\end{array}$ & & & $\begin{array}{c}0.25^{\#} \\
(0.03)\end{array}$ & $\begin{array}{c}0.58^{*} \\
(<0.0001)\end{array}$ & $\begin{array}{c}-0.47^{*} \\
(<0.0001)\end{array}$ \\
\hline Eye temp. & $\begin{array}{l}-0.38^{\star} \\
(0.003)\end{array}$ & $\begin{array}{c}0.35^{*} \\
(0.006)\end{array}$ & $\begin{array}{c}0.53^{*} \\
(<0.0001)\end{array}$ & $\begin{array}{c}0.52^{*} \\
(<0.0001)\end{array}$ & $\begin{array}{c}0.36^{*} \\
(0.005)\end{array}$ & $\begin{array}{c}0.49^{*} \\
(<0.0001)\end{array}$ & $\begin{array}{c}-0.42^{*} \\
(0.0009)\end{array}$ \\
\hline Heart rate & $\begin{array}{l}-0.29^{\star} \\
(0.02)\end{array}$ & $\begin{array}{c}0.50^{*} \\
(<0.0001)\end{array}$ & & & & $\begin{array}{c}0.51^{*} \\
(<0.0001)\end{array}$ & $\begin{array}{c}-0.52^{*} \\
(<0.0001)\end{array}$ \\
\hline
\end{tabular}

b)

\begin{tabular}{|c|c|c|c|c|c|c|c|c|c|c|}
\hline & $\begin{array}{c}\text { Separation } \\
\text { time }\end{array}$ & $\begin{array}{c}\text { Separation } \\
\text { run }\end{array}$ & $\begin{array}{c}\text { Separation } \\
\text { score }\end{array}$ & $\begin{array}{l}\text { Pre- } \\
\text { handling } \\
\text { score }\end{array}$ & $\begin{array}{l}\text { Time until } \\
\text { corner }\end{array}$ & $\begin{array}{l}\text { Handlings } \\
\text { run }\end{array}$ & $\begin{array}{l}\text { Time in } \\
\text { corner }\end{array}$ & $\begin{array}{c}\text { Try } \\
\text { escape }\end{array}$ & $\begin{array}{l}\text { Handling } \\
\text { score }\end{array}$ & Age \\
\hline Testosterone & & & & & $\begin{array}{c}-0.32 \\
(0.004)\end{array}$ & $\begin{array}{c}-0.32 \\
(0.005)\end{array}$ & $\begin{array}{c}0.25 \\
(0.03)\end{array}$ & & & \\
\hline Cortisol & $\begin{array}{c}0.36^{*} \\
(0.001)\end{array}$ & $\begin{array}{c}0.37^{*} \\
(0.0008)\end{array}$ & $\begin{array}{c}0.38^{*} \\
(0.0005)\end{array}$ & $\begin{array}{c}0.30^{*} \\
(0.006)\end{array}$ & $\begin{array}{c}0.44 \\
(<0.0001)\end{array}$ & $\begin{array}{c}0.36 \\
(0.001)\end{array}$ & $\begin{array}{c}-0.43^{\#} \\
(<0.0001)\end{array}$ & $\begin{array}{l}0.28^{*} \\
(0.01)\end{array}$ & $\begin{array}{c}0.44^{*} \\
(<0.0001)\end{array}$ & $\begin{array}{c}-0.47^{*} \\
(<0.0001)\end{array}$ \\
\hline Eye temp. & $\begin{array}{l}0.32^{*} \\
(0.01)\end{array}$ & $\begin{array}{c}0.34^{*} \\
(0.008)\end{array}$ & $\begin{array}{c}0.45^{\star} \\
(0.0003)\end{array}$ & $\begin{array}{c}0.53^{*} \\
(<0.0001)\end{array}$ & $\begin{array}{c}0.75^{\star} \\
(<0.0001)\end{array}$ & $\begin{array}{c}0.70^{*} \\
(<0.0001)\end{array}$ & $\begin{array}{c}-0.65^{\star} \\
(<0.0001)\end{array}$ & $\begin{array}{c}0.49^{*} \\
(<0.0001)\end{array}$ & $\begin{array}{c}0.68^{*} \\
(<0.0001)\end{array}$ & $\begin{array}{c}-0.42^{*} \\
(0.0009)\end{array}$ \\
\hline Heart rate & $\begin{array}{c}0.38^{\star} \\
(0.002)\end{array}$ & $\begin{array}{c}0.39^{*} \\
(0.001)\end{array}$ & $\begin{array}{c}0.46^{*} \\
(0.0001)\end{array}$ & $\begin{array}{c}0.37^{*} \\
(0.002)\end{array}$ & $\begin{array}{c}0.52^{*} \\
(<0.0001)\end{array}$ & $\begin{array}{c}0.48 \\
(<0.0001)\end{array}$ & $\begin{array}{c}-0.60^{*} \\
(<0.0001)\end{array}$ & $\begin{array}{l}0.31^{*} \\
(0.01)\end{array}$ & $\begin{array}{c}0.45^{\star} \\
(0.0002)\end{array}$ & $\begin{array}{c}-0.52^{*} \\
(<0.0001)\end{array}$ \\
\hline
\end{tabular}


c)

\begin{tabular}{ccccc} 
& Testosterone & Cortisol & Eye temp. & Heart rate \\
\hline Testosterone & & & -0.35 & -0.40 \\
Cortisol & & & 0.62 & 0.50 \\
Eye temp. & & & & 0.68 \\
Heart rate & $(0.007)$ & $(<0.0001)$ & & \\
& $(0.001)$ & $(<0.0001)$ & $(<0.0001)$ &
\end{tabular}

d)

\begin{tabular}{|c|c|c|c|c|c|c|c|c|c|c|c|}
\hline & $\begin{array}{l}\text { Separation } \\
\text { time }\end{array}$ & $\begin{array}{l}\text { Separation } \\
\text { run }\end{array}$ & $\begin{array}{l}\text { Separation } \\
\text { score }\end{array}$ & $\begin{array}{c}\text { Pre- } \\
\text { handling } \\
\text { score }\end{array}$ & $\begin{array}{l}\text { Time } \\
\text { until } \\
\text { corner }\end{array}$ & $\begin{array}{l}\text { Handlings } \\
\text { run }\end{array}$ & $\begin{array}{l}\text { Time in } \\
\text { corner }\end{array}$ & $\begin{array}{c}\text { Try } \\
\text { escape }\end{array}$ & $\begin{array}{c}\text { Flight } \\
\text { distance }\end{array}$ & $\begin{array}{l}\text { Handling } \\
\text { score }\end{array}$ & Age \\
\hline Entry Score & & & $\begin{array}{l}-0.25 \\
(0.02)\end{array}$ & $\begin{array}{c}-0.33 \\
(0.002)\end{array}$ & $\begin{array}{c}-0.39 \\
(0.0004)\end{array}$ & $\begin{array}{c}-0.31 \\
(0.005)\end{array}$ & $\begin{array}{c}0.36 \\
(0.001)\end{array}$ & $\begin{array}{l}-0.27 \\
(0.01)\end{array}$ & $\begin{array}{c}-0.30 \\
(0.007)\end{array}$ & $\begin{array}{c}-0.35 \\
(0.001)\end{array}$ & $\begin{array}{c}0.22 \\
(0.05)\end{array}$ \\
\hline $\begin{array}{l}\text { Weighing } \\
\text { score }\end{array}$ & & $\begin{array}{c}0.21 \\
(0.05)\end{array}$ & $\begin{array}{c}0.31 \\
(0.004)\end{array}$ & $\begin{array}{c}0.33 \\
(0.002)\end{array}$ & $\begin{array}{c}0.43 \\
(<0.0001)\end{array}$ & $\begin{array}{c}0.36 \\
(0.001)\end{array}$ & $\begin{array}{c}-0.41 \\
(0.0001)\end{array}$ & $\begin{array}{c}0.330 \\
(0.003)\end{array}$ & $\begin{array}{c}0.22 \\
(0.05)\end{array}$ & $\begin{array}{c}0.50 \\
(<0.0001)\end{array}$ & $\begin{array}{c}-0.29 \\
(0.009)\end{array}$ \\
\hline $\begin{array}{c}\text { Tail } \\
\text { movement }\end{array}$ & & & & $\begin{array}{c}0.26 \\
(0.02)\end{array}$ & $\begin{array}{c}0.30 \\
(0.008)\end{array}$ & $\begin{array}{c}0.30 \\
(0.008)\end{array}$ & $\begin{array}{l}-0.27 \\
(0.01)\end{array}$ & & & & $\begin{array}{l}-0.28 \\
(0.01)\end{array}$ \\
\hline $\begin{array}{l}\text { Leaving } \\
\text { score }\end{array}$ & & $\begin{array}{c}0.22 \\
(0.05)\end{array}$ & & $\begin{array}{c}0.27 \\
(0.01)\end{array}$ & & & $\begin{array}{l}-0.28 \\
(0.01)\end{array}$ & $\begin{array}{c}0.24 \\
(0.03)\end{array}$ & & & $\begin{array}{l}-0.24 \\
(0.03)\end{array}$ \\
\hline $\begin{array}{l}\text { Flight \& } \\
\text { speed score }\end{array}$ & & & & $\begin{array}{c}0.22 \\
(0.05)\end{array}$ & & & & & & & $\begin{array}{l}-0.35 \\
(0.002\end{array}$ \\
\hline Docility scale & & & $\begin{array}{c}0.29 \\
(0.009)\end{array}$ & $\begin{array}{c}0.25 \\
(0.02)\end{array}$ & $\begin{array}{c}0.36 \\
(0.001)\end{array}$ & $\begin{array}{c}0.29 \\
(0.009)\end{array}$ & $\begin{array}{c}-0.37 \\
(0.0007)\end{array}$ & $\begin{array}{c}0.32 \\
(0.003)\end{array}$ & & $\begin{array}{c}0.50 \\
(<0.0001)\end{array}$ & $\begin{array}{l}-0.25 \\
(0.05)\end{array}$ \\
\hline Age & $\begin{array}{c}-0.38 \\
(0.0004)\end{array}$ & $\begin{array}{c}-0.39 \\
(0.0003)\end{array}$ & $\begin{array}{c}-0.42 \\
(<0.0001)\end{array}$ & $\begin{array}{c}-0.31 \\
(0.004)\end{array}$ & $\begin{array}{c}-0.36 \\
(0.0009)\end{array}$ & $\begin{array}{c}-0.32 \\
(0.004)\end{array}$ & $\begin{array}{c}0.43 \\
(<0.0001)\end{array}$ & $\begin{array}{l}-0.25 \\
(0.02)\end{array}$ & $\begin{array}{l}-0.25 \\
(0.02)\end{array}$ & $\begin{array}{c}-0.36 \\
(0.001)\end{array}$ & \\
\hline
\end{tabular}




\subsection{DISCUSSION}

The animals from both farms/breeds were raised under equal management systems. All heifers were born indoors, were familiar with humans and regularly had human contact on both farms. Although effects of the farms cannot be excluded, the difference in temperament and behavior can therefore be assumed to be mainly attributable to breed differences.

\subsubsection{Physiological parameters}

Charolais heifers turned out to have higher testosterone levels compared with Simmental heifers (Figure 4). The higher hormone levels of singleton born animals compared with twin born animals can be a sign for a higher vitality later in life due to an easier development during ontogeny in these animals.

Based on the physiological parameters cortisol (Figure $4 \mathrm{~b}$ ), heart rate (Figure $4 \mathrm{c}$ ), and eye temperature (Figure $4 \mathrm{~d}$ ), Simmental heifers seem to be more nervous and stressed than Charolais heifers. The negative correlations of testosterone with the eye temperature and heart rate (Figure $4 \mathrm{c}$ ) indicated that cows with higher eye temperature and heart rate exhibited lower testosterone levels. In contrast, the presumed stress parameters cortisol, eye temperature and heart rate were positively correlated with each other. Thus, low testosterone levels may indicate a stressed animal. Also in stressed race horses compared to healthy horses (Baker et al., 1982) and exhausted camels after a camel racings (Hadi et al., 2001) lower testosterone levels were found.

However, the cortisol level decreased significantly from the first to the second measurement (Table 10) independent of the breed, which indicates that habituation to the handling procedures took place. The habituation to human handling resulting in decreased cortisol levels has been shown for example for cows (Grandin, 1997) and dogs (Bergamasco et al., 2010). Habituation to human presence in general may also be reflected by the higher cortisol level in younger rather than older animals. In addition, no correlations were seen between the steroidal hormones testosterone and cortisol in this study (Table $12 \mathrm{c}$ ). A similar result was observed under resting conditions by Thun and Eggenberger (1996). 


\subsubsection{Chute test}

All behavioral parameter of the chute test revealed significant breed differences. Simmental heifers were generally more agitated, for example demonstrated by a higher weighing score and docility scale, but faster to be driven into the chute compared with Charolais heifers. Also in other studies, the breed German Simmental was more distressed in the chute test compared with other breeds (Plachta, 2009). An exception is the parameter Entry Score which indicated Simmental heifers to behave in a more desirable manner. However, in particular this parameter can easily be influenced by the mode of handling by the surrounding people. Therefore, the Entry Score potentially is not a highly suitable parameter to evaluate the animals' temperament. The fact that animals which need more pressure to enter the chute (in this study the breed Charolais), left the chute after the test more slowly, was also observed by Gauly et al. (2001 a) and Urban (2007).

Habituation effects, as they occur for example after repeated weighing of Zebu cattle (Andrade et al., 2001), were in the present study only seen in a few parameters for docility and cortisol. Habituation from first to second measurement was greater for Simmental which likely is a result of overall higher values in this breed.

For the behavioral parameters of the chute test, significant correlations with testosterone were only observed with the leaving score (Table 12 a). The negative correlations demonstrate that animals with higher testosterone levels left the chute more slowly, indicating an easier temperament with higher testosterone levels. Negative correlations of the physiological stress parameters cortisol, eye temperature and heart rate with the entry score indicate that it was more difficult to move stressed animals in the chute.

\subsubsection{Separation and restraint test}

Except for the separation score and the flight distance all parameters of the separation and restraint test showed significant breed differences. Similar as with the chute test, Simmental heifers were more agitated and less docile than Charolais heifers. This was demonstrated by the longer separation time and separation/handlings running time, a longer time which was needed to drive the animal in the corner and a shorter restraint time in the corner, as well as higher behavior scores for the Simmental heifers. Also, for most of the parameters of a separation- and restraint test conducted by Urban (2007), significant breed 
differences were detected, with German Simmental cattle being more agitated compared with the German Angus cattle (Urban, 2007). Moreover breed differences in temperament were seen before e.g. by Gauly et al. (2001b) who found German Angus to be easier to handle compared with German Simmental in a separation and restraint test. The same was observed by Mathiak (2002), who also detected more aggressive behavior in German Simmental during handling situations.

The correlations between behavior and testosterone in the separation and restraint test indicate that animals with a higher testosterone level spent less time running and more time in the corner during the test (Table $12 \mathrm{~b}$ ). Thus testosterone does seem to be linked to a certain extent to docility.

\subsubsection{Repeatability and further correlations}

Of all parameters, heart rate showed the highest repeatability, indicating this parameter to be very consistent within test situations for individuals. Similar results were found for horses: Mean heart rate measured in temperament tests generally showed higher repeatability than behavioral parameters (König v. Borstel et al., 2011). Unfortunately, the repeatability of testosterone was low, and the high standard error (Table 11) indicated uncertainty of this parameter.

As described earlier by Fordyce and Goddard (1984), also in the present study a more difficult temperament was observed in younger animals that likely had less experience with handling routines. The correlations between behavior and testosterone indicate that animals with a higher testosterone level are calmer during the behavior test. Thus testosterone does seem to be linked to a certain extent to docility in cattle. However, correlations between cortisol and behavioral parameters generally were higher than those between testosterone and behavior. Therefore, cortisol should be preferred over testosterone as a biomarker for docility, although relationships between behavior and cortisol levels are nevertheless at a low level. A low relationship between cortisol and behavior can be explained due to circadian and ultradian rhythms of cortisol (Lefcourt et al., 1993) and by the time dependent measure of the hormone. For the use of cortisol as an indicator for short term stress, it must be considered that for saliva cortisol it takes 10-20 minutes until the peak values are reached (Lay et al., 1997). Therefore brief handling procedures can be finished before the cortisol level could rise (Grandin,1997, Tume and Shaw, 1992). In addition the collection of salivary, as well as of plasma cortisol is not stress-free and 
saliva cortisol levels generally show lower levels of the hormone compared to plasma cortisol (Negrao et al., 2004). However, low correlations between behavior and cortisol are not necessarily surprising, as correlations between behavior in the different test situations were likewise at a rather low level. Similar results were obtained for the evaluation of the suitability of parameters such as oxytocin and cortisol as biomarkers for maternal behavior in cattle (Geburt et al., 2015). Although disappointing with regard to the search for biomarkers, such incomplete relationships between behavior in different test situations are not surprising as behavior is by definition plastic (König v. Borstel, 2013). As a result, particularly high correlations between behavior or physiological parameters measured in different situations cannot be expected.

\subsection{CONCLUSION}

While Charolais heifers exhibited higher testosterone levels compared with Simmental heifers, behavioral as well as stress-correlated physiological parameters revealed the breed Simmental to be more stressed and nervous during the handling. Based on the weak relationships between testosterone and behavioral and other physiological parameters the hypothesis that a higher testosterone level in beef cows is associated with a more aggressive behavior and lower docility must be rejected. Indeed, the opposite seems to be the case, and it can be assumed that maybe due to lower fearfulness, cows with a higher testosterone levels seem to be more calm, relaxed and easier to handle.

\section{Acknowledgements}

Many thanks to the head and staff of the (research) farms for making this research project possible. The authors acknowledge funding by the Federal Ministry of Education and Research (BMBF) within the project "Phenomics", Network of Competence of Agricultural and Nutritional Research under the project number: 0315536J. 


\section{REFERENCES}

Ahmad, N., Shahab, M., Anzar, M., Arslan, M., 1991. Changes in the behavior and androgen levels during pubertal development of the buffalo bull. Applied Animal Behaviour Science 32, 101-105.

Andrade, O., Orihuela, A., Solano, J., Galina, C.S., 2001. Some effects of repeated handling and the use of mask on stress responses in zebu cattle during restraint. Applied Animal Behaviour Science 71, 175-181.

Baker, H.W.G., Baker, I.D.C., Epstein, V.M., Hudson, B., 1982. Effect of stress on steroid-hormone levels in racehorses. Australian Veterinary Journal 58, 70-71.

Barna, J., Mezes, M., 1994. Evaluation of testosterone response to intramuscular injection of $\mathrm{GnRH}$ and its correlation with sperm quality parameters in cockerels. Acta veterinaria Hungarcia 42, 481-485.

Beaver, B.V., Amoss, M.S., 1982. Aggressive behavior associated with naturally elevated serum testosterone in mares. Applied Animal Ethology 8, 425-428.

Bergamasco, L., Osella, M.C., Savarino, P., Larosa, G., Ozella, L., Manassero, M., Badino, P., Odore, R., Barbero, R., Re, G., 2010. Heart rate variability and saliva cortisol assessment in shelter dog: Human-animal interaction effects. Applied Animal Behaviour Science 125, 56-68.

Boivin, X., Le Neindre, P., Chupin, J.M., Garel, J.P., Trillat, G., 1992. Influence of breed and early management on ease of handling and open-field behavior of cattle. Applied Animal Behaviour Science 32, 313-323.

Burrow, H.M., 1997: Measurement of temperament and their relationship with performance traits of beef cattle, Animal Breeding Abstracts 65, 478-495.

Deen, A., 2008. Testosterone profiles and their correlation with sexual libido in male camels. Research in veterinary science $85,220-226$.

Edmonson, A.J., Lean, I.J., Weaver, L.D., Farver, T., Webster, G. 1989. A Body Condition Scoring Chart for Holstein Dairy Cows. Journal of Dairy Science 72 , 68-78.

Falconer, D.S., 1984. Einführung in die quantitative Genetik (Introduction to quantitative genetics). Stuttgart, Germany, Eugen Ulmer GmbH \& Co, p.184.

Fordyce, G., Dodt, R.M. Wythes, J.R., 1988. Cattle temperaments in extensive beef herds in northern Queensland 1. Factors affecting temperament. Australian Journal of Experimental Agriculture 28, 683-687.

Fordyce, G., Goddard, M.E., 1984. Maternal influence of the temperament of bos indicus cross cows. Animal Production in Australia 15, 345-348. 
Gastal, M.O., Gastal, E.L., Beg, M.A., Ginther, O.J., 2007. Stallion-like behavior in mares: Review of incidence, characteristics, ovarian activity, and role of testosterone. Journal of Equine Veterinary Science 27, 390-393.

Gauly, M., Mathiak, H., Hoffmann, K., Kraus, M. Erhardt, G., 2001b. Estimating genetic variability in temperamental traits in German Angus and Simmental cattle. Applied Animal Behaviour Science 74, 109-119.

Gauly, M., Mathiak, H., Kraus, M., Hoffmann, K. Erhardt, G., 2001a. Difference in temperament of beef cattle regarding breed and sex. Deutsche Tierärztliche Wochenschrift 108, 206-210.

Geburt, K., Friedrich, M., Piechotta, M., Gauly, M., König v. Borstel, U. 2015. Validity of physiological biomarkers for maternal behavior in cows - a comparison of beef and dairy cattle. Physiology and Behavior 139, 361-368.

Grandin, T., 1993. Behavioral agitation during handling of cattle is persistent over time. Applied Animal Behaviour Science 36, 1-9.

Grandin, T., 1997. Assessment of stress during handling and transport. Journal of Animal Science 75, 249-257.

Hadi, A.A.A., Wasfi, I.A., 2001. 17ß-Estradiol and testosterone level in post-racing plasma of mature female and male racing camels. Emirates Journal of Agricultural Sciences 13, 33-38.

König v. Borstel, U., 2013. Assessing and influencing personality for improvement of animal welfare: a review of equine studies. CAB Reviews 8, 006, 1-27.

König v. Borstel, U., Euent, S., Graf, P., König, S., Gauly, M., 2011. Equine behavior and heart rate in temperament tests with or without rider or handler. Physiology \& Behavior 104, 454-463.

Lanier, J.I., Grandin, T., 2002. The relationship between bos taurus feedlot cattle temperament and cannon bone measurements. Journal of Animal Science 80, 105.

Lay, D.C., Friend, T.H.Jr., Bowers,C.L., Grissom, K.K., Jenkins, O.C., 1992. A comparative physiological and behavioral study of freeze and hot-iron branding using dairy cows. Journal of Animal Science, 70, 1121-1125.

Le Neindre, P., Trillat, G., Sapa, J., Menissier, F., Bonnet, J.N., Chupin, J.M., 1995. Individual-differences in docility in Limousin cattle. Journal of Animal Science $73,2249-2253$.

Lefcourt A.M., Bitman, J., Kahl, S., Wood, D.L., 1993. Circadian and ultradian rhythms of peripheral cortisol concentrations in lactating dairy cows. Journal of Dairy Science 76, 2607-2612. 
Mathiak, H., 2002. Genetische Parameter von Merkmalen des Temperaments und der Umgänglichkeit bei den Rassen Dt. Angus und Dt. Fleckvieh. PhD-thesis Justus-Liebig-Universität Gießen, Germany.

Negrao, J.A., Porcionato, M.A., De Pasille, A.M., Rushen, J., 2004: Cortisol in saliva and plasma of cattle after ACTH administration and milking. Journal of Dairy Science 87, 1713-1718.

Okuliarova, M, Skrobanek, P., Zeman, M., 2007. Effect of increasing yolk testosterone levels on early behavior in Japanese quail hatchlings. Acta veterinaria $76,325-331$.

Plachta, C., 2009. Untersuchungen zum Temperament von Dt. Angus und Dt. Fleckvieh Rindern sowie deren reziproken Kreuzung anhand verschiedener Testverfahren unter besonderer Berücksichtigung von Kreuzungseffekten. PhDthesis, Justus-Liebig-Universität Gießen, Germany..

Plusquellec, P., Bouissou, M.F., 2001. Behavioral characteristics of two dairy breeds of cows selected (Herens) or not (Brune des Alpes) for fighting and dominance ability. Applied Animal Behaviour Science 72, 1-21.

Price, E.O., Adams, T.E., Huxsoll, C.C., Borgwardt, R.E., 2003. Aggressive behavior is reduced in bulls actively immunized against gonadotropin-releasing hormone. Journal of Animal Science 81, 411-415.

Roberds, J.H., Strom, B.L., 2006. Repeatability estimates for oleoresin yield measurements in three species of the southern pines. Forest Ecology and Management 228, 215-224.

Swanson, H.H., Schuster, R., 1987. Cooperative social coordination and aggression in male laboratory rats - effects of housing and testosterone. Hormones and behavior 21, 310-330.

Thun, R., Eggenberger, E., 1996. Relationship between cortisol and testosterone under resting conditions, after acute stress and hormonal stimulation in the bull. Schweizer Archiv für Tierheilkunde 138, 225-233.

Tulloh, N.M., 1961: Behaviour of cattle in yards. II. A study of temperament. Animal Behavior 9, 25-30.

Tume, R.K., Shaw, F.D., 1992. Beta-andorphine and cortisol concentrations in plasma of blood samples collected during exsanguination of cattle. Meat Science 31, 211-217.

Urban, C., 2007. Untersuchungen zum genetischen Hintergrund von Temperament und Umgänglichkeit bei Mutterkühen und Kälbern der Rassen Dt. Angus und Dt. Fleckvieh anhand der Validierung von geeigneten Testverfahren. PhDthesis, Justus-Liebig-Universität Gießen, Germany. 
Van Loo, P.L.P., Mol, J.A., Koolhaas, J.M., Van Zutphen, B.F.M., Baumans, V., 2001. Modulation of aggression in male mice: influence of group size and cage size. Physiology \& Behavior 72, 675-683.

Vandenheede, M., Bouissou, M.F., 1993a. Sex-differences in fear reactions in sheep. Applied Animal Behaviour Science 37, 39-55.

Vandenheede, M., Bouissou, M.F., 1993b. Effect of androgen treatment on fear reactions in ewes. Hormones and behavior 27, 435-448. 


\section{CHAPTER VI}

\section{GENERAL DISCUSSION AND CONCLUSION}

\subsection{MATERNAL ABILITY}

The maternal ability of beef and dairy cattle was compared in this study (chapter IV). A diminished maternal ability of dairy cows, due to centuries of calf rearing of humans, is assumed by Le Neindre (1989). Furthermore, only limited responses of dairy cows after removal of their calves were observed (Hopster et al. 1995). Other sources in literature report on strong behavioural and vocal responses of dairy cattle after separation of their calves (Weary and Chua, 2000; Hudson and Mullord, 1977; Lidfors, 1996). Also in this study the dairy cows showed behavioural reactions during the handling of their calves, although they were not such agitated like the beef cows. As assumed before, breed differences in maternal ability were detected in this study, similar to for example Hoppe et al. (2008), although to the best of my knowledge there are no other comparisons of maternal ability of beef and dairy cows in the literature. Contrary to the hypothesis the beef cows did not demonstrate a generally higher maternal behaviour compared with the dairy cattle. This was shown by the fact that cow-calf-interactions were more frequently demonstrated by the dairy cattle, what disagreed with the assumption of Le Neindre (1989). However, the beef cows in this study expressed a higher defending behaviour against humans when their calves were handled, what is in agreement with the general belief.

Like in studies of Stehulova et al. (2013), Jensen (2011) or Lidfors (1996), the maternal care, here expressed by the interactions of the cow to the calf and other behavioural parameters, was decreasing fast with time. This points out that the maternal protecting behaviour does not exist for a long time in beef and dairy cows.

Differences in maternal behaviour caused by the parity of the cow were described several times in literature. Multiparous cows have a greater bond to their calf (Ungerfeld et al., 2011, Dwyer, 2008), resulting in a higher frequency of suckling and licking events (Vanheede et al., 2001), a higher vigilance to protect their calf (Florcke et al., 2012) and a more close contact to the calf (Price et al., 1986). Also in the 
present work, differences in the protecting behaviour of the cow, caused by the parity, were could be observed. During handling the calves, the multiparous cows expressed a higher protecting behaviour compared with the heifers. But contrary to Edwards and Broom (1982), no abnormal behaviour of the primiparous cows, like rejection and aggressions against the calf, were detected in this study.

\subsection{DOCILITY}

In this study (chapter V), the docility of heifers in a chute test as well as in a separation- and restraint test was compared between the breeds German Simmental (beef) and Charolais. Breed differences in docility are known from several studies after the performance of the chute test (Gauly et al., 2001a, Tulloh, 1961, Hoppe et al., 2010) likewise the separation- and restraint test (Gauly et al., 2001,b). Similar to these studies, breed differences in this experiment were as well detected. On the basis of the findings for the parameters docility scale, weighing score, leaving score and flight and speed score in the chute test, the breed Simmental could be evaluated as more agitated, while the Charolais heifers were appraised as more calm and relaxed. In the separation- and restraint test, the parameters separation time, prehandling score, handling score, handling run, time until corner and time in the corner prove the breed Charolais to be easier to handle and have therefore the better docility compared with Simmental heifers. Similar to these results, Gauly et al. (2001a,b) and Mathiak (2002) evaluated the breed Simmental as more agitated and more difficult to handle, as well as more stressed by handling procedures (Gauly et al., 2002) compared with the breed German Angus. In the past, the breed German Simmental were raised under more intensive production systems compared with the breed German Angus, so the Simmental cattle were selected for docility (Gauly et al., 2002). Due to the masking of genetically based temperament by intensive handling, less docile animals can be found more frequently in cattle breeds which were reared in intensive production systems (Grandin, 1994). In contrast, Hoppe et al. (2010) estimated both breeds Simmental and Charolais cattle to be agitated in a chute test and have an unfavourable temperament compared with other beef breeds. Younger animals show themselves in the separation- and restraint test as more nervous, by what longer times were needed to separate these animals from their flock. This can 
occur in younger animals due to less experience in handling routine (Fordyce and Goddard, 1984).

\subsection{BIOMARKER}

Different opinions about the role of oxytocin in maternal behaviour exist in the literature. Disbelief about the general role of the hormone in maternal ability is expressed by Young et al. (1997). In the same way, Rubin et al. (1983) and Bolwerk and Swanson (1984) will not affirm the rapid induction of maternal behaviour by the hormone. However, many studies argue for a relationship between the oxytocin level and maternal bonding and behaviour (for example: Levine et al., 2007; Williams et al., 2001; Kendrick et al., 1987, Boccia et al., 2007). Likewise a relationship between the hormone and the maternal behaviour and checking behaviour (Feldman et al., 2007) and the frequency of the infants grooming and nursing was found (Maestripieri et al., 2009). Also in the present work (chapter IV), the maternal care, expressed by the cow-calf-interactions, which were more frequently in the dairy breed, was correlated to oxytocin. The oxytocin level was also clearly higher in the dairy breed. The hormone seems to influence the maternal care, like licking events, positively in the early postpartum phase. Due to the fact of missing correlations to parameters like the protecting behaviour, a relationship of oxytocin and therefore the use as a biomarker for the whole maternal behaviour cannot be confirmed. Due to the high correlations to each other and mostly high repeatability's, the behavioural parameters maternal ability score, defence score, total motherliness and maternal ability scale (chapter IV), turned out to be good biomarkers for the maternal ability.

Testosterone is often referred in context as a hormone which has impact on the behaviour of animals: Fear reactions which are normally higher in ewes compared with rams (Vanheede and Boissou, 1993a), can be reduced in ewes after testosterone treatments (Vanheede and Boissou, 1993b). This is in contrast to Okuliarova et al. (2007) who found increased fearfulness in Japanese quail chicks after the injection of testosterone in the eggs. The aggressiveness is another behaviour trait which can be influenced by testosterone: Price et al. (2003) ascertained reduced aggressive behaviour in bulls after immunocastration, which reduced the testosterone level of the bulls. Furthermore, negative correlations were discovered between the hormone and aggressiveness in male mice at which the 
more dominant animals had the higher testosterone levels (Van Loo et al., 2001). Plusquellec and Bouissou (2001) identified a relation between the hormone, fear and aggressiveness in different breeds of dairy cattle. A more dominant dairy breed expressed higher testosterone levels, less fear, less aggressiveness in the group, but more difficult handling in test situations (Plusquellec and Bouissou, 2001). In this study (chapter V), real aggressiveness did not occur in both of the breeds. Because the breeds were not kept together, also no statement can be given about a dominant or aggressive behaviour in the group. But due to the fact that the breed Charolais, which was evaluated as the more docile breed in both handling tests, expressed the higher testosterone levels, a better docility of cows seems not to be dependent on a low level of testosterone. This is in contrast to the prediction of Plusquellec and Bouissou (2001). Based on the fact that in the chute test animals with higher testosterone levels were leaving the chute more slowly, indicated the easier temperament for animals with the higher testosterone level. In the separation- and restraint test, the better docility of animals with higher testosterone levels was given by less time which was needed until the animal was in the corner, less time which the animal was running during the handlings period and the longer time the animal could be detained in the corner.

Concerning the stress parameters heart frequency and cortisol, different usability's as biomarkers for stress were found in chapter IV and chapter V. In chapter IV, no correlations were detected to any behavioural parameter and regarding the other physiological parameters, only between the heart frequency and infrared thermography. This is against the study of Feldman et al. (2007) who observed a negative correlation between cortisol and oxytocin. While in the first experiment in chapter IV, no differences in cortisol could be detected between the breeds, the second experiment in chapter $\mathrm{V}$ showed higher cortisol levels for the breed Simmental. In both experiments, the heart frequency of the German Simmental cows were higher compared with the German Black Pied Cattle or Charolais. In the second experiment, all three stress parameters cortisol, heart frequency and infrared thermography specified the breed Simmental as more stressed and agitated. The correlations indicated the same animals as stressed. The higher agitation of stressed animals was revealed by the correlations between the physiological stress parameters and different behavioural parameters of the handling tests. For chapter $\mathrm{V}$, the correlations within the physiological parameters show that a higher level of 
testosterone is not a sign for a stressed animal. In the study, no correlations existed between cortisol and testosterone. This is in accordance with Thun and Eggenberger (1996), who also found no correlations between the hormones in resting conditions and stress situations. Chapter $\mathrm{V}$ pointed out many correlations for cortisol and the heart frequency to behavioural parameters in the chute test and especially in the separation- and restraint test, in which to every behavioural parameter correlations were found to cortisol and the heart frequency. Differences in the usability of cortisol and heart frequency are also reflected in the higher repeatability's of these physiological stress parameters in chapter $\mathrm{V}$. A reason for the varying results of cortisol and heart frequency and therefore the usefulness of the parameters as biomarkers for stress could maybe exist due to the different seasons when the experiments occur. While for the second experiment (chapter $\mathrm{V}$ ) both breeds were tested in winter month under equal weather conditions, the first experiment (chapter IV) happened for the German Simmental cows in two month of the winter season and for the German Black Pied Cattle mostly in warmer month between spring and autumn. This was a consequence of the different calving times of beef and dairy cattle farms.

Regarding the infrared thermography, also varying usability's as biomarkers for stress parameter between the two experiments were seen. In literature, different sources confirm the usability of infrared thermography to assess stress. Example are: the stress at horse jumping events (Valera et al., 2012), the fear caused by handling procedures in cattle (Stewart et al., 2008) or the stress level at slaughtering in pigs (Warriss et al., 2006). The correlations in chapter IV demonstrated that a higher temperature is seen in animals with less maternal and protecting behaviour, with higher heart frequencies as well as for cows with lower calving weights and a low parity number. But in this study, the results were not repeatable. Due to the inconsistent test conditions in summer and winter, the parameter is evaluated as disadvantageous for this study. This is different from the experiment in chapter $\mathrm{V}$ where animals could be tested under nearly similar the same conditions. Here, animals with high temperatures had unfavourable temperaments and docility in both handlings tests and were especially available in younger animals. The influence of the ambient temperature on the temperature measured by infrared thermography, was also reported by Franze et al. (2012) and Alsaaod and Buescher (2012). Palmer (1981) and Turner (1991) even report the necessity of a draft-free, temperature- and 
sunlight controlled place in a stable in order to obtain reasonable results from the infrared thermography. Because of many potential influencing factors, the parameter infrared thermography can only be seen as useful biomarker for stress when equal conditions in the experiment can be ensured.

\subsection{CONCLUSION}

Contrary to our hypothesis, beef and dairy cows show high maternal behaviour. Compared with the German Simmental cattle more interactions to the calf were expressed by the German Black Pied Cattle. However, in the handling situation the protecting behaviour of the cow to the calf was stronger in the German Simmental cattle. Multiparous cows exhibited a greater protecting behaviour compared with primiparous cows. The maternal care decreased fast in all cows.

On the basis of different parameters of the separation- and restraint test, the breed Charolais was evaluated as easier to handle and has therefore the better docility compared with German Simmental. Like in other studies described before, the breed German Simmental demonstrated a more agitated temperament. Younger animals show themselves in the handling tests to be more nervous.

The usage of oxytocin as a biomarker for maternal behaviour can only be partially confirmed. While oxytocin seems to influence the maternal care, like licking events, positively in the early postpartum phase, correlations to the protection of the calf were missing. Due to the high correlations and repeatability's, beside the hormone oxytocin, also behavioural parameters of behaviour tests can be used as biomarkers for the maternal ability.

In this study a better docility of cows was not dependent on a low level of testosterone. Results of the behavioural parameters in the chute and separation- and restraint test show the Charolais heifers compared with the German Simmental heifers as the more docile breed, which also expressed higher testosterone levels. Therefore, a higher testosterone level can be seen as favourable for docility in handling tests.

The usefulness of physiological parameters like heart frequency, cortisol and especially infrared thermography as biomarkers for stress could only be ensured under equal test conditions for all animals. In this case, good results with high correlations between physiological and behavioural parameters, as well as high 
repeatability's can be seen particularly for the heart frequency. The infrared thermography is a method which is highly susceptible for interference specifically for inconsistent weather conditions. 


\section{REFERENCES}

Alsaaod, M., Buscher, W., 2012. Detection of hoof lesions using digital infrared thermography in dairy cows. Journal of Dairy Science 95: 735-742.

Boccia, M.L., Goursaud, A.P.S., Bachevalier, J., Anderson, K.D., Pedersen, C.A., 2007. Peripherally administered non-peptide oxytocin antagonist, L368,899((R)), accumulates in limbic brain areas: A new pharmacological tool for the study of social motivation in non-human primates. Hormones and Behavior 52, 344-351.

Bolwerk, E.J.M., Swanson, H.H., 1984. Does oxytocin play a role in the onset of maternal behaviour in the rat? Journal of Endocrinology 101, 353-357.

Dwyer, C.M., 2008. Individual variation in the expression of maternal behaviour: A review of the neuroendocrine mechanisms in the sheep. Journal of Neuroendocrinology 20, 526-534.

Edwards, S.A., Broom, D.M., 1982. Behavioral interactions of dairy cows with their newborn calves and the effects of parity. Animal Behaviour 30, 525-535.

Feldman, R., Weller, A., Zagoory-Sharon, O., Levine, A., 2007. Evidence for a neuroendocrinological foundation of human affiliation - Plasma oxytocin levels across pregnancy and the postpartum period predict mother-infant bonding. Psychological Science 18, 965-970.

Florcke, C., Engle ,T.E., Grandin, T., Deesing, M,J., 2012. Individual differences in calf defence patterns in Red Angus beef cows. Applied Animal Behaviour Science 139, 203-208.

Fordyce, G., Goddard, M.E., 1984. Maternal influence on the temperament of Bos indicus cross cows. Animal Production in Australia 15, 345-348.

Franze, U., Geidel, S., Heyde, U., Schroth, A., Wirthgen, T.,Zipser, S., 2012. Investigation of infrared thermography for automatic health monitoring in dairy cows. Züchtungskunde 84: 158-170.

Gauly, M., Mathiak, H., Kraus, M., Hoffmann, K., Erhardt, G., 2001a. Difference in temperament of beef cattle regarding breed and sex. Deutsche Tierärztliche Wochenschrift 108, 206-210.

Gauly, M., Mathiak, H., Hoffmann, K., Kraus, M., Erhardt, G., 2001b. Estimating genetic variability in temperamental traits in German Angus and Simmental cattle. Applied Animal Behaviour Science 74, 109-119.

Gauly, M., Mathiak, H., Erhardt, G., 2002. Genetic background of behavioural and plasma cortisol response to repeated short-term separation and tethering of beef calves. Journal of Animal Breeding and Genetics, 119, 379-384. 
Grandin, T., 1994. Solving livestock handling problems. Veterinary medicine 89, 989990.

Hoppe, S., Brandt, H.R., Erhardt, G., Gauly, M., 2008. Maternal protective behaviour of German Angus and Simmental beefcattle after parturition and its relation to production traits. Applied Animal Behaviour Science Volume 114, Pages 297306.

Hoppe, S., Brandt, H.R., König, S., Erhardt, G., Gauly, M., 2010. Temperament traits of beef calves measured under field conditions and their relationships to performance. Journal of Animal Science, 88, 1982-1989.

Hopster, H., Oconnell, J.M., Blokhuis, H.J., 1995. Acute effects of cow-calf separation on heart-rate, plasma-cortisol and behavior in multiparous dairy-cows. Applied Animal Behaviour Science 44, 1-8.

Hudson, S.J., Mullord, M.M., 1977. Investigations of maternal bonding in dairy-cattle. Applied Animal Ethology 3, 271-276.

Jensen, M.B., 2011. The early behaviour of cow and calf in an individual calving pen. Applied Animal Behaviour Science 134, 92-99.

Kendrick, K.M., Keverne, E.B., Baldwin, B.A., 1987. Intracerebroventricular oxytocin stimulates maternal-behavior in the sheep. Neuroendocrinology 46, 56-61.

Le Neindre, P., 1989. Influence of cattle rearing conditions and breed on social relationships of mother and young. Applied Animal Behaviour Science Volume 23, Pages 117-127.

Levine, A., Zagoory-Sharon, O., Feldman, R., Weller, A., 2007. Oxytocin during pregnancy and early postpartum: individual patterns and maternal-fetal attachment. Peptides 28, 1162-1169.

Lidfors, L.M., 1996. Behavioural effects of separating the dairy calf immediately or 4 days post-partum. Applied Animal Behaviour Science 49, 269-283.

Maestripieri, D., Hoffman, C.L., Anderson, G.M., Carter, C.S., Higley, J.D., 2009. Mother-infant interactions in free-ranging rhesus macaques: Relationships between physiological and behavioral variables. Physiology \& Behavior 96, 613619.

Mathiak, H., 2002. Genetische Parameter von Merkmalen des Temperaments und der Umgänglichkeit bei den Rassen Dt. Angus und Dt. Fleckvieh. Dissertation zur Erlangung des Doktorgrades am Fachbereich Agrarwisssenschaften, Ökotrophologie und Umweltmanagement der Justus-Liebig-Universität Gießen.

Okuliarova, M., Skrobanek, P., Zeman, M., 2007. Effect of increasing yolk testosterone levels on early behaviour in Japanese quail hatchlings. Acta. Veterinaria 76, 325-331. 
Palmer, S., 1981. Use of the portable infrared thermometer as a means of measuring limb surface temperature in the horse. American Journal of Veterinary Research 42, 105-108.

Plusquellec, P., Bouissou, M.F., 2001. Behavioural characteristics of two dairy breeds of cows selected (Herens) or not (Brune des Alpes) for fighting and dominance ability. Applied Animal Behaviour Science 72, 1-21.

Price, E.O., Smith, V.M., Thos, J., Anderson, G.B., 1986. The effects of twinning and maternal experience on maternal-final social relationships in confined beefcattle. Applied Animal Behaviour Science 15, 137-146.

Price, E.O., Adams, T.E., Huxsoll, C.C., Borgwardt, R.E., 2003. Aggressive behavior is reduced in bulls actively immunized against gonadotropin-releasing hormone. Journal of Animal Scence. 81, 411-415.

Rubin, B.S., Menniti, F.S., Bridges, R.S., 1983. Intracerebroventricular administration of oxytocin and maternal-behavior in rats after prolonged and acute steroid pretreatment. Hormones and Behavior 17, 45-53.

Stehulova, I., Spinka, M., Sarova, R., Machova, L., Knez, R., Firla, P., 2013. Maternal behaviour in beef cows is individually consistent and sensitive to cow body condition, calf sex and weight. Applied Animal Behaviour Science 144, 89-97.

Stewart, M., Schaefer, A., Hale, D.B., Colyn, J., Cook, N.J., Stafford, K.J., Webster, J.R., 2008. Infrared thermography as a non-invasive method for detecting fearrelated responses of cattle to handling procedures. Animal Welfare 17: 387-393.

Thun, R., Eggenberger, E., 1996: Relationship between cortisol and testosterone under resting conditions, after acute stress and hormonal stimulation in the bull. Schweizer Archiv für Tierheilkunde, 138, 225-233.

Tulloh, N.M., 1961: Behaviour of cattle in yards. II. A study of temperament. Animal Behaviour 9, 25-30.

Turner, T. A., 1991. Thermography as an aid to the clinical lameness evaluation. Veterinary Clinics of North America-Equine Practice 7: 311-338.

Ungerfeld, R., Hotzel, M.J., Scarsi, A., Quintans, G., 2011. Behavioral and physiological changes in early-weaned multiparous and primiparous beef cows. Animal 5, 1270-1275.

Valera, M., Bartolome, E., Sanchez, M.J., Molina, A., Cook, N., Schaefer, A., 2012. Changes in eye temperature and stress assessment in horses during show jumping competitions. Journal of Equine Veterinary Science 32: 827-830.

Vandenheede, M., Bouissou, M.F., 1993a. Sex-differences in fear reactions in sheep. Applied Animal Behaviour Science 37, 39-55. 
Vandenheede, M., Bouissou, M.F., 1993b. Effect of androgen treatment on fear reactions in ewes. Hormones and Behaviour 27, 435-448.

Vandenheede, M., Nicks, B., Desiron, A., Canart, B., 2001. Mother-young relationships in Belgian Blue cattle after a Caesarean section: characterisation and effects of parity. Applied Animal Behaviour Science 72, 281-292.

Van Loo, P.L.P., Mol, J.A., Koolhaas, J.M., Van Zutphen, B.F.M., Baumans, V., 2001. Modulation of aggression in male mice: influence of group size and cage size. Physiology \& Behavior 72, 675-683.

Warriss, P. D., Pope, S. J.,Brown, S.N., Wilkins, L.J., Knowles, T.G., 2006. Estimating the body temperature of groups of pigs by thermal imaging. Veterinary Record 158: 331-334.

Weary, D.M., Chua, B., 2000. Effects of early separation on the dairy cow and calf 1. Separation at $6 \mathrm{~h}, 1$ day and 4 days after birth. Applied Animal Behaviour Science 69, 177-188.

Williams, G.L., Gazal, O.S., Leshin, L.S., Stanko, R.L., Anderson, L.L., 2001. Physiological regulation of maternal behavior in heifers: Roles of genital stimulation, intracerebral oxytocin release, and ovarian steroids. Biology of Reproduction 65, 295-300.

Young, L.J., Winslow, J.T., Wang, Z.X., Gingrich, B., Guo, Q.X., Matzuk, M.M., Insel, T.R., 1997. Gene targeting approaches to neuroendocrinology: Oxytocin, maternal behavior, and affiliation. Hormones and Behavior 31, 221-231. 


\section{SUMMARY}

This work investigates different non-invasive biomarkers for behaviour traits in beef and dairy cow. After a general introduction on behaviour tests, animal stress and biomarkers, the work is divided into three parts: In the first part, infrared thermography (IRT) is discussed as a method for the diagnosis of animal welfare, pain, disease, inflammation and stress in a literature review in chapter III. The second part (chapter IV) describes an experiment to compare the maternal ability in German Simmental (beef) and German Black Pied cattle. The objectives of the study were 1) to test if dairy cows have a less distinctive motherliness than beef cows and 2) to prove if oxytocin is a potential biomarker for the maternal behaviour. The third part in chapter $\mathrm{V}$ describes the experiment in which the docility of the breeds Charolais and German Simmental (beef) was tested with the help of two handling tests. The goal of the experiment was to proof if the hormone level of testosterone has an influence on the docility of the cattle.

Infrared thermal imaging has gained popularity in various disciplines of animal science. However, the usefulness of IRT differs for diverse diseases, infections and other purposes. Stress caused by pain, especially at disbudding, cattle branding, tail docking or surgical castration can be detected by IRT. The measurement of psychological stress, e.g. at horse jumping events or during the slaughtering of pigs, can be performed well by IRT. While a good suitability was attested for detection of virus infections, the usability of IRT for detection of diseases of the locomotor system and udder infections is often limited to a supplementary tool. Different reliabilities of IRT can be found in literature for the detection of diverse diseases, as the sensitivity and specificity are strongly dependent on the temperature cut-off value, the time of measurement (clinical or post-clinical stage) as well as the evaluation routine, assuming that all or only the maximum temperatures are included in the evaluation. In farm animal research, plenty of animal and environmental related factors show an influence on the measurements obtained by IRT, limiting the informative value of the technique. Thus, IRT cannot be considered as a panacea and should also not be used as the sole technique, but it can provide a good, non-invasive assistance for many areas of animal research and practical issues, like the detection of stress and diseases. 
The second part focused on the experiment on maternal behaviour, in which 20 cowcalf dyads each of Simmental (S) and German Black Pied Cattle (BP) was examined on the $2^{\text {nd }}$ and again on the $3^{\text {rd }}$ day of the calf's life during situations with and without human handling of the calf. For one hour the frequency of interactions between cow and calf were quantified. During handling the calf, the cow's willingness to defend her calf and the overall maternal behaviour was scored. For the detection of stress, saliva samples for cortisol and oxytocin analysis, heart rate and thermal images of the eye were taken. The oxytocin concentration in saliva was used to test the hormone as a biomarker for maternal ability. The mixed model analysis revealed that the BP cattle had significantly higher oxytocin and cortisol levels, but lower heart rates than $S$ cattle. The heart frequency and the defensive behaviour showed that during handling the calf, $S$ cattle are more agitated and more difficult to handle than BP cattle. Although the beef cattle (S) showed more defensive behaviour, a lower number of interactions were presented to their calf compared to BP. Therefore, beef cows do not seem to be per se more maternal compared to dairy cows. As only the correlation of oxytocin to the interactions to the calf existed, it cannot be clearly stated that a higher oxytocin level in cows is correlated with greater total maternal ability.

The objective of the experiment in the third part was to ascertain if a higher testosterone level in beef cows is associated with more aggressive behaviour and lower docility during behaviour tests. Therefore, 21 German Simmental (S) and 20 Charolais heifers $(C)$ were subjected with one repetition to a chute test as well as a separation- and restraint test. Beside the collection of behavioural parameters, the heart rate, thermal images of the eye and saliva samples for cortisol and testosterone analysis were collected during the tests. For all physiological and most of the behavioural parameters, significant breed differences were detected. Different behavioural parameters of the chute test and the separation- and restraint test indicated that breed $\mathrm{C}$ is easier to handle and has the better docility compared with the breed $\mathrm{S}$. The physiological parameters for stress as well as behavioural parameters specified the $S$ heifers to be more agitated and harder to handle. Due to the fact that the $C$ heifers had considerably higher testosterone levels compared with $S$ heifers, a higher level of the hormone testosterone can be interpreted as adjuvant for a better temperament. Contrary to our hypothesis, heifers with a higher 
testosterone level seem to be more calm, relaxed and easier to handle, probably due to less fearfulness.

\section{ZUSAMMENFASSUNG}

In dieser Arbeit werden verschiedene nicht-invasive Biomarker für Verhaltensmerkmale bei Fleischrindern und Milchkühen untersucht. Nach einer einführenden Einleitung zu Verhaltenstests, Stress und Biomarkern gliedert sich die Arbeit in drei Teile: Im ersten Teil (Kapitel III) wird die Infrarot Thermografie (IRT) als eine Methode zur Diagnose von Animal welfare, Schmerzen, Krankheiten, Entzündungen und Stress bei Nutztieren in einer Literaturübersicht evaluiert. Der zweite Teil (Kapitel IV) beschreibt das Experiment zum Vergleich der Mütterlichkeit der Rassen Deutsch Fleckvieh (Fleisch) und Deutsches Schwarzbuntes Niederungsrind. Ziel der Studie war es herauszufinden, ob 1) Milchkühe eine weniger ausgeprägte Mütterlichkeit aufweisen als Fleischrinder und 2) ob das Hormon Oxytocin als ein Biomarker für mütterliches Verhalten eingesetzt werden kann. Im dritten Teil (Kapitel V) wurde die Umgänglichkeit der Rassen Charolais und Deutsch Fleckvieh (Fleisch) anhand zweier Verhaltenstests bewertet. Fragestellung des Experiments war, ob die Hormonkonzentration von Testosteron die Umgänglichkeit der Kühe beeinflusst.

Infrarot Thermographie (IRT) als bildgebendes Temperaturmessverfahren wird in verschiedenen Disziplinen der Nutztierwissenschaften eingesetzt. Die Nützlichkeit der Methode variiert jedoch bei den verschiedenen Einsatzbereichen. Durch Schmerz verursachter Stress, beispielsweise durch Vorgänge der Enthornung, Brandzeichnung, Schwanzkupierung und Kastration, kann mittels IRT gut erkannt werden. Auch psychologischer Stress der z.B. im Turniersport der Springpferde oder bei Schweineschlachtungen entsteht, kann mit Hilfe von IRT gut gemessen werden. Während mit der Methode verschiedene Virusinfektionen gut feststellbar sind, ist die Nützlichkeit zur Erkennung von Krankheiten des Bewegungsapparates und bei Euterinfektionen eingeschränkt und eher als ergänzende Erkennungsmethode einsetzbar. In den Nutztierwissenschaften gibt es vielfältige tierbezogene und umweltabhängige Faktoren, welche die Messergebnisse und den informativen Wert der IRT zum Teil deutlich beeinflussen. Die alleinige Nutzung von IRT zur 
Identifizierung von Stress, Schmerzen und Krankheiten ist daher nicht geeignet. IRT kann aber als nicht-invasive Methode ergänzend in vielen Bereichen der Nutztierwissenschaften und in der Praxis sinnvoll eingesetzt werden.

Im zweiten Teil der Arbeit wurde das mütterliche Verhalten von je 20 Kuh-KalbPaaren der Rassen Deutsches Schwarzbuntes Niederungsind und Deutsch Fleckvieh (Fleisch) am zweiten und dritten Lebenstag des Kalbes, in Situationen mit und ohne handelnde Menschen untersucht. Dabei wurden für eine Stunde alle Interaktionen zwischen Kuh und Kalb erfasst. Während der Handlingssituation des Kalbes wurde die Verteidigungsbereitschaft der Kuh sowie ihre generelle Mütterlichkeit bewertet. Zur Stressmessung der Kuh wurden Speichelproben zur Bestimmung von Cortisol, die Herzfrequenz sowie thermografische Messungen des Auges herangezogen. Speichelproben für Oxytocin dienten der Validierung des Hormons als Biomarker für Mütterlichkeit. Die Ergebnisse des gemischten Modells ergaben, dass die Milchkühe verglichen mit den Fleischrindern signifikant höhere Oxytocin- und Cortisolwerte, aber geringere Herzfrequenzen aufwiesen. Die höhere Herzfrequenz und Verteidigungsbereitschaft der Fleckviehkühe zeugte von deren Unruhe und ihren Schwierigkeiten im Handling. Trotz der höheren Verteidigungsbereitschaft zeigten die Fleckviehkühe weniger Interaktionen zu ihrem Kalb. Eine allgemeine höhere Mütterlichkeit der Fleischrinder verglichen mit Milchkühen kann daher nicht bestätigt werden. Da nur eine Korrelation zwischen Oxytocin und den Interaktionen zum Kalb vorlag, kann auf keinen Zusammenhang zwischen einem höheren Oxytocinlevel und einer generellen höheren Mütterlichkeit geschlossen werden.

Zur Fragestellung des zweiten Experiments, ob eine höhere Testosteronkonzentration von Fleischrindern mit einem aggressiveren Verhalten und einer schlechteren Umgänglichkeit in Verhaltenstests einhergeht, wurden 20 Charolais Rinder und 21 Deutsch Fleckvieh (Fleisch) Rinder mit einer Wiederholung einem Wiegetest sowie einem Separier- und Rückhaltetest unterzogen. Neben den Verhaltensparametern wurden die Herzfrequenz, thermografische Bilder des Auges, Speichelcortisol und Speicheloxytocin während der Tests erfasst. Für alle physiologischen Parameter sowie die meisten Verhaltensparameter konnten signifikante Rassenunterschiede nachgewiesen werden. Verschiedene Verhaltensparameter beider Tests deuteten auf eine höhere Umgänglichkeit und das einfachere Handling der Charolais Rinder hin. Die physiologischen Parameter für 
Stress, sowie die Verhaltensparameter bestimmten die Fleckvieh Rinder als unruhiger und schwerer zu handeln. Aufgrund der höheren Testosteronwerte der Rasse Charolais verglichen mit Fleckvieh, kann ein höherer Testosteronspiegel als nützlich für ein besseres Temperament angesehen werden. Rinder mit einem höheren Testosterongehalt zeigen sich als ruhiger und leichter zu handeln, was vermutlich auf eine verminderte Ängstlichkeit zurückzuführen ist. 


\section{ERKLÄRUNGEN}

1. Hiermit erkläre ich, dass diese Arbeit weder in gleicher noch in ähnlicher Form bereits anderen Prüfungsbehörden vorgelegen hat.

Weiter erkläre ich, dass ich mich an keiner anderen Hochschule um einen Doktorgrad beworben habe.

Göttingen, den

(Unterschrift)

2. Hiermit erkläre ich eidesstattlich, dass diese Dissertation selbständig und ohne unerlaubte Hilfe angefertigt wurde.

Göttingen, den

(Unterschrift) 